\title{
The Dutch heart health community intervention 'Hartslag Limburg' : an evaluation
}

Citation for published version (APA):

Ronda, G. M. (2003). The Dutch heart health community intervention 'Hartslag Limburg' : an evaluation. [Doctoral Thesis, Maastricht University]. Universiteit Maastricht. https://doi.org/10.26481/dis.20030523gr

Document status and date:

Published: 01/01/2003

DOI:

10.26481/dis.20030523gr

Document Version:

Publisher's PDF, also known as Version of record

\section{Please check the document version of this publication:}

- A submitted manuscript is the version of the article upon submission and before peer-review. There can be important differences between the submitted version and the official published version of record.

People interested in the research are advised to contact the author for the final version of the publication, or visit the DOI to the publisher's website.

- The final author version and the galley proof are versions of the publication after peer review.

- The final published version features the final layout of the paper including the volume, issue and page numbers.

Link to publication

\footnotetext{
General rights rights.

- You may freely distribute the URL identifying the publication in the public portal. please follow below link for the End User Agreement:

www.umlib.nl/taverne-license

Take down policy

If you believe that this document breaches copyright please contact us at:

repository@maastrichtuniversity.nl

providing details and we will investigate your claim.
}

Copyright and moral rights for the publications made accessible in the public portal are retained by the authors and/or other copyright owners and it is a condition of accessing publications that users recognise and abide by the legal requirements associated with these

- Users may download and print one copy of any publication from the public portal for the purpose of private study or research.

- You may not further distribute the material or use it for any profit-making activity or commercial gain

If the publication is distributed under the terms of Article $25 \mathrm{fa}$ of the Dutch Copyright Act, indicated by the "Taverne" license above, 
The Dutch Heart Health Community Intervention 'Hartslag Limburg'

An Evaluation 



\title{
The Dutch Heart Health Community Intervention 'Hartslag Limburg'
}

\author{
An Evaluation
}

\section{PROEFSCHRIFT}

ter verkijging van de graad van doctor aan de Universiteit Maastricht,

op gezag van de Rector Magnificus,

Prof. dr. A. C. Nieuwenhuizen Kruseman,

volgens het besluit van het College van Decanen,

in het openbaar te verdedigen op vrijdag 23 mei 2003 om I 2.00 uur

door

Gabriëlle Maria Ronda 


\section{Promotor}

Prof. dr. ir.J. Brug

\section{Co-promotor}

Dr. P. van Assema

\section{Beoordelingscommissie}

Prof. dr. N. K. de Vries (voorzitter)

Prof. dr. ir. P.A. van den Brandt

Dr.W. F. M. de Haes (GGD Rotterdam)

Prof. dr. G.J. Kok

Prof. dr.J.P. Mackenbach (Erasmus MC Rotterdam)

\section{Colofon}

Lay-out: Nora Oosting \& Leo Zander, Maastricht Druk: Unigraphic, Maastricht

ISBN: 90-5681-168-1

The studies presented in this dissertation were conducted under the auspices of The Maastricht Research Institute for Prevention and Care (HEALTH) at Maastricht University, The Netherlands. HEALTH is part of the Netherlands School of Primary Care Research ( $\mathrm{CaRe})$, which has been acknowledged since 1995 by the The Royal Netherlands Academy of Art en Sciences (KNAW).

The studies described in this thesis were supported by a grant of the Netherlands Heart Foundation (NHF - 6073।I.3).

Financial support by the Netherlands Heart Foundation for the publication of this thesis is gratefully acknowledged. 


\section{CONTENTS}

$\begin{array}{ll}\text { General Introduction } & 7\end{array}$

Chapter I The Dutch Heart Health Community Intervention

'Hartslag Limburg': Evaluation Design and Baseline Data

Chapter 2 Stages of change, psychological factors and awareness of physical activity levels in the Netherlands

Chapter 3 The Dutch Heart Health Community Intervention 'Hartslag Limburg': Results of an Effect Study at Individual Level

Chapter 4 The Dutch Heart Health Community Intervention 'Hartslag Limburg': Effects on Smoking Behavior

Chapter 5 The Dutch Heart Health Community Intervention 'Hartslag Limburg': Design and Results of a Process Study

Chapter 6 The Dutch Heart Health Community Intervention 'Hartslag Limburg': Results of an Effect Study at Organizational Level

Chapter 7 General Discussion

References 



\section{GENERAL INTRODUCTION}

Cardiovascular diseases (CVD) are one of the main public health problems, nowadays not only in the developed world, but also globally (Marmot, 1992; WHO, 1997). In 1999, 36\% of all deaths in the Netherlands were caused by CVD (Reitsma and Bonsel, 2001). Moreover, CVD is also a major cause of morbidity, and estimated to be the greatest cause of disability adjusted life years (DALYs) (years of healthy life lost by premature mortality and by living with a disability) in the developed world (Ezzati et al., 2002). CVD is multicausal, and behavioral or lifestyle factors, such as smoking, dietary habits and lack of physical activity, are generally regarded as important determinants of CVD risks (Blackburn, 1992; Schram et al., 2001; Ezzati et al., 2002). These factors are also important risk factors for other frequently occurring serious diseases: smoking, nutrition and physical activity influence cancer risk, and nutrition and physical activity are related to the risk of non-insulin-dependent diabetes mellitus and obesity (Menotti, 1992; Pate et al., 1995; Schram et al., 2001; Ezzati et al., 2002). It has been estimated that, in 2000 , approximately $15 \%$ of all deaths in the Netherlands were caused by smoking, $5 \%$ by an excess intake of saturated fat, $5 \%$ by an insufficient intake of fruit and vegetables, and $6 \%$ by insufficient physical activity (Van Oers, 2002). In West-European countries like the Netherlands, smoking is also the leading cause of DALYs, but nutrition-related risk factors and lack of physical activity also make important contributions (Ezatti et al., 2002). Changing these behavioral risk factors is therefore an important means of reducing and preventing CVD and other diseases, as well as preventing the consequences of these diseases (Blackburn, 1992; Wilhelmsen and Johansson, 1992; Schram et al., 2001; Ezatti et al., 2002).

To meet this challenge, stakeholders in the Maastricht region of the province of Limburg in the Netherlands, and supported by the Netherlands Heart Foundation, have jointly created a CVD prevention program called Hartslag Limburg (Dutch for Heartbeat Limburg), which integrates two different strategies: a population strategy aimed at all inhabitants and specifically at low socioeconomic status groups (the community project), and a high-risk strategy (the high-risk project), specifically focusing on inhabitants diagnosed with CVD or diagnosed as having multiple physical risk factors for CVD. It was expected that both strategies would contribute to CVD prevention. The high-risk strategy was expected to produce substantial behavior changes among individuals at risk, but its impact on the total burden of disease was thought to be small, since such a high-risk strategy only targets a relatively small numbers of inhabitants. The population strategy was expected to induce mostly small changes in CVDrelated risk behaviors, but to reach much larger proportions of the population of the Maastricht region, and thus have a greater impact on the total burden of disease. However, both strategies can easily be regarded as mutually supportive or as two components of a single strategy. Population-wide intervention activities may be essential for individuals in the community to start making life-style 
changes, while advice given to high-risk individuals may diffuse outwards (Rose, 1992). In the Hartslag Limburg project, it was expected that both approaches would interact and complement each other.

Hartslag Limburg is a joint project involving a number of partners. The main partners in the community project are the local council of Maastricht and the councils of four adjacent municipalities, the Maastricht Regional Public Health Institute (RPHI), two community social work organizations, and the regional community health care organization. Collaboration between these partners is achieved through nine local Health Committees, which organize activities for inhabitants that promote and facilitate a healthy lifestyle. The main partners in the high-risk project are the general practitioners (GPs) in the region, cardiologists, the University Hospital, Maastricht University, and again the RPHI. One category of key actors in the high-risk project was specifically created for the project, that of the Health Advisors. These Health Advisors counsel mostly individuals with a high CVD-risk, but they also form an important link between the community project and the high-risk project.

The major goal of the project was - and continues to be, since the Hartslag Limburg project is not over yet - to reduce CVD risk by encouraging behavioral change, i.e., a reduction in saturated fat consumption, increased physical activity, and smoking cessation. A comprehensive evaluation design to study the project's effects and the processes that lead to the expected outcomes, as well as an evaluation of the cost-effectiveness of the entire project, are integral parts of the project (Ruland et al., 1999).

This thesis presents the evaluation of the community project. Contemporary health promotion and community evaluation literature emphasize the importance of program effect measurement at different social levels, as well as the importance of process evaluation in addition to effect evaluation, and the use of a theoretical model to guide the evaluation (Goodman, 1998; Cheadle et al., 2000; Kegler et al., 2000). The evaluation design that was used to evaluate the community part of Hartslag Limburg was based on a comprehensive conceptual framework. The evaluation consisted of an effect study at the so-called individual level, measuring changes in the three CVD risk behaviors and their psychosocial determinants among inhabitants of the study communities, and an effect study at the so-called organizational level, primarily measuring changes in the availability of CVD health promoting activities. In addition, a process study was conducted to describe the actual course of action during the intervention, both at the population and organizational level. 


\section{OUTLINE OF THE THESIS}

The first chapter presents the evaluation design of the community intervention, the conceptual framework on which the intervention and its evaluation was based, and baseline data. The conceptual framework of the community intervention and its evaluation study was based on program planning and evaluation models, and consisted of several stages. Within this framework, community organization principles and methods and health education theories and methods were applied. To assess the appropriateness of the conceptual model that was used for the development of the intervention activities, and to confirm the need to carry out the project, baseline data of the Maastricht region was used. This data also provided specific input for the identification of objectives of the intervention program. The purpose of the study described in Chapter 2 was to investigate potential determinants of physical activity, in order to identify specific objectives of physical activity promotion. The data for this study were also derived from the baseline measurement in the Maastricht region. It was decided to investigate these factors in relation to physical activity in greater depth, because new recommendations for physical activity were introduced in the Netherlands about the same time that the project started, making it especially important to gain insight into factors that could be related to behavior consistent with these new recommendations. Chapters 3 and 4 deal with the effect evaluation of the community intervention at the individual level. A pretestposttest control group design with two posttests was used to evaluate the intervention. At baseline, representative random cohort research samples were selected in the Maastricht region and in a control region. Chapter 3 presents the results on dietary fat intake and physical activity. Data on fat intake and physical activity, and on the psychosocial determinants of these behaviors, was gathered by means of structured questionnaires, sent by mail. The effects on smoking behavior were studied in a separate sample and are presented in chapter 4. Data on smoking behavior and its determinants was gathered by means of short structured telephone interviews. Chapter 5 presents the design and results of the process study. This study was conducted to describe the actual course of action during the intervention, and to examine why expected effects were or were not achieved. Data was collected using multiple data sources and/or methods to assess indicators of intervention implementation. Community interventions tend to, and ought to be, autonomous and therefore difficult to plan, making it extremely important to monitor what has really happened during the intervention. Chapter 6 reports the results of the effect study at the organizational level. Organizational changes were an intermediate goal of the community intervention, since different organizations were expected to develop, implement and diffuse intervention activities aimed at behavior change among individual inhabitants of the Maastricht region. A pretest-posttest control group design was used to assess organizational changes. Data was gathered by means of structured questionnaires, sent by mail to organization representatives. Finally, the seventh and last chapter of this thesis relates the main findings of the studies to each 
other, discusses possible explanations for the findings, presents an overall conclusion, and provides recommendations for the evaluation of community interventions. 


\title{
CHAPTER I
}

\author{
THE DUTCH HEART HEALTH COMMUNITY \\ INTERVENTION 'HARTSLAG LIMBURG': \\ EVALUATION DESIGN AND BASELINE DATA
}

Accepted for publication as:

Ronda, G., Van Assema, P., Ruland, E., Steenbakkers, M. and Brug, J. (in press)

The Dutch Heart Health Community Intervention 'Hartslag Limburg':

Evaluation Design and Baseline Data. Health Education. 


\begin{abstract}
Hartslag Limburg, a cardiovascular diseases (CVD) prevention program, integrates a community strategy and a high-risk strategy. The present paper presents the evaluation design and baseline data of the community intervention. The conceptual framework of the community intervention and its evaluation study are based on program planning and evaluation models. Within this framework, community organization principles and methods and health education theories and methods are applied. Pretest-posttest control group designs are used to study changes at the individual and the organizational level. Individual baseline data of the intervention region revealed that $65 \%$ of the respondents had a high fat intake, $28 \%$ of the respondents were smokers, and $58 \%$ percent of the respondents did not meet the recommended target for physical activity. Further, many respondents were unaware of performing CVD-risk behaviors. The results at the organizational level showed that there was much interest in participation in health promoting activities. The baseline results confirm the need to carry out a comprehensive CVD prevention community project, and the appropriateness of the conceptual model that is used for the development of interventions. Further, these results provide specific input for the identification of specific objectives of the intervention program.
\end{abstract}




\section{INTRODUCTION}

In the Netherlands, as in most developed societies, a large part of morbidity and mortality can be attributed to cardiovascular diseases (CVD) (Marmot, 1992; Konings-Dalstra and Reitsma, 1999). CVD is multicausal, and behavioral factors, such as smoking, lack of physical activity and dietary habits, are important determinants of CVD risks. This also means that CVD risks can be reduced and CVD may be prevented to a certain extent, by encouraging behavioral changes (Blackburn, 1992). The Netherlands has a tradition of primary prevention through a community-based approach (e.g., Van Assema et al., 1994; Bokma et al., 1994). In 1998, a new regional CVD prevention program was started in the Maastricht region of the province of Limburg, which had special characteristics, both in terms of intervention approach and in evaluation design: Hartslag Limburg (Dutch for Heartbeat Limburg). Hartslag Limburg integrates two strategies, namely: a population strategy (the community project) aiming at all inhabitants and specifically at low socioeconomic status groups, and a highrisk strategy (the high-risk project), focusing on individuals diagnosed with CVD or diagnosed with multiple physical risk factors for CVD. A comprehensive evaluation design to study the effects and the processes that lead to the expected outcomes, as well as an evaluation of the cost-effectiveness of the entire project, are integral parts of the project.

Previous studies on community-based prevention programs and their evaluation methods made it clear that changes occur and should be measured at multiple social levels, for multiple risk factors, and at multiple stages in the change process (e.g., Shea and Basch, 1990; Goodman, 1998; Glasgow et al., 1999). The evaluation design that is used to evaluate the community part of Hartslag Limburg attempts to incorporate findings obtained from these studies, and consists of an effect and a process study with measures at both the individual and organizational level.

First, the present article presents a brief overview of the community intervention program. Second, the design of the community project and the design of the evaluation study are presented. We will further describe in greater detail the methods of the effect evaluation study. Finally, we will present the individual and organizational baseline data of the intervention region, as well as baseline differences between the intervention and a control region. Detailed baseline data of the intervention region are presented as a first step to a needs assessment for this region and to assess the appropriateness of the conceptual model that was used to guide the overall project and the development of interventions. Based on these data, specific intervention objectives will be identified. 


\section{Hartslag Limburg: main partners and their links (Figure I.I)}

The main partners in the community project are the city council of Maastricht and four adjacent municipalities, the Regional Public Health Institute Maastricht (RPHI), two community social work organizations, and the regional community health care organization. Collaboration between these partners is achieved through nine local Health Committees which organize activities that promote and facilitate a healthy lifestyle. The main partners in the high-risk project are the general practitioners (GPs) in the region, cardiologists in the University Hospital, the University Hospital, Maastricht University, and again the RPHI. One category of key actors in the high-risk project was specifically established for the project: Health Advisors. These Health Advisors counsel individual patients, and they form an important linchpin between the community project and the high-risk project.

\section{The community project}

The community project attempts to encourage the general population in the Maastricht region to reduce their intake of saturated fat, to stop smoking, and to increase their level of physical activity. The Maastricht region consists of the city of Maastricht (the capital of the province Limburg), with 120,000 inhabitants and four smaller adjacent municipalities, with 12,000 to 21,000 inhabitants, making a total of 180,000 inhabitants.

\section{Theoretical design}

Especially since the introduction of Green and Kreuter's PRECEDE-PROCEED model (Green and Kreuter, 1991), it has been a well-established concept that careful planning and theoretical foundation are important determinants of success in health promotion programs. The same goes, of course, for community health promotion programs (Koepsell et al., 1992; Goodman, 1998). The conceptual framework of Hartslag Limburg's community project is based on program planning and evaluation models, and consists of several stages (Table 1.1) (e.g., Green and Kreuter, 1999). It shows how the program will produce its postulated effects and serves as the program planning as well as evaluation framework. It posits that the expected results on a specific stage can only be achieved if the expected results at previous stages are achieved. The ultimate goal of the project is a reduction in the incidence and prevalence of CVD. This can be achieved by changes in related risk behaviors. Behavioral change can be achieved by changes in behavioral determinants. Changes in behavioral determinants can be expected if and when the project results in activities that focus on these determinants. Moreover, these activities should indeed reach the population. This can be achieved by the realization of community principles, which depends, in turn, on accurate implementation of project components.

Within the framework, community organization principles and methods as 


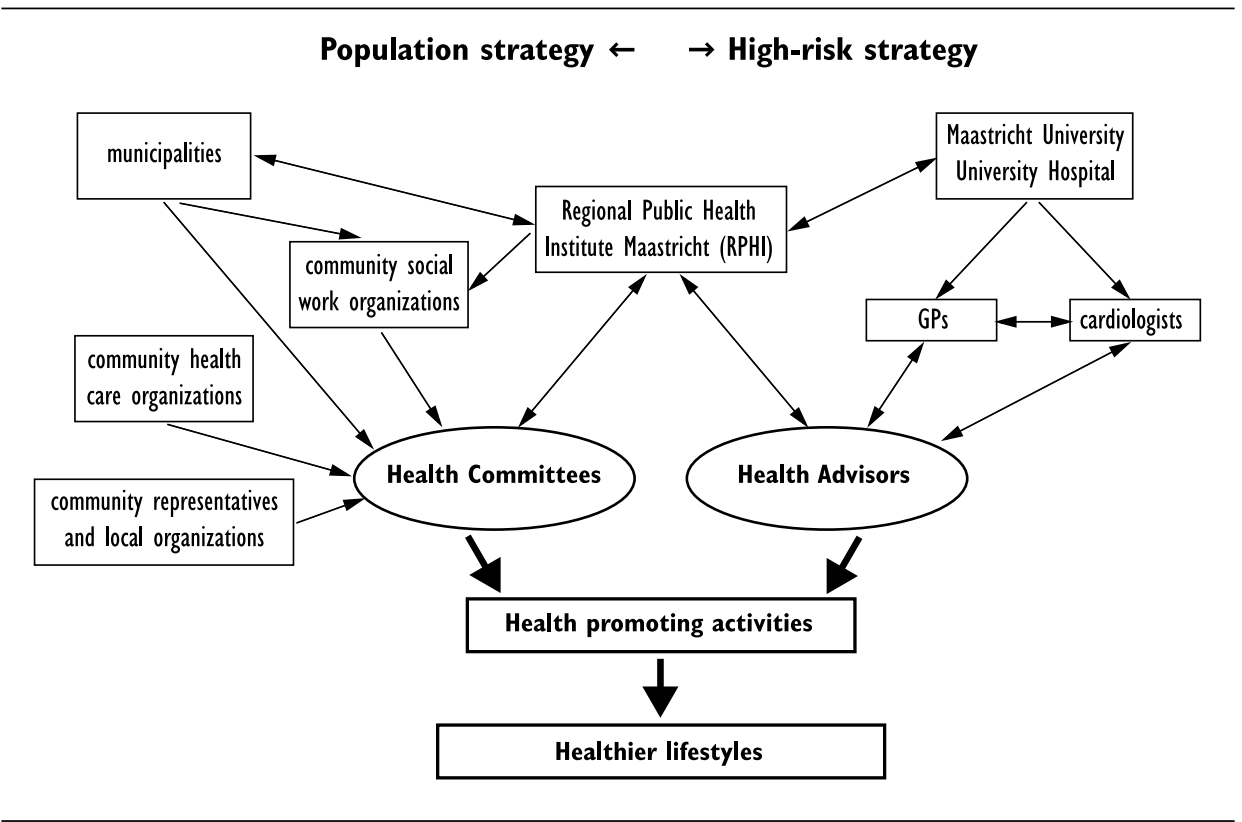

Figure I. I: Hartslag Limburg's main partners and their links

Table I.I: Conceptual framework of the community project and the evaluation study

\begin{tabular}{|c|c|c|c|c|c|}
\hline A Health & $\begin{array}{l}\text { B Risk behaviors } \\
+-\end{array}$ & $\begin{array}{l}\text { C Psychosocial } \\
\text { determinants }\end{array}$ & $\begin{array}{l}\text { D Prevention } \\
\text { activities }\end{array}$ & E Community principles & F Project components \\
\hline- CVD & $\begin{array}{l}\text { - high fat intake } \\
\text { - smoking } \\
\text { - not enough } \\
\quad \text { physical activity }\end{array}$ & $\begin{array}{l}\text { - attitudes } \\
\text { - social influences } \\
\text { - self-efficacy } \\
\text { - awareness } \\
\text { - stage of change }\end{array}$ & $\begin{array}{l}\text { - number } \\
\text { - reach } \\
\text { - effects }\end{array}$ & $\begin{array}{l}\text { - participation } \\
\text { - intersectoral collaboration } \\
\text { - link-up with current } \\
\text { situation } \\
\text { - social network approach } \\
\text { - environmental strategy } \\
\text { - multi-media and } \\
\text { multi-method strategy }\end{array}$ & $\begin{array}{l}\text { - community analyses } \\
\text { - Health Committees } \\
\text { - quality control }\end{array}$ \\
\hline
\end{tabular}

well as health education theories and methods are applied. The main community organization principles that are included in the project are participation of the community in the planning and implementation of the project, intersectoral collaboration between local organizations, link-up with the current situation (e.g., supporting existing CVD health promoting initiatives), a social network approach, an environmental strategy (e.g., providing healthier food choices in 
cafeterias), and a multi-media and multi-method strategy (e.g., Minkler and Wallerstein, 1998; Bracht et al., 1999). The specific intervention activities are based on a conceptual model that integrates different theoretical frameworks, and theoretical concepts, i.e., the precaution adoption model (Weinstein, 1988), the stage of change concept (Prochaska and DiClemente, 1992), and the Attitude - Social influence - Self-Efficacy (ASE) model (De Vries et al., 1988). These concepts are described in the questionnaire section.

\section{Practical design}

In order to apply the intervention framework, nine local Health Committees were set up: one in each of the four smaller municipalities, one in each of four underprivileged Maastricht neighborhoods, and one to coordinate and implement regional activities. Each Health Committee consists of approximately ten members who are generally representatives of local organizations that may play a key role in healthy behavior promoting activities. Moreover, each Committee is supported by a health educator from the RPHI Maastricht, a social worker and a civil servant from the municipality. The aim of the Health Committees is to organize within their area or municipality, activities that facilitate and encourage people to adopt a healthier lifestyle, i.e., to reduce their intake of saturated fat, to stop smoking, and to increase their physical activity level. Furthermore, the RPHI organizes activities that can, potentially, affect the entire Maastricht region. In order to facilitate and improve the quality of the work of the Health Committees, the RPHI encourages and assists the Health Committees in organizing as many healthy behavior promoting activities as possible, which were carefully selected on the basis of proven effectiveness and reach in earlier studies (Ronda and Van Assema, 1997). Examples of ongoing interventions include computer-tailored nutrition education (Brug et al., 1998), nutrition education tours in supermarkets (Van Assema et al., 1998), a regional campaign to promote physical activity among individuals over 55 (NOC*NSF, 1999), and a regional smoking cessation campaign (Ruland et al., 2001). A more comprehensive description of the project was published elsewhere (Ruland et al., 1999).

The project started in 1998 and will run until at least 2003. It is the intention and part of the planning that the project becomes a structural part of local health policy.

\section{Evaluation design}

The main evaluation measures are summarized in Table 1.2. Evaluation measures were developed for all the stages of the intervention and evaluation framework, except for stage A (incidence and prevalence of CVD), since no detectable effects on this level can be expected within a limited number of years. The evaluation study consists of an effect study and a process study. The purpose of the effect study is to study effects at both the individual and organizational level. At the individual level, the effects on the prevalence of the risk behaviors, and on the psychosocial determinants of these behaviors are studied. At the organizational level, the effects on the number of organizations that 
Table 1.2: Summary of evaluation measures

\begin{tabular}{|c|c|c|c|c|}
\hline Conceptual stage & Evaluation measure & Data collection instrument & Evaluation type & Evaluation level \\
\hline B Risk behaviors & $\begin{array}{l}\text { - effects on prevalence of risk } \\
\text { behaviors }\end{array}$ & $\begin{array}{l}\text { - written questionnaires } \\
\text { - telephone interviews }\end{array}$ & - effect & - individual \\
\hline C Determinants & $\begin{array}{l}\text { - effects on psychosocial } \\
\text { determinants and stage of } \\
\text { behavioral change }\end{array}$ & $\begin{array}{l}\text { - written questionnaires } \\
\text { - telephone interviews }\end{array}$ & - effect & - individual \\
\hline D Activities & $\begin{array}{l}\text { - number of organizations } \\
\text { that organize activities } \\
\text { - total number of prevention } \\
\text { activities }\end{array}$ & - written questionnaires & - effect & - organizational \\
\hline D Activities & $\begin{array}{l}\text { - number of people reached } \\
\text { by overall project and } \\
\text { separate activities } \\
\text { - intermediate effects of } \\
\text { innovative activities on } \\
\text { psychosocial determinants }\end{array}$ & $\begin{array}{l}\text { - telephone interviews } \\
\text { - written questionnaires } \\
\text { - separate evaluation } \\
\quad \text { plans }\end{array}$ & - process & - individual \\
\hline E Principles & - realization of principles & $\begin{array}{l}\text { - telephone interviews } \\
\text { - face to face interviews } \\
\text { - contents analyses of } \\
\text { minutes of meetings }\end{array}$ & - process & - organizational \\
\hline F Project components & $\begin{array}{l}\text { - implementation of project } \\
\text { components according to } \\
\text { plan }\end{array}$ & $\begin{array}{l}\text { - telephone interviews } \\
\text { - face to face interviews } \\
\text { - contents analyses of } \\
\text { minutes of meetings }\end{array}$ & - process & - organizational \\
\hline
\end{tabular}

organize CVD health promoting activities, and on the total number of health promoting activities are studied. The purpose of the process study is to gain insight in why the expected effects were or were not achieved and to provide short-loop feedback to those involved in the planning and organization of the project. The methods and baseline data of the effect study are presented in greater detail in the next sections. The process evaluation study will be discussed in a forthcoming paper. 


\section{EFFECT EVALUATION}

First, the methods for the measures at the individual level are presented, followed by a description of the methods for the measures at the organizational level.

\section{The design and the sample for measures at the individual level}

To assess differences between the experimental and the control region at the individual level, a pretest-posttest control group design was used, with two posttests (Cook and Campbell, 1979). The baseline measurement was conducted in 1998, the first posttest in 2000, and the second posttest in 2001. At baseline, representative random cohort research samples were selected from the population registers in both regions. In the Maastricht region, a stratified random sample of 1,450 inhabitants (age 14 and over) was selected from a total sample of 5,000 (1,000 in each municipality) that was less representative as it did not take into account the number of inhabitants per municipality. The samples of 1,000 inhabitants in each of the five municipalities in the Maastricht region were used for more explorative and descriptive purposes. In the control region, a stratified random sample of 1,200 inhabitants (age 14 and over) was selected. Furthermore, a cohort research population of 1,200 smokers (age 18 and over) was recruited in each region by taking a stratified random sample of 6,500 inhabitants from the computerized telephone registers in both regions. This additional sample was necessary to attain a large enough sample of smokers. The sample sizes are based on a power of .95 to detect a priori postulated effect sizes at a significance level of 0.05 .

The control region was comparable with respect to the incidence and prevalence of CVD, number of inhabitants, number of municipalities, and degree of urbanization, and there were no plans in place for similar prevention projects in the near future.

\section{The questionnaire for measures at the individual level}

The data were gathered by means of structured questionnaires, sent by mail. Questions were asked about dietary behavior, smoking behavior and physical activity, as well as about psychosocial determinants of these behaviors.

Additional data from smokers about their smoking behavior and the psychosocial determinants of their smoking behavior was gathered by means of short telephone interviews.

\section{Risk behaviors}

Dietary fat intake was assessed using a validated questionnaire covering nineteen (groups of) food products resulting in a fat consumption score ranging from 0 to 80 points (Van Assema et al., 2001). Fat scores of 15 points for women and 
18 points for men are the approximated upper levels of recommended dietary intake. The relative validity of the questionnaire was investigated by comparison with a seven-day diet record $(\mathrm{R}=0.71)$ (Van Assema et al., 2001). Smoking behavior was assessed by asking respondents whether they had smoked in the last seven days. Physical activity levels were assessed with a newly developed short questionnaire based on the recommended levels of physical activity to promote health (Ronda et al., 2001b). The recommended level of physical activity for adults is to engage in at least 30 minutes of moderate intensity physical activity on at least five, but preferably all, days of the week (Kemper et al., 2000). The relative validity of the questionnaire was investigated by comparison with a seven-day physical activity record $(\mathrm{R}=0.50)$ (Koremans et al., 2000).

\section{Psychosocial determinants}

A selection of psychosocial determinants of target behaviors was included in the evaluation questionnaires in order to assess intermediate intervention effects (see Table 1.1). The selection of these psychosocial factors was based on theories of psychosocial determinants of health behavior and on recent empirical evidence on determinants of the target behaviors. In the most often used theories on psychosocial determinants of health behaviors, intentions are regarded as the most proximal determinant of behavior (De Vries et al., 1988; Ajzen, 1991). Furthermore, three psychosocial factors are recognized as important predictors of behavior intentions: attitudes, social influences and self-efficacy expectations (De Vries et al., 1988; Ajzen, 1991). Many studies have been conducted in recent years to identify additional important psychosocial determinants. For dietary behaviors as well as physical activity, awareness of one's own performance has been identified as such an additional factor (Brug et al., 1994; Ronda et al., 2001b). A further development in health behavior change theory is the inclusion of stages of change models. In such models behavioral change is regarded as a process in which distinctive stages can be distinguished. The stages of change concept from the Transtheoretical model is probably the most popular among these stage models (Prochaska and DiClemente, 1992).

Attitudes, perceived behavior of others, social support, self-efficacy expectations, self-rated behavior and stages of change related to increasing physical activity, decreasing dietary fat intake, and smoking cessation were therefore included in the effect evaluation. These psychosocial factors towards changing the target behaviors were assessed with single items for each target behavior. Respondents were asked to evaluate their attitudes towards the different behaviors on a 'badgood' scale (How good or bad do you think it would be for you to be more physically active/eat less fat/stop smoking). Perceived behavior of others was assessed by asking respondents to assess the behavior of other people in their direct social environment ('important others', e.g., spouse, family, friends, colleagues). Perceived social support was assessed by asking respondents how much support they experienced from these important others to change their behavior. Self-efficacy towards changing the target behaviors was assessed by asking respondents how confident they were about their ability to change behaviors. 
Intention to change was assessed for each behavior by asking respondents whether they intended to change their behavior in the future. All items, with the exception of perceived social support, could be answered on bipolar five-point scales. For perceived social support, unipolar three-point scales were used.

Self-rated dietary fat intake and self-rated physical activity were assessed by asking respondents whether they rated their fat intake and physical activity level as low or high (bipolar five-point scale). Respondents were allocated to four categories of awareness, on the basis of their self-rated levels as compared to the results of the more objective behavior assessments. Respondents who had low fat consumption levels but who rated their fat consumption levels as (rather) high, were classified as pessimistic about their intake level. Respondents who did not have low fat consumption levels and rated their fat consumption as intermediate or lower, were classified as optimistic about their intake level. The remaining respondents were classified as realistic about their fat intake level. A similar procedure was used to classify respondents on awareness of physical activity.

The algorithm used to categorize respondents into stages of change was similar to the one used in earlier studies (Brug et al., 1997b). For all three behaviors respondents were asked if they intended to change their behavior within the next six months (yes/no) and, if so, whether they planned to do this within the next 30 days (yes/no). In addition, respondents were asked if they had changed their dietary fat intake or their level of physical activity in the past six months (increase/decrease/no change). Respondents who had low fat consumption levels or met the recommended physical activity target were classified as being in action if they indicated they had decreased their fat consumption or increased their physical activity level in the past six months. Otherwise, they were classified as being in maintenance. The remaining respondents were classified as being in preparation if they reported to have the intention to change their behavior within 30 days, in contemplation if they intended to change their behavior within six months but not within 30 days, and in precontemplation if they had no intentions to change their behavior within the next six months.

Finally, questions about sex, age, and education were included in the questionnaire.

\section{Design and sample for measures at the organizational level}

To assess changes at the organizational level about the number of organizations that were involved in health promoting activities, and the total number of activities, a pretest-posttest control group design was used, with one posttest (Cook and Campbell, 1979). The baseline measurement was conducted in 1998 and the posttest in 2001. At baseline, 700 organizations were selected in the Maastricht region, and 577 in the control region. Organizations that were potential significant agents in health promoting activities were included, e.g., work sites with more than 50 employees, schools, supermarkets, medical and 
paramedical practices, civic and social clubs, sports clubs, and health organizations. Names and addresses of these organizations were obtained from the local Chambers of Commerce and from telephone directories.

\section{The questionnaire for measures at the organizational level}

Data about the organizations were gathered by means of structured questionnaires, sent by mail to organization representatives. The questionnaire included items on background data (i.e. the number of members or clients, whether there were persons within the organization concerned with health); health promoting activities conducted in the last year with respect to dietary behavior, smoking behavior and physical activity; characteristics of the activities (i.e. how often the activity was offered, the number of people reached); interest in and plans for future health promoting activities; and (plans for) collaboration with other organizations in health promotion. The questionnaire included examples of possible health promoting activities, e.g. courses, workshops, lectures, environmental changes (i.e. changes to healthier foods in cafeterias, establishment of non-smoking areas, providing fitness facilities), the distribution of brochures and pamphlets, articles in company magazines, et cetera.

\section{Statistical analysis}

Results reported in this paper consist of frequencies or means and standard deviations of the baseline variables. A multiple logistic regression analysis was used to identify potential baseline differences between the Maastricht region and the control region. The dependent variable was a binary variable reflecting condition (Maastricht region versus control region). The independent variables in this analysis were the baseline values for gender, age, education, fat consumption, smoking behavior and physical activity level. All analyses were performed using the SPSS 10.0 statistical package (SPSS, 2000). Differences were considered to be statistically significant if $\mathrm{p}<0.05$.

\section{BASELINE DATA}

Individual level

Results reported below are baseline data from the random sample of 5,000 in the Maastricht region, and baseline data from the stratified random samples of the Maastricht $(n=1,450)$ and the control region $(n=1,200)$. The overall response to these baseline surveys was $56 \%$. 
Table 1.3: Baseline characteristics of the Maastricht region $(n=2,775)$ with respect to risk behaviors and their psychosocial determinants

\begin{tabular}{lccc}
\hline Variable & $\begin{array}{c}\text { Dietary } \\
\text { fat intake }\end{array}$ & Smoking & Physical activity \\
\hline
\end{tabular}

Risk behaviors

- Fat score (\% above the recommended level)

- Smokers (\%)

64.5

- Physical activity level

27.8

(\% not meeting the recommended target)

Psychosocial determinants

- Self-rated fat intake (\% (rather)high)

- Self-rated physical activity (\% (rather)low)

- Attitude (mean; score 2, -2)**

- Perceived behavior others (mean; score $2,-2$ )**

- Perceived social support (mean; score 2, 0)**

- Self-Efficacy (mean; score 2, -2)**

- Intention (mean; score 2, -2)**

- Category of awareness (\%)

- realistic, inadequate

- pessimistic, adequate

- optimistic, inadequate

- realistic, adequate

- Stage of change (\%)

- precontemplation

- contemplation

- preparation

$\begin{array}{rrr}0.98 & 1.38 * & 1.28 \\ -0.14 & -0.01 * & 0.10 \\ 0.43 & 0.67 * & 0.53 \\ 1.22 & 0.51 * & 1.00 \\ 0.02 & 0.33 * & 0.39\end{array}$

- action

- maintenance

* only smokers were included in the analyses

** higher scores indicate more positive determinants

\section{Maastricht region}

\section{Respondents}

Mean age was 45 years ( $\mathrm{SD}=17.2$ ), ranging from 14 to 95 . There were marginally more women (53\%) than men among the respondents. Thirty-one percent of the respondents had a low level of education (primary or basic vocational school), 46\% an intermediate level (secondary vocational school or high school degree), and 23\% a high level of education (higher vocational school, college degree or university degree). 
Table 1.4: Baseline demographic characteristics and prevalence of risk behaviors in the Maastricht and control region

\begin{tabular}{|c|c|c|}
\hline Variable & $\begin{array}{l}\text { Maastricht region } \\
\qquad(\mathrm{n}=820)\end{array}$ & $\begin{array}{l}\text { Control region } \\
\quad(n=624)\end{array}$ \\
\hline Age (mean; SD)* & $44.7(17.7)$ & $48.3(17.1)$ \\
\hline \multicolumn{3}{|l|}{ Gender $(\%)^{*}$} \\
\hline - male & 42.8 & 31.7 \\
\hline - female & 57.2 & 68.3 \\
\hline \multicolumn{3}{|l|}{ Education $(\%)^{*}$} \\
\hline- low & 30.8 & 38.9 \\
\hline - intermediate & 44.4 & 43.9 \\
\hline- high & 24.8 & 17.2 \\
\hline Fat score $(\% \text { above the recommended level })^{*}$ & 63.5 & 68.5 \\
\hline Smokers $(\%)$ & 30.3 & 24.6 \\
\hline Physical activity level (\% not meeting the recommended target)* & 57.4 & 53.4 \\
\hline
\end{tabular}

* significant baseline differences between Maastricht and control region (logistic regression analysis)

Dietary fat intake, smoking behavior, and physical activity (Table I.3)

Sixty-five percent of the respondents had a fat score above the approximated upper level of recommended dietary intake. Sixteen percent of the respondents rated their own dietary fat intake as (rather) high. Fifty-three percent of the respondents underestimated their fat intake, and $45 \%$ were in the precontemplation stage towards dietary fat reduction. Twenty-eight percent of the respondents reported that they had smoked in the last seven days. Of those who smoked, $68 \%$ were in the precontemplation stage. Fifty-eight percent of the respondents did not meet the recommended target for physical activity, and $30 \%$ rated their own physical activity as (rather) low. Thirty-five percent of the respondents overestimated their physical activity level, and 29\% were in the precontemplation stage. The general attitude towards changing all three (risk) behaviors, and self-efficacy towards dietary fat reduction and increasing physical activity were rather positive, although not optimal. Self-efficacy towards smoking cessation, perceived social support towards changing all three (risk) behaviors, the intention towards changing the (risk) behaviors, and especially the perceived behavior of others, were not very positive.

Baseline comparison between the Maastricht and control region

Table 1.4 presents baseline demographic characteristics and the prevalence of the three risk behaviors in the stratified random samples of the Maastricht and the control region. Logistic regression analysis revealed that respondents from the Maastricht region were significantly younger, more often male, higher edu- 
cated, more often had a fat score within the recommended level and were less often meeting the physical activity target than respondents from the control region.

\section{Organizational level}

The response to the organization survey in the Maastricht region was $49 \%$ $(n=340)$. Thirty-one percent of the organizations in the Maastricht region were involved in at least one health promoting activity regarding healthy eating, 30\% organized activities regarding smoking behavior, and $46 \%$ regarding physical activity. The mean number of activities within those organizations regarding healthy eating was 1.9 , regarding smoking behavior 1.4, and regarding physical activity 2.0. In $37 \%$ of the organizations there was at least one person within the organization concerned with health. Forty-five percent of the organizations were interested in and had plans for future health promoting activities, while $31 \%$ collaborated (or intended to collaborate) with other organizations in health promotion activities.

\section{DISCUSSION}

Individual baseline data of the intervention region reveal that substantial proportions of the respondents were performing the three risk behaviors. These data definitely warrant the development and implementation of a CVD-risk prevention program. Further, the baseline results confirm the appropriateness of the conceptual model that is used for the development of interventions and provide specific intervention objectives. Many respondents indeed are not aware of their risk behavior with respect to dietary fat intake and physical activity. Previous research has shown that people who are not aware of their risk behavior are not or less motivated to change their behavior (Weinstein, 1988; Ronda et al., 2001b). Therefore, it is important that information should focus on these misconceptions as a first step towards behavior change motivation.

Furthermore, a considerable percentage of the respondents was in the precontemplation stage towards changing the CVD risk behaviors, and self-efficacy towards smoking cessation, perceived social support towards changing the CVD risk behaviors, the perceived behavior of others, and the intention towards

24 changing the risk behaviors were far from optimal. Previous research on dietary change, smoking cessation, and exercise behavior has shown that psychosocial factors such as attitudes, perceived social influences, and self-efficacy expectations may differ between stages of change (Brug et al., 1997b; Lechner and De Vries, 1995). A recent study on exercise, for example, found that attitudes, per- 
ceived social support and self-efficacy were lower among precontemplators than among people in contemplation and preparation (Ronda et al., 2001b). As a consequence, changing attitudes, improving self-efficacy and creating a supportive (social) environment may be especially important among precontemplators.

The appropriateness of the choice of activities is confirmed by recent Dutch research with respect to health and its determinants. The population itself regarded dietary behavior and physical activity as the most important determinants of health. In addition, also smoking behavior was ranked high (Commers and De Leeuw, 2001). The results at the organizational level show that there are good opportunities for involving various organizations in the health promoting activities incorporated within Hartslag Limburg, as well as for increasing collaboration between these organizations in health promotion.

It is important to note some limitations of the present study. Firstly, the results are based on self-reports. Although the relative validity and reliability of the instruments that were used in the present study were found to be better or comparable to those used in other studies (Block et al., 1989; Pols et al., 1996), self-reports are often biased. Especially respondents within the intervention condition may be inclined to overreport desirable health behaviors and underreport undesirable behaviors (Koepsell et al., 1992; Windsor et al., 1994). To reduce this possible bias in the intervention condition, in both regions questions about health promoting activities were included in the questionnaire, giving both intervention and control participants the suggestion to be in the intervention condition. Furthermore, because of reasons of practical applicability, the number of questionnaire items for each health behavior had to be limited since multiple health behaviors were included, the psychosocial factors were measured with single items. Nevertheless, secondary analysis showed that these single-item assessments had significant and quite strong associations with intentions, which is a clear indication of the relative validity of the assessments of the psychosocial factors. The use of self-report data is 'usual practice' in community research (e.g., Brownson et al., 1995; Tudor-Smith et al., 1998). Because of practical constraints (i.e. large samples) it is hardly possible to use more objective impact indicators in community analyses. For example, taking and analyzing bloodsamples to evaluate dietary fat intake, or using accelerometers to assess levels of physical activity are very expensive and time consuming. Further, such measurements may interact with intervention activities and may lead to lower response rates (Windsor et al., 1994). The present response rates may not be optimal, but they are quite acceptable for a mail survey (Miller, 1994). Nevertheless, the present response rates may result in low external validity because the representativeness of the sample is not assured (Windsor et al., 1994).

A number of significant differences at baseline were found between the Maastricht and the control region (e.g., age, gender and educational level). This is a common complicating factor in evaluation studies on community-based interventions. Within community-based interventions it is impossible to randomly assign individuals to the intervention and control region. Therefore no equality on key variables can be expected. However up-to-date techniques for 
statistical analysis make it possible to control for potential confounding factors. Variables identified as being statistically different $(\mathrm{p}<0.05)$ between respondents from the Maastricht region and the control region, will be included as independent variables in future regression analyses of differences between the Maastricht and control region.

Furthermore, in the present study only one intervention and one control region were included, although both consist of several municipalities, and allocation to intervention or control region was nonrandom. It is a limitation of this type of community research that it is rarely possible to involve several communities and to random allocate them to intervention or control conditions. Cost and feasibility considerations usually limit the intervention and evaluation to a small number of communities, and allocation to treatment groups is often done beforehand by funding agencies or communities themselves (Koepsell et al., 1992). Besides that, 'blinding' of communities is not possible. Most community interventions have used the 'one-group-per-condition' design and this design is a well accepted design in the field of community intervention research (e.g., Carleton et al., 1995; Tudor-Smith et al., 1998). To partly overcome the design weakness, our future analyses of differences between the Maastricht and the control region will use the pre-intervention level of the outcome variables as an independent variable in all effect analyses. Furthermore, multilevel analysis will be used to take into account possible dependencies among individuals within the same municipality (Hedeker et al., 1994). Several other community projects used statistical procedures for adjustments for dependencies among individuals within municipalities (e.g., Carleton et al., 1995; Brownson et al., 1996). Multilevel analysis evaluations of community-based interventions is however regarded as superior, but has not often been applied yet.

Moreover, community interventions should not be considered solely as a trial of treatment (Shelley et al., 1995). The strengths of community interventions lies also in process evaluation which can make important contributions to the development and implementation of future interventions and health promotion programs (McGraw et al., 1994; Shelley et al., 1995; Goodman, 1998).

The evaluation design that is used to evaluate the community part of Hartslag Limburg is an attempt to incorporate findings from other studies with respect to the evaluation of community-based programs (Shea and Basch, 1990; Koepsell et al., 1992; Goodman, 1998; Glasgow et al., 1999), and follows to a large extent the recommendations for health promotion evaluation (Koelen et al., 2001). This has resulted in an extensive and comprehensive evaluation design. Because of the use of a conceptual framework, the evaluation will result in information beyond mere conclusions about the presence or absence of health behavior change. The evaluation will provide information about the 26 assumed relationships between the different stages. When certain expected results on behavior change are not found, using the framework may enable conclusions about the step of the intervention process depicted in Table 1.1 in which the change chain was broken, and lessons to be learned from this evaluation may possibly be applied to future research and programs. 
In conclusion, baseline results show that there is a great need for changing CVD risk behaviors, but little willingness to do so. This confirms the need for a comprehensive CVD prevention community project, with special attention to people who are not yet motivated to change, and who are unaware of their risk behavior. This project should be evaluated on impact as well as process at different levels of the community in order to be able to assess changes at multiple social levels. 



\section{CHAPTER 2}

\section{STAGES OF CHANGE, PSYCHOSOCIAL FACTORS AND AWARENESS OF PHYSICAL ACTIVITY LEVELS \\ IN THE NETHERLANDS}

\section{Published as:}

Ronda, G.,Van Assema, P. and Brug, J. (200I) Stages of change, psychological factors and awareness of physical activity levels in the Netherlands. Health Promotion International, 16, 305-314. 


\section{ABSTRACT}

The purpose of this study was to investigate physical activity levels, stages of change, awareness, and differences in psychosocial factors relating to physical activity in an adult Dutch population, in order to identify specific objectives for physical activity promotion.

Physical activity levels, self-rated physical activity, stages of change, awareness, attitudes, social influences, and self-efficacy relating to physical activity were assessed among a random sample of 2,608 adults using structured questionnaires.

Almost $60 \%$ of the respondents did not meet the recommended target for physical activity to promote health. Half of these respondents were in the precontemplation stage, and $>60 \%$ were overestimating their physical activity level. Furthermore, respondents who were not aware of their inadequate physical activity level had a less positive intention to increase their level of physical activity than those who rated their own physical activity level as low. Respondents in the precontemplation and maintenance stages had a less positive attitude, perceived less social support and had lower self-efficacy expectations towards increasing physical activity than those in the contemplation, preparation and action stages.

The results suggest that interventions aimed at increasing physical activity in the studied population should be aimed at increasing awareness of personal activity levels and should be stage-matched. 


\section{INTRODUCTION}

Regular physical activity is regarded as an important component of a healthy lifestyle, decreasing, for example, the risk of cardiovascular diseases, noninsulin-dependent diabetes mellitus, hypertension, colon cancer, and obesity (Pate et al., 1995; U.S. Department of Health and Human Services, 1996). Also, physical activity is important for the health of muscles, bones, and joints (U.S. Department of Health and Human Services, 1996; Vuori, 1998). More and more health promotion efforts are therefore being initiated to persuade the public to exercise on a regular basis. Planned health promotion aimed at behavioral change should be based on empirical knowledge about present behavior, behavioral determinants and mechanisms of behavioral change (Green and Kreuter, 1991). The present study aims to contribute to our understanding of motivation to increase physical activity levels in an adult population, in order to identify specific objectives for physical activity promotion among adults.

\section{How much physical activity is recommended?}

Until recently, the standard recommendation was to engage in moderate to high intensity (performed at $60-90 \%$ of maximum heart rate) physical exercise at least three times a week, for a continuous 20 to 60 minutes (Pate et al., 1995; Van Mechelen, 1996). This advice was primarily aimed at improving or maintaining physical fitness. However, the present view is that health promotion and disease prevention can also be achieved with regular, moderately intensive activities. Therefore, the current recommendation is that all adults should accumulate 30 minutes or more of moderate-intensity physical activity on at least five, preferably all, days of the week (Pate et al., 1995; Kemper et al., 2000). Such activities may include for example gardening, brisk walking, bicycling, housework, and dancing (Pate et al., 1995; Jones et al., 1998). People who are currently physically inactive can be those who benefit most from increasing their activity to the recommended level. However, most people who are already regularly physically active can also expect health and fitness benefits from becoming more physically active (Pate et al., 1995; U.S. Department of Health and Human Services, 1996; Kemper et al., 2000).

\section{How physically active are the Dutch?}

Only two studies have been published that investigated the prevalence of activity and inactivity among Dutch adults, based on the moderate intensity recommendations. According to these studies, $40-53 \%$ of Dutch adults met the present target (Hoeben, 1998; Hildebrandt et al., 1999).

More data on physical activity levels have been collected in the U.S. The Surgeon General's Report on Physical Activity and Health, published in 1996, 
brings together what has been learned about physical activity and health from decades of research in the United States. According to this report less than $40 \%$ of the American adults achieved the amount of physical activity recommended for health promotion (U.S. Department of Health and Human Services, 1996). An Australian study showed that $56 \%$ of the employees of 20 worksites could be classified as physically active (Simpson et al., 2000).

\section{Why are some people sufficiently physically active while others are not?}

Little is known about the reasons why Dutch adults engage in physical activity or may decide to increase their activity levels. A single Dutch study on the psychosocial determinants of starting participation in an employee fitness program revealed that it was important to be convinced of the advantages of the fitness program, such as improved physical condition, and of the personal ability and possibilities to participate in the program (Lechner and De Vries, 1995).

However, this study did not focus on the type of physical activity referred to in the recommendations, and was conducted among a specific population group.

The Surgeon General's Report on Physical Activity and Health found that confidence in one's ability to engage in regular physical activity, enjoyment of physical activity, support from others, positive beliefs concerning the benefits of physical activity, and lack of perceived barriers to being active were consistent influences on physical activity patterns among adults and young people in the U.S. (U.S. Department of Health and Human Services, 1996).

\section{Theoretical framework}

The Stages of Change concept from Prochaska and DiClemente's Transtheoretical model has been used extensively to study different health related behaviors including exercise (Prochaska and DiClemente, 1992; Lechner and De Vries, 1995; European Commission, 1999; Laforge et al., 1999). Five stages of change can be distinguished: precontemplation, contemplation, preparation, action and maintenance. In the precontemplation stage, people are not considering increasing their physical activity level, at least not within six months. In contemplation, people are considering increasing their physical activity level within six months, and in the preparation stage they intend to increase their physical activity level within 30 days, and they are often making specific plans to do so. In the action stage, people have already started to exercise more, while people in maintenance are sustaining the desired level of physical activity. An important implication of stages of change is that people in different stages may need stage-matched interventions to proceed to a further stage of change since people in earlier stages of change may differ in psychosocial factors, experiences, skills and abilities from people in later stages of change. The stage-matched Physician-based Assessment and Counseling for Exercise (PACE) intervention 
was shown to be effective in a short-term study in the United States (Calfas et al., 1996).

Awareness of personal risk behavior is supposed to be especially important to proceed from precontemplation to contemplating behavior change. Based on Weinstein's Precaution Adoption model, it can be expected that people may only proceed to contemplation when they are aware that they personally engage in too little physical activities (Weinstein, 1988). For health risk behaviors that are clearly defined, often dichotomous, and for all to see (like for example smoking), awareness is not an issue. For more complex health risk behaviors research has shown that many people are indeed not aware of their risk behavior and consequently do not perceive a need to change. As a result, they may not be motivated to change (Brug et al., 1994; Lechner et al., 1997). Physical activity is a complex health related behavior in that it consists of a possibly large number of different activities and behaviors that are spread out over each day, like cycling to the mall, walking the stairs at work, jogging in the evening, et cetera. Therefore, evaluating the adequacy of one's own level of physical activity may be difficult, which makes awareness of personal activity level a potential determinant of the intention to increase activity levels. Awareness of personal physical activity level has not been studied as a determinant of increasing physical activity before.

Earlier studies on exercise behavior, smoking cessation and dietary change, have shown that psychosocial factors like attitudes, perceived social influences and self-efficacy expectations may differ in subjects being in different stages of change (Marcus et al., 1992, De Vries and Backbier, 1994; Lechner and De Vries, 1995; Godin et al., 1995; Brug et al., 1997a; Brug et al., 1997b; De Vries and Mudde, 1998). This may have further consequences for stage-tailored interventions.

\section{Research questions}

The present study specifically aimed to analyze stages of change and awareness levels of physical activity among the general population, utilizing an integration of the above-mentioned models. The research questions were as follows.

- What proportion of Dutch adults achieve the recommended level of physical activity, and what physical activities are most common?

- How are adults distributed over the different stages of behavioral change related to physical activity, and which psychosocial factors are important in differentiating persons who are in the different stages of behavioral change?

- How many adults are aware of their activity levels, and does the intention to increase physical activity levels vary according to the level of awareness of physical activity? 


\section{METHODS}

\section{Respondents and procedures}

Data were derived from a baseline measurement for the community-based intervention project called Hartslag Limburg (Heartbeat Limburg), which was conducted in June 1998. This project attempts to encourage the general population in Southern Limburg (a province of the Netherlands) to increase their level of physical activity, to reduce their fat intake, and to stop smoking. The project started in 1998 and will continue until at least 2003. A full description of the project has been published elsewhere (Ruland et al., 1999). At baseline, a cohort research sample was selected by taking a random sample of 1,000 inhabitants (aged 14 and over) from the population registers of each of the five municipalities of Southern Limburg (total sample size of 5,000). Data were gathered by means of structured questionnaires, sent by mail (two attempts were made). Questions were asked about physical activity, dietary habits, and smoking habits as well as about psychosocial determinants of these behaviors. The present study used only data with respect to physical activity from respondents aged 18 and over in the five Southern Limburg municipalities. After the exclusion of respondents $<18$ years of age,

2,608 respondents remained. The response rate for this study population was $56 \%$.

\section{Questionnaire}

\section{Physical activity}

Physical activity levels were assessed with a newly developed short questionnaire based on the recommended levels of physical activity to promote health.

Respondents were asked to indicate on how many days a week they engaged in various physical activities for at least five minutes at a time. Respondents were further asked to indicate for how many minutes a day, on average, they engaged in these activities. The examined physical activities are listed in Table 2.1.

This questionnaire allowed a physical activity score to be calculated in minutes and in sessions per week. In addition, respondents were asked to indicate directly on how many days a week they were physically active for at least 30 minutes. Respondents who had a physical activity score of at least 150 minutes per week and at least five sessions per week, and who indicated that they were physically active for at least five days a week for at least 30 minutes a day, were classified as meeting the recommended target.

The relative validity of the questionnaire was investigated by comparison with a seven-day physical activity record. The Spearman rank order coefficient between the two methods was 0.50 and Cohens kappa was 0.33 . The Spearman rank order coefficient for the test-retest reliability was 0.73 and Cohens kappa was 0.58 (Koremans et al., 2000). These relative validity data are in the same order as those reported in other studies with respect to physical activity (Richardson et al., 1995; Pols et al., 1996; Pols et al., 1997). 


\begin{tabular}{|c|c|c|c|}
\hline \multirow{5}{*}{ Self-rated physical activity } & \multicolumn{2}{|c|}{ Objectively assessed physical activity } & \multirow{5}{*}{$\begin{array}{l}\text { (rather) high } \\
\text { intermediate }\end{array}$} \\
\hline & not meeting the recommended target & meeting the recommended target & \\
\hline & Overestimator & Realistic, adequate & \\
\hline & Realistic, inadequate & Underestimator & \\
\hline & & & \\
\hline
\end{tabular}

Figure 2.I: Classification of respondents into categories of awareness

\section{Psychosocial factors}

Attitudes towards increasing physical activity levels were measured with two items. Respondents were asked to evaluate their attitude towards increasing their physical activity level on a five-point 'bad-good' scale and on a five-point 'unpleasant-pleasant' scale $(\alpha=0.53)$. Because an alpha higher than 0.5 can be considered to be sufficient for summation of item scores in explorative research (Nunnally, 1967), one attitude score was calculated by computing the mean score of the two items. Perceived behavior of others was measured by asking respondents to assess how physically active other people in their direct social environment ('important others ', e.g., spouse, family, friends, colleagues) were on average on a five-point scale, with answers ranging from 'hardly active' to 'highly active'. Perceived social support was measured by asking respondents how much support they received from these important others to increase their physical activity level on three-point scale, with answers ranging from 'no support' to 'much support'. Self-efficacy towards increasing physical activity levels was assessed by asking respondents how confident they were about their ability to increase their physical activity level on a five-point scale, with answers ranging from 'not confident' to 'very confident'. Intention to increase physical activity levels was assessed by asking respondents whether they intended to increase their physical activity level in the future on a five-point scale, with answers ranging from 'certainly not' to 'certainly'.

Self-rated physical activity was assessed by asking respondents whether they rated their physical activity level as low or high on a five-point scale (low, rather low, intermediate, rather high, high). Respondents were allocated to four categories of awareness, based on their self-rated physical activity level as compared to the results of the more objective assessment from the physical activity questionnaire (Figure 2.1). Respondents who met the recommended physical activity target, but who rated their activity levels as (rather) low were classified 


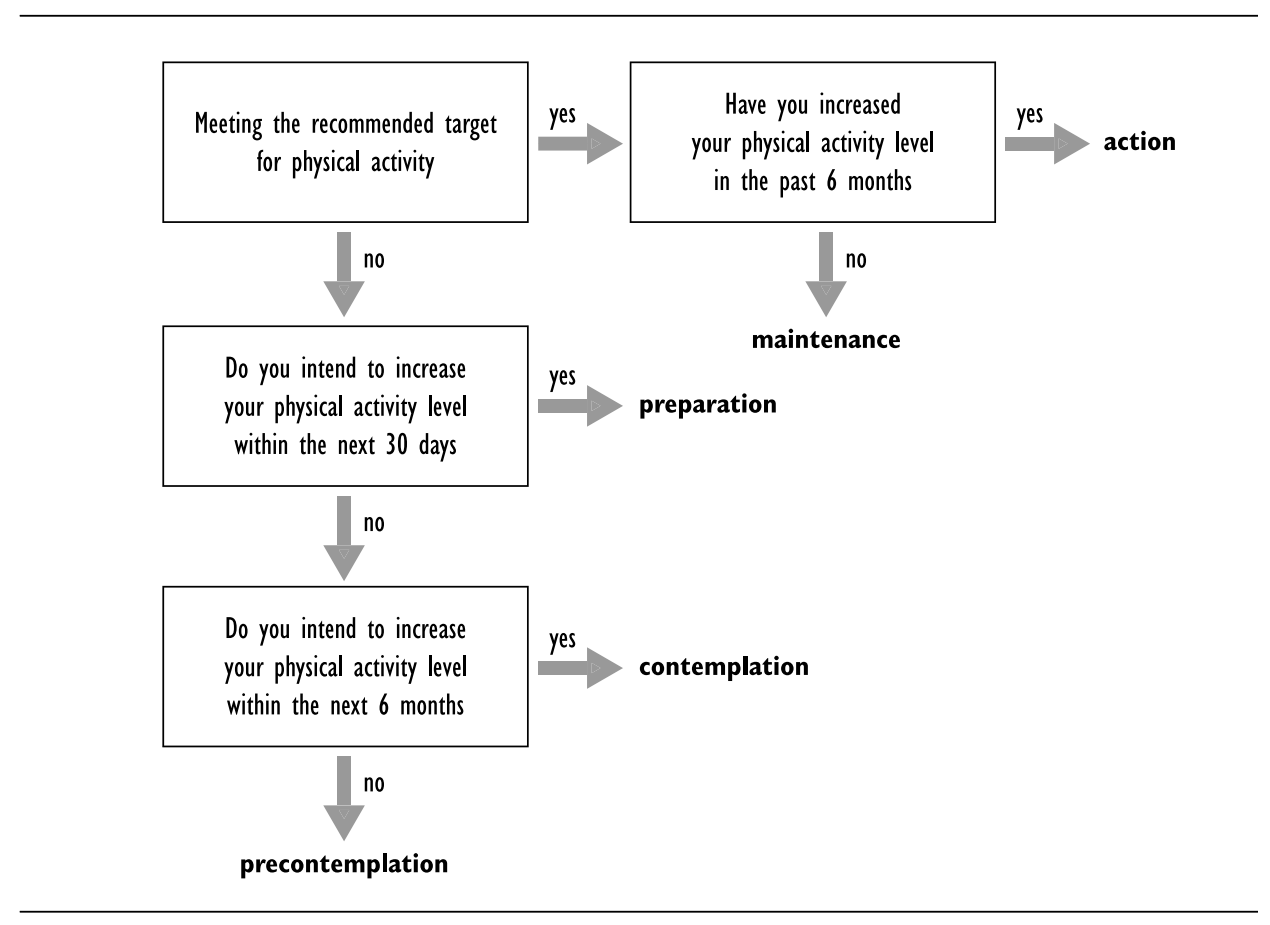

Figure 2.2: Classification of respondents into stages of change

as underestimators. Respondents who did not meet the recommendations and rated their physical activity level as intermediate or higher were classified as overestimators. The remaining respondents had realistic self-assessments about their adequate or inadequate activity level.

The algorithm used to categorize respondents into stages of change is presented in Figure 2.2. First, respondents were asked if they intended to increase their physical activity level within the next six months (yes/no) and, if so, whether they planned to do this within the next 30 days (yes/no). In addition, respondents were asked if they had changed their level of physical activity in the past six months (increase/decrease/no change). Respondents who met the recommended physical activity target were classified as being in action if they indicated they had increased their physical activity level in the past six months. Otherwise, they were classified as being in maintenance. The remaining respondents were classified as being in preparation if they reported the intention to 36 increase their physical activity level within 30 days, in contemplation if they intended to increase their physical activity level within six months, and in precontemplation if they had no intentions to increase their physical activity level.

Finally, questions about sex, age, and education were included in the questionnaire. 


\section{Statistical analysis}

Descriptive statistics (frequencies) were used to answer the question: 'How many Dutch adults achieve the recommended level of physical activity, and what physical activities are most common?', and to compute the distribution over stages of change and different awareness categories. One-way analysis of variance with Scheffé's multiple comparison test was used to test for significant differences in mean scores for attitude, perceived behavior of others, perceived social support, self-efficacy expectations, and self-rated physical activity between the five stages of change. Furthermore, one-way analysis of variance with Scheffé's multiple comparison test was used to test for significant differences in the intention to increase physical activity levels between the four categories of awareness. Differences were considered to be statistically significant if $\mathrm{p}<0.05$. All analyses were performed using the SPSS 7.5 statistical package (SPSS, 1997).

\section{RESULTS}

\section{Respondents}

Mean age was 46 years ( $\mathrm{SD}=16)$, ranging from 18 to 95. There were marginally more women (53\%) than men among the respondents. Thirty-one percent of the respondents had a low level of education (primary or basic vocational school), $45 \%$ a medium level (secondary vocational school or high school degree), and $24 \%$ a high level of education (higher vocational school, college degree or university degree). Compared with the general Dutch adult population, the higher educated were somewhat $(5 \%)$ over-represented in the present sample (Statistics Netherlands, 1997).

\section{Physical activity}

Although $51.4 \%$ of the respondents reported to be physically active for $30 \mathrm{~min}$ utes on at least five days a week, not all of these respondents had a physical activity score of at least 150 minutes per week distributed over at least five weekly sessions. Therefore, after corrections for all three criteria, $41,7 \%$ met the recommended physical activity levels.

Table 2.1 shows the proportions of respondents engaged in various physical activities. The most common activities were stairwalking (76\%), heavy housework $(62 \%)$, brisk walking (61\%), bicycling (52\%), and gardening (52\%). 
Table 2.1: Percentages of respondents engaged in the various activities on at least one day a week, for at least five minutes at a time $(n=2,608)$

\begin{tabular}{ll}
\hline Activity & $\%$ \\
\hline Stairwalking & 76 \\
Heavy housework (like washing floors) & 62 \\
Brisk walking & 61 \\
Bicycling & 52 \\
Gardening & 52 \\
Home repair/do-it-yourself & 37 \\
Gymnastics/aerobics/fitness, and such & 22 \\
Swimming & 12 \\
Other activities, like dancing & 12 \\
In- and outdoor team sports & 9 \\
Jogging/running & 8 \\
Tennis/squash & 7 \\
Skating/roller-skating & 2 \\
Combat sports & 1 \\
Rowing/canoeing & 1 \\
\hline
\end{tabular}

Table 2.2: Mean scores on psychosocial factors and self-rated physical activity for the five stages of behavioral change: precontemplation $(P)$, contemplation $(C)$, preparation $(P R)$, action $(A)$, and maintenance $(M)$ $(n=2,380)$

\begin{tabular}{|c|c|c|c|c|c|c|}
\hline Psychological factors & $P$ & C & $P R$ & A & M & $\begin{array}{l}\text { Scheffe's multiple comparison test } \\
(P<0.05)\end{array}$ \\
\hline Attitude* & 0.83 & 1.38 & 1.56 & 1.27 & 0.99 & $P<M<C, \operatorname{Pr}, A ; A<\operatorname{Pr}$ \\
\hline Perceived behavior others** & 0.04 & 0.08 & 0.05 & 0.16 & 0.17 & \\
\hline Perceived social support*** & 0.42 & 0.57 & 0.67 & 0.70 & 0.47 & $P, M<P r, A ; P<C$ \\
\hline Self-efficacy* & 0.67 & 1.16 & 1.32 & 1.35 & 1.01 & $P<M<P r, A ; P<C$ \\
\hline Self-rated activity** & 0.01 & -0.48 & -0.44 & 0.48 & 0.36 & $C, P R<P<A, M$ \\
\hline
\end{tabular}

* score ranges from -2 (most negative answer towards increasing physical activity) to +2 (most positive answer towards increasing physical activity)

** score ranges from -2 (low physical activity level) to 2 (high physical activity level)

**** score ranges from 0 (no support towards increasing physical activity) to 2 (much support towards increasing physical activity) 
Table 2.3: Mean scores of intention to increase physical activity levels for the four categories of awareness $(n=2,428)$

\begin{tabular}{lc}
\hline Category of awareness & $\begin{array}{c}\text { Intention* } \\
\text { score ranges from }-2\end{array}$ \\
\hline & (certainly not) to +2 (certainly) \\
Realistic, inadequate (RI) & 0.66 \\
Underestimator (U) & 0.70 \\
Overestimator (0) & 0.33 \\
Realistic, adequate (RA) & 0.23 \\
\hline
\end{tabular}

Significant differences in Scheffé's multiple comparison test $(\mathrm{P}<0.05)$ : RA, $\mathrm{O}<\mathrm{RI}, \mathrm{U}$

\section{Stages of change and differences in psychosocial factors and self-rated physical activity between subjects in different stages}

Of the respondents $29.6 \%$ were in the precontemplation stage, $10.4 \%$ in contemplation, $18.3 \%$ in preparation, $10.1 \%$ in action, and $31.6 \%$ in the maintenance stage. Approximately half of the respondents (50.8\%) with an inadequate activity level (i.e. they were not meeting the recommended target), did not intend to increase their levels of physical activity (i.e. they were in precontemplation).

Table 2.2 shows that respondents in the precontemplation stage had a significantly less positive attitude, perceived significantly less social support and had significantly lower self-efficacy expectations towards increasing their physical activity level than respondents in the contemplation, preparation, and action stages. Furthermore, self-rated physical activity in precontemplation was significantly higher than in the contemplation and preparation stages.

\section{Awareness and differences in intention according to awareness}

Most respondents were realistic about their level of physical activity (57.1\%) (34.5\% were realistic about their adequate physical activity level and $22.6 \%$ about their inadequate level) but a substantial proportion of the respondents (35.6\%) were overestimating their physical activity level, and a small minority (7.2\%) underestimated their physical activity level. Among respondents with an inadequate activity level, a majority (61.1\%) overestimated their physical activity.

Respondents who overestimated their physical activity level were significantly less likely to intend to increase their activities than respondents who were aware of their inadequate level of physical activity (Table 2.3). 


\section{DISCUSSION}

Almost $60 \%$ of the respondents in the present study did not meet the current recommendations for physical activity to promote health. Half of these respondents were in the precontemplation stage, and $>60 \%$ of those who did not meet the recommendation were overestimating their physical activity level. Furthermore, respondents who were not aware of their inadequate physical activity level had a less positive intention to increase their level of physical activity than those who rated their own physical activity level as low, which was also reflected in the higher self-rated physical activity levels among precontemplators. Some further differences were found in psychosocial factors between respondents in different stages of change. Generally, respondents in the precontemplation and maintenance stages had a less positive attitude, perceived less social support and had lower self-efficacy expectations than those in the contemplation, preparation and action stages.

Despite the different methods used to assess moderate physical activity participation rates, the physical activity levels that were found in the present study were in line with the results of the two earlier studies in the Netherlands (Hoeben, 1998; Hildebrandt et al., 1999). As in the present study, walking, cycling, and gardening were found to be popular physical activities in the panEU (European Union) consumer attitudinal survey (European Commission, 1999). Stairwalking and heavy housework were not assessed in the pan-EU survey. However, it seems unlikely that so many $(76 \%)$ respondents in the present study walked stairs for at least five minutes at a time. A probable explanation for this high proportion of intensive stairwalking might be that respondents accumulated their stairwalking time throughout the day.

Two studies that used the same descriptions of the stages of change, but somewhat different definitions of regular exercise behavior, found that approximately half of the respondents were in the pre-action stages (precontemplation, contemplation, or preparation), and that a substantial proportion of these respondents were in the precontemplation stage (European Commission, 1999; Laforge et al., 1999). The present study suggests that awareness of the adequacy of personal activity levels is important for the motivation to increase activity levels. Among inactive people self-rated physical activity was highest in subjects in precontemplation. Unrealistic self-assessment may be an important barrier to encourage precontemplators to move forward in the behavioral change process. This finding is in line with earlier studies on different complex health-related behaviors like fat intake and fruit and vegetable consumption (Brug et al., 1997a; Lechner et al., 1997).

The differences in psychosocial factors that were found in subjects being in 40 different stages of change further imply that health education aimed at physical activity should be stage-matched. Differences in psychosocial factors between subjects in the different stages of behavioral change were also found in other studies of exercise behavior (Marcus et al., 1992; Lechner and De Vries, 1995; Godin et al., 1995). However, such a comparison should be interpreted with 
caution, since different staging algorithms were used, partly because the behaviors of interest were not the same and because different population groups were studied. Nevertheless, these studies also found the lowest scores on attitude and self-efficacy measures in persons in the precontemplation stage. In the present study, psychosocial scores of respondents in maintenance were quite similar to those in precontemplation. Psychosocial factors were measured in relation to behavior change (increasing physical activity) and not in relation to present behavior. Therefore, respondents in maintenance might not be motivated to increase their physical activity level since their physical activity level is already according the current recommendations, which might cause their psychosocial scores to be quite similar to those in precontemplation.

It is important to note some limitations of the present study. Firstly, the present study had a cross-sectional design, so no conclusions about causality can be drawn. Secondly, the results were based on self-reports. For example, no objective measures of energy expenditure were obtained. However, using instruments like the accelerometer to assess long-term physical activity patterns may be asking too much from study participants and may result in selection bias and response bias. The validity and reliability of the instrument used in the present study was reasonable. The results were comparable with those found in other studies with respect to physical activity (Richardson et al., 1995; Pols et al., 1996; Pols et al., 1997).

Furthermore, the psychosocial factors were measured with a very short questionnaire with single items. However, secondary analysis showed that these single-item assessments had significant and quite strong associations with exercise intentions (e.g. the correlation between self-efficacy and intention was 0.44). This is a clear indication of the relative validity of the assessments of the psychosocial factors. Self-rated physical activity was also assessed in a rather crude manner. Further research is therefore warranted to confirm the present findings with more extensive assessment instruments. Finally, the results were based on inhabitants of the Southern Limburg region and the response was not optimal. Our results may therefore not be representative of the general Dutch population, although regional differences within a relatively small and generally affluent country like the Netherlands do not tend to be large. Furthermore, a response rate of $56 \%$ is quite acceptable for a mail survey (Miller, 1994).

\section{Practical implications}

Despite the above-mentioned limitations, some practical implications of the present study can be suggested. First of all, the substantial proportion of people who do not meet the minimum recommended physical activity levels confirms the need for public health initiatives aimed at getting people to increase their physical activity. But people who overestimate their level of physical activity may not be susceptible to interventions aimed at increasing their level of physical activity because they see no need to change. For this reason, improving 
physical activity awareness may be an important first step in physical activity interventions. Communication about the present recommendations accompanied by a self-test to assess one's own physical activity level may offer a good strategy for increasing this awareness. Furthermore, so-called computer tailored interventions are used nowadays to give people personalized advice on physical activity. Feedback on adequacy of current personal activity levels is often part of these tailored interventions (De Vries and Brug, 1999).

Health education aimed at encouraging people to increase physical activity levels should further be aimed at more positive attitudes, at coping with an unsupportive social environment, and at increasing self-efficacy expectations, especially for people in the earlier stages of change. Attitudes may be influenced by communicating the possible benefits of physical activity. Apart from the longer term health consequences, possible short term benefits in particular should be emphasized (Baranowski et al., 1997). This could include communications about physical activity e.g. as a good way to meet people, and as a good way to cope with work stress and to feel better. In order to negate possible negative beliefs about physical activity, it may be important to emphasize that it is not necessary to engage in vigorous, continuous exercise to gain health benefits. As a way of increasing self-efficacy expectations, we may communicate that a moderate amount of physical activity can be achieved in a variety of ways, and that people may select activities that they enjoy, that fit into their daily routines and for which no specific skills are necessary. The above-mentioned implications for attitudes and self-efficacy expectations are very much in line with the recommendations based on data from the pan-EU consumer attitudinal survey (European Commission, 1999).

It has been postulated that the low and declining levels of physical activity in our modern society is caused primarily by environmental changes.

Mechanization and automatization of transportation and labor, urbanization with lack of opportunities to exercise in city environments have reduced our daily energy expenditure (Hill and Peters, 1998). Increasing awareness of individual exercise levels may motivate people in precontemplation but in order to proceed to action and maintenance, environmental changes may also be essential.

In conclusion, the present study has provided some insights into the physical activity habits and the psychosocial determinants of increasing physical activity levels in an adult Dutch population. The study provides starting-points for interventions aimed at increasing physical activity levels, and a base-line level to evaluate these interventions. 


\title{
CHAPTER 3
}

\author{
THE DUTCH HEART HEALTH COMMUNITY \\ INTERVENTION 'HARTSLAG LIMBURG': \\ RESULTS OF AN EFFECT STUDY AT INDIVIDUAL LEVEL
}

Submitted for publication as:

Ronda, G., Van Assema, P., Candel, M., Ruland, E., Steenbakkers, M., Van Ree, J. and Brug, J. The Dutch Heart Health Community Intervention 'Hartslag Limburg': Results of an Effect Study at Individual Level. 


\begin{abstract}
Hartslag Limburg (Dutch for Heartbeat Limburg), a regional cardiovascular diseases (CVD) prevention program, integrates a community strategy and a highrisk strategy to reduce CVD risk behaviors. The present paper focuses on the effects of the community intervention on fat intake and physical activity. The project was based on community organization principles and health education theories and methods. In order to implement the intervention, nine local Health Committees were set up, each organizing activities that facilitate and encourage people to adopt a healthier lifestyle. A pretest-posttest control group design with two posttests was used to evaluate the intervention. At baseline, representative random cohort research samples were selected in the Maastricht region and in a control region. Data on fat intake and physical activity, and on the psychosocial determinants of these behaviors, were gathered by means of structured questionnaires. The present study indicates that the intervention had a significant effect on fat reduction, especially among respondents aged $\leq 48$ years (median age). Respondents in the Maastricht region were also more realistic about their fat intake at posttest as compared to the control region. Only a limited effect on intentions to increase physical activity was found. It is concluded that the results of the present study lend some support to the assumption that a reduction in CVD-related behaviors can be achieved by means of a community intervention.
\end{abstract}




\section{INTRODUCTION}

The greatest cause of morbidity and mortality in the Netherlands is cardiovascular disease (CVD) (Konings-Dalstra and Reitsma, 1999). Since behavioral factors, such as smoking, lack of physical activity and dietary habits, are important determinants of CVD risks, encouraging behavioral changes may help to reduce and prevent these risks (Blackburn, 1992).

In 1998, a regional CVD prevention program was started in the Maastricht region of the province of Limburg, called Hartslag Limburg (Dutch for Heartbeat Limburg). The major goal of the project is to reduce cardiovascular diseases in the Maastricht region. The Maastricht region has approximately 180,000 inhabitants and consists of the city of Maastricht (the capital of the province of Limburg, 120,000 inhabitants) and four smaller adjacent municipalities (12,000 to 21,000 inhabitants each). Hartslag Limburg is a joint project of the municipal authorities of the Maastricht region, the Maastricht Regional Public Health Institute (RPHI), two community social work organizations, the regional community health care organization, general practitioners, cardiologists, Maastricht University, the University Hospital, and various local organizations, clubs and companies. The project is to continue until at least 2003. The ultimate goal of the project is an organizational structure in which the collaboration between the main partners is given a formal and permanent basis, so that long-term continuity in terms of attention to the prevention of CVD is assured. Hartslag Limburg has special characteristics, both in terms of its intervention approach and its evaluation design. Firstly, it integrates two strategies: a population strategy (which is the focus of the present article) aiming at all inhabitants and specifically at low socioeconomic status groups, and a high-risk strategy, focusing on individuals diagnosed with CVD or diagnosed as having multiple physical risk factors for CVD. Furthermore, the intervention is based on community organization principles and methods as well as on health education theories and methods. Moreover, a comprehensive evaluation design to study the effects and processes that lead to the expected outcomes, as well as an evaluation of the cost-effectiveness of the entire project, are integral parts of the project (Ruland et al., 1999). Contemporary community evaluation literature emphasizes the importance of program effect measurement at different social levels, the importance of process evaluation in addition to effect evaluation, and the use of a theoretical model to guide the evaluation (e.g., Goodman, 1998; Glasgow et al., 1999; Thompson and Kinne, 1999). The evaluation design that was used to evaluate the community part of Hartslag Limburg incorporated findings obtained from these studies, and consisted of an effect study and a process study, using measures at both the individual and organizational level (Ronda et al., in press).

The present article presents the methods and results of the effect study of the community intervention on individual behaviors, i.e., the effects on dietary fat intake and physical activity, as well as the effects on the psychosocial determinants of these behaviors. 


\section{The community intervention program and its evaluation study}

The conceptual framework of Hartslag Limburg's community project is based on program planning and evaluation models, and consists of several stages (Table 3.1) (e.g., Green and Kreuter, 1999). The framework indicates how the program is expected to produce its postulated effects and serves as the program planning as well as evaluation framework (Ronda et al., in press). Within the framework, community organization principles and methods and health education theories and methods are applied. The main community organization principles included in the project are participation of the community in the planning and implementation of the project, intersectoral collaboration between local organizations, link-up with the current situation (e.g., supporting existing CVD health-promoting initiatives), a social network approach, an environmental strategy (e.g., providing healthier food choices in cafeterias), and a multi-media and multi-method strategy. The specific intervention activities are based on a conceptual model that integrates different theoretical frameworks and theoretical concepts, i.e., the precaution adoption model (Weinstein, 1988) and the Attitude - Social influence - Self-Efficacy (ASE) model (De Vries et al., 1988; Ajzen, 1991). These concepts are described in the questionnaire section.

In order to implement the intervention, nine local Health Committees were set up: one in each of the four smaller municipalities, one in each of four underprivileged Maastricht neighborhoods, and one to coordinate and implement regional activities. Each Health Committee organizes, within its district or municipality, activities that facilitate and encourage people to adopt a healthier lifestyle, i.e., to reduce their intake of (saturated) fat, to increase their physical activity level, and to stop smoking. Prior to the official start of the project, in the spring of 1998, community analyses were conducted by the RPHI, and by two community social work organizations. Key figures in the five communities and the four neighborhoods were interviewed. The major goals of these analyses were to introduce the project in the communities, to achieve early community involvement, and to evaluate the local situations in order to assess which members from which organizations and community sectors should be approached for participation in the Health Committees. Reports on the results of these community analyses were sent to all key figures interviewed. Afterwards, members of organizations and community sectors identified during these community analyses were approached to participate in the Health Committees. Throughout the rest of the year 1998, the Health Committees were set up. Each Health Committee consists of approximately ten members, who are generally representatives of local organizations that may play a key role in healthy behavior promoting activities, such as women's associations, associations of the elderly and health organizations. The Health Committees meet approximately ten times a year. The community intervention was officially started in October 1998 with a regional campaign to promote physical activity among individuals over 55, which was organized by the RPHI in collaboration with a national organization, and with the help of many other organizations and 
Table 3.I: Conceptual framework of the community project and the evaluation study

\begin{tabular}{|c|c|c|c|c|c|}
\hline A Health & $\begin{array}{l}\text { B Risk behaviors } \\
+-\end{array}$ & $\begin{array}{l}\text { C Psychosocial } \\
\text { determinants }\end{array}$ & $\begin{array}{l}\text { D Prevention } \\
\text { activities }\end{array}$ & E Community principles & $\begin{array}{l}\text { F Project components } \\
-\end{array}$ \\
\hline- CVD & $\begin{array}{l}\text { - high fat intake } \\
\text { - smoking } \\
\text { - not enough } \\
\quad \text { physical activity }\end{array}$ & $\begin{array}{l}\text { - attitudes } \\
\text { - social influences } \\
\text { - self-efficacy } \\
\text { - awareness } \\
\text { - intention }\end{array}$ & $\begin{array}{l}\text { - number } \\
\text { - reach } \\
\text { - effects }\end{array}$ & $\begin{array}{l}\text { - participation } \\
\text { - intersectoral collaboration } \\
\text { - link-up with current } \\
\text { situation } \\
\text { - social network approach } \\
\text { - environmental strategy } \\
\text { - multi-media and } \\
\quad \text { multi-method strategy }\end{array}$ & $\begin{array}{l}\text { - community analyses } \\
\text { - Health Committees } \\
\text { - quality control }\end{array}$ \\
\hline
\end{tabular}

volunteers in the region (NOC*NSF, 1999). At about the same time, the Health Committees officially started their activities. In order to facilitate the work of the Health Committees, the RPHI encourages and assists them in organizing as many healthy behavior promoting activities as possible, which have been carefully selected on the basis of earlier studies (Ronda and Van Assema, 1997). Moreover, each Committee is supported by a health educator from the Maastricht RPHI, a social worker and a civil servant of the municipality. At 32 months into the project, 293 activities had been registered. One hundred and sixty-six of these activities concerned nutrition, 84 physical activity, 15 smoking, and 28 activities were more general and targeted more than one risk behavior. Specific activities were tested in controlled preliminary studies. Examples of such (ongoing) activities include computer-tailored nutrition education (Brug et al., 1998), nutrition tours in supermarkets (Van Assema et al., 1998), a regional daily television program 'Heartbeat on the move' to promote physical activity (Ronda et al., 2001a), walking and cycling months (Ruland et al., 2001), a regional smoking cessation campaign (Ruland et al., 2001), and a non-smoking campaign for the parents of children in playgroups (Ruland et al., 2001). In addition, there are ongoing activities trying to draw attention to the project and its specific activities, such as commercials on local television and radio, newspaper articles, and posters and pamphlets. The main partners in the Hartslag Limburg community intervention are the city councils of Maastricht and four adjacent municipalities, the RPHI, two community social work organizations, the regional community health care organization, and various local organizations. Collaboration between these partners is achieved through the Health Committees. Scientific evaluation of the community project is carried out by Maastricht University and by the National Institute for Public Health and Environment. Initial project funding came from the Netherlands Heart Foundation, which continues to fund the scientific evaluation of the project. Planning for continuation of the project, along with long-term commitment by 
the partners and regional stakeholders, started from the beginning. Meanwhile, national project funding has been replaced by locally based funding by the participating municipalities and a health insurance company. In January 2001, the World Health Organization (WHO) selected Hartslag Limburg as one of twelve so-called 'field projects', based on its potential to meet pre-established criteria of the WHO project 'Towards Unity for Health' (Boelen, 2001).

Evaluation measures were developed for all stages of the intervention and evaluation framework (Table 3.1), except for stage A (Health), since no detectable effects at this level can be expected within a limited number of years. The evaluation study consisted of an effect study (reported on in the present paper), and a process study. The purpose of the effect study was to study effects at both individual and organizational levels. At the individual level, it examined the effects on the prevalence of the risk behaviors, and on the psychosocial determinants of these behaviors. At the organizational level, it examined the effects on the number of organizations organizing CVD health promoting activities, and on the total number of health promoting activities.

The methods and results of the effect study at the individual level are presented in the next sections.

\section{METHODS}

The objective of the effect study at the individual level was to evaluate the effects of the community intervention (i.e., the overall program of interventions) on the prevalence of the selected CVD risk behaviors: (high) dietary fat intake, physical inactivity, and smoking, as well as on the determinants of these behaviors. The present article reports on the effects on dietary fat intake and physical activity, as well as the effects on their psychosocial determinants. Effects on smoking behavior were studied in a separate sample and will be reported elsewhere.

The research questions for the present paper were: 1) Has there been a positive change in dietary fat intake and physical activity levels in the Maastricht region compared with the control region?, and 2) Has there been a positive change in the psychosocial determinants related to decreasing dietary fat intake and increasing physical activity in the Maastricht region compared with the control region?

\section{Design and sample}

To assess differences between the experimental and the control region at the individual level, a pretest-posttest control group design was used, with two 
posttests (Cook and Campbell, 1979). The baseline measurement was conducted in May 1998, the first posttest in May 2000, and the second posttest in May 2001. Each survey was conducted in May to minimize seasonal confounding. At baseline, representative random cohort research samples were selected in both regions. In the Maastricht region, a stratified random sample of 1,450 inhabitants (age 14 and over), based on the number of inhabitants in each of the five municipalities, was selected from the population registers of each of the five municipalities. A stratified random sample of 1,200 inhabitants (age 14 and over), based on the number of inhabitants in each municipality, was selected from the population registers of six municipalities of a comparable control region. These sample sizes were based on a power of .95 to detect a priori hypothesized effect sizes at a significance level of 0.05 .

The control region was selected on the basis of the following characteristics: 1) comparable with respect to the incidence and prevalence of CVD;2) comparable with respect to the number of inhabitants, number of municipalities, and degree of urbanization; and 3) no plans for a similar prevention project in the near future.

\section{The questionnaire}

Data on dietary fat intake and physical activity level, and on the determinants of these behaviors, were gathered by means of structured questionnaires, sent by mail. Non-responders were reminded once at baseline and twice at follow-up, a new copy of the questionnaire being included with the reminders.

\section{Risk behaviors}

Dietary fat intake was assessed using a validated questionnaire covering nineteen (groups of) food products that contribute most to the consumption of saturated fat in the Netherlands. A fat consumption score ranging from 0 to 80 points was calculated (Van Assema et al., 2001). Fat scores of 15 points for women and 18 points for men are the approximate upper levels of recommended dietary intake. The relative validity of the questionnaire was investigated by comparison with a seven-day diet record $(\mathrm{R}=0.71)$ (Van Assema et al., 2001). Physical activity levels were assessed with a newly developed short questionnaire based on the recommended levels of physical activity promoting health (Ronda et al., 2001b). This questionnaire allowed a physical activity score to be calculated in minutes and in sessions per week. In addition, respondents were asked to indicate directly on how many days a week they were physically active for at least 30 minutes. Respondents who had a physical activity score of at least 150 minutes per week and at least five sessions per week, and who indicated that they were physically active for at least 30 minutes a day on at least five days a week, were classified as meeting the recommended target. The relative validity of the questionnaire was investigated by comparison with a seven-day physical activity record $(R=0.50)$ (Koremans et al., 2000; Ronda et al., 2001b). 


\section{Psychosocial determinants}

Measures of a selection of psychosocial determinants of the target behaviors were included in the evaluation questionnaires in order to assess intermediate intervention effects. The selection of these psychosocial factors was based on theories of determinants of health behavior and on recent empirical evidence on determinants of the specific target behaviors. In the most commonly used theories on psychosocial determinants of health behaviors, intentions are regarded as the most proximal determinant of behavior (De Vries et al., 1988; Ajzen, 1991). Furthermore, three psychosocial factors are recognized as important predictors of behavioral intentions: attitudes, social influences and self-efficacy expectations (De Vries et al., 1988; Ajzen, 1991). Many studies have been conducted in recent years to identify additional important psychosocial determinants. Based on Weinstein's Precaution Adoption model, it can be expected that only people who are aware of their own behavior will contemplate changing their risk behavior (Weinstein, 1988). For dietary behaviors as well as physical activity, awareness of one's own performance has been identified as an important factor (Brug et al., 1994; Ronda et al., 2001b). Attitudes, social support, self-efficacy expectations, and intentions related to decreasing dietary fat intake and increasing physical activity, as well as self-rated dietary fat intake and physical activity level were therefore included in the effect evaluation. These psychosocial factors relevant in changing the two behaviors were assessed with single items for each target behavior, except for attitudes towards physical activity (two items). Respondents were asked to evaluate their attitudes towards the different behaviors on a 'bad-good' scale, and for physical activity also on an 'unpleasantpleasant' scale (e.g., how good or bad do you think it would be for you to be more physically active/eat less fat ). Afterwards, one score for attitude towards increasing physical activity was calculated by computing the mean score of the two items $(R=0.52)$. Furthermore, the questionnaire asked respondents if they intended to change each of the two behaviors in the future (intention), how confident they were about their ability to make such changes (self-efficacy), and if they experienced support from important others to change the behaviors (directly perceived social support). All items, with the exception of perceived social support (yes/no), could be answered on bipolar five-point scales.

Self-rated dietary fat intake and self-rated physical activity were assessed by asking respondents whether they rated their own fat intake and physical activity level as low or high (bipolar five-point scale). Respondents were allocated to two categories of awareness (aware/unaware) on the basis of their self-rated levels as compared to the results of the more objectively assessed levels.

Respondents whose fat consumption levels were low, but who rated them (rather) high were classified as unaware of their intake level. Respondents whose fat consumption levels were not low, but who rated them as intermediate or low, were also classified as unaware of their intake level. The remaining respondents were classified as realistic. A similar procedure was used to classify respondents on awareness of physical activity. 
Furthermore, the first and second posttest included a question measuring respondents' familiarity with a health project in their municipality. Familiarity with a health project was measured as an assessment of conscious exposure to an intervention and to assess whether familiarity in the Maastricht region exceeded familiarity in the control region. Finally, respondents were questioned about their sex, age and education.

\section{Statistical analysis}

Descriptive statistics (frequencies and means) were used to describe demographic characteristics, dietary fat consumption, physical activity level, and familiarity with a health project. A multiple logistic regression analysis was conducted to identify potential dropout bias (with attendance versus dropout as the dependent variable and baseline values for gender, age, education, fat consumption, physical activity level, and condition as independent variables). A further multiple logistic regression analysis was used to identify potential baseline differences between the Maastricht region and the control region. The dependent variable was a binary variable reflecting condition (Maastricht region versus control region). The independent variables in this analysis were the baseline values for gender, age, education, fat consumption, and physical activity level. Only respondents who completed all surveys were included. These preliminary analyses were performed using the SPSS 10.0 statistical package (SPSS, 2000). Variables identified as being statistically different $(\mathrm{p}<0.05)$ between respondents who participated in all three surveys and dropouts, and between respondents from the Maastricht region and the control region, were included as independent variables in subsequent, regression analyses of differences between the Maastricht region and the control region.

To study differences in risk behaviors and their psychosocial determinants between the Maastricht and the control region, multilevel regression analysis was used for all outcome variables (continuous, dichotomous and ordinal), using the MlwiN (Rasbash et al., 1999) statistical package and the MIXOR statistical package (Hedeker and Gibbons, 1996). Multilevel regression analysis was used to take into account possible dependencies among individuals within the same municipality (Snijders and Bosker, 1999). Ordinary regression analysis at the individual level assumes that each observation is independent. However, individuals within a municipality cannot be assumed to be independent, and misinterpretations may result when cluster influences are not accounted for. On the other hand, in the cases in which multilevel analysis reveals that the individuals within municipalities can be regarded as independent, ordinary regression at the individual level will also be possible, since ordinary regression at the individual level is a special case of the multilevel model when all the cluster effects equal zero (Hedeker et al., 1994). Therefore, when this was the case (i.e., all cases, except with fat scores as dependent variable), analyses were repeated using 'ordinary' regression within the SPSS statistical package. Results 
in SPSS (SPSS, 2000) were consistent with the results found with 'one level' models in MlwiN (Rasbash et al., 1999) and MIXOR (Hedeker and Gibbons, 1996).

The main independent variable included in all analyses was condition (Maastricht region versus the control region). Furthermore, several other independent variables were included, on the basis of their known or suspected relation with the outcome variables. Firstly, we controlled for the pre-intervention scores on the relevant effect indicators (fat intake, physical activity level and determinants of these behaviors). Furthermore, gender, age, education, and familiarity with a health project, and the interaction terms of these variables with condition were included as independent variables in all analyses. Also, the intention to change behavior (i.e., decrease fat intake and increase physical activity) at baseline, self-rated behavior at baseline, and their interaction terms with condition were included as independent variables in the analyses of behavioral change. In the cases for which significant $(\mathrm{p}<0.05)$ interactions were found, subsequent 'simple effects analyses', i.e., subgroup analyses, were done. For subgroup analyses concerning age, this variable was dichotomized at the median (48 years).

All analyses were done in a so-called 'TOP-DOWN' procedure, in which all variables were first included in the model, after which non-significant variables (with the exception of condition) were excluded from the model in a hierarchical and stepwise procedure.

All of the analyses used a two-sided significance level of 5\% (with the exception of random cluster effects, for which a one-sided significance level of 5\% was used, since these random parameters are zero or greater than zero). Because the analyses comprised many tests, and the expected number of Type I errors increases with the number of tests, exact values are provided for all p-values $<0.05$ relating to the research questions, so that readers can evaluate the $\mathrm{p}$ values for themselves.

Overall condition effects, main effects of other independent variables, interaction effects, as well as condition effects of subgroup analyses are presented in the next section.

\section{RESULTS}

\section{Respondents}

Response to the baseline survey was $55.5 \%(\mathrm{n}=1,444 ; 820(57.5 \%)$ in the Maastricht region and 624 (52.9\%) in the control region (46 questionnaires were undeliverable). Fifteen cases were excluded from analysis because of 
Table 3.2: Demographic characteristics at T0, and key-variables at TO,TI, and T2 in the Maastricht region $(n=505)$ and in the control region $(n=392)$

\begin{tabular}{lllll}
\hline Variable & Group & T0 & T1 & T2 \\
\hline Age (mean; SD)* & Maastricht & $47.8(16.9)$ & & \\
& control & $49.3(15.8)$ & & \\
Gender (\%)* & & & & \\
- male & Maastricht & 43.2 & & \\
& control & 33.7 & & \\
- female & Maastricht & 56.8 & & \\
& control & 66.3 & & \\
Education & & & & \\
- low & Maastricht & 30.5 & & \\
& control & 37.8 & & \\
- intermediate & Maastricht & 44.8 & & \\
& control & 40.8 & & \\
- high & Maastricht & 24.8 & & $17.3(5.8)$ \\
& control & 21.4 & & $19.4(6.3)$ \\
Fat score (mean; SD)* & Maastricht & $18.6(6.2)$ & $18.7(6.1)$ & \\
& control & $20.1(6.9)$ & $20.0(6.3)$ & \\
Physical activity level & Maastricht & 57.2 & 60.8 & 57.9 \\
(\% not meeting the target) & control & 51.8 & 54.0 & 50.9 \\
Familiarity with a health project & Maastricht & - & 23.2 & 23.2 \\
(\% familiar) & control & - & 17.9 & 17.3 \\
\hline
\end{tabular}

* significant baseline differences between Maastricht and control region (logistic regression analysis)

** significant differences between Maastricht and control region (logistic regression analysis)

incomplete data, leaving 809 respondents in the experimental region, and 620 in the control region. Attrition rate from baseline (T0) to second posttest (T2) was $37.2 \%$ in the total group. Because of 92 undeliverable questionnaires in 2000 and 28 undeliverable questionnaires in 2001, the net attrition rate from T0 to T2 was $31.5 \%$. Overall, 897 respondents completed all three questionnaires: 505 in the experimental region and 392 in the control region. Logistic regression analysis revealed that attrition did not differ between the two regions. However, dropouts were found to be younger and less educated than those who participated in all three measurements. Table 3.2 shows baseline demographic characteristics, dietary fat intake and physical activity level at baseline, first and second posttest, and familiarity with a health project at first and second posttest. Respondents from the Maastricht region were significantly younger, more often male, and had a lower dietary fat intake at baseline than respondents from the control region (Table 3.2). 


\section{Familiarity with a health project}

In 2000 (T1) and in 2001 (T2), respondents' familiarity with a health project in their municipality was measured in both regions (Table 3.2). In 2000, $23.2 \%$ of the respondents in the Mastricht region reported to be familiar with a health project in their municipality. This proportion was $17.9 \%$ in the control region. In 2001 , these percentages were $23.2 \%$ and $17.3 \%$ respectively. The differences were statistically significant in both years.

\section{Dietary fat intake and psychosocial determinants}

Table 3.3 shows the parameter estimates for dietary fat intake and its determinants at the first (T1) and second (T2) posttest. There was an overall condition effect on the fat score at T1. Respondents in the Maastricht region had a lower fat score at T1 than respondents in the control region. Furthermore, there was an interaction effect between age and condition on the fat score at T1. Further exploration of this interaction showed that the overall condition effect on the fat score was fully attributable to the younger half ( $<49$ years) of the population studied. Respondents younger than 49 years in the Maastricht region had a lower fat score than respondents of that age in the control region $(B=-1.207 ; p=.003)$. A similar interaction effect between age and condition on the fat score was detected at T2, and further exploration showed again that respondents younger than 49 years in the Maastricht region had a lower fat score than respondents of that age in the control region $(\mathrm{B}=$-.992; $\mathrm{p}=.026)$. A further interaction effect between familiarity with a health project and condition on the fatscore was present at T2. Further exploration of this interaction effect showed that respondents who were familiar with a health project in the Maastricht region had a lower fat score than respondents who were familiar with a health project in the control region, but this effect was not statistically significant $(p=.078)$.

Respondents who were familiar with a health project in their community reported more social support towards decreasing their fat intake at T2 than those who were not familiar with such a health project $(\mathrm{OR}=1.463 ; \mathrm{p}=.045)$. Besides, there was an overall condition effect on self-efficacy in the opposite direction at T2. Respondents in the control condition had higher self-efficacy expectations towards decreasing their fat intake than respondents in the Maastricht region $(\mathrm{OR}=1.31 ; \mathrm{p}=.037)$. There was also an overall condition effect on awareness of one's own fat intake at T1. Respondents in the Maastricht region were more realistic about their fat intake at $\mathrm{T} 1$ than respondents in the control region $(\mathrm{OR}=1.401 ; \mathrm{p}=.034)$. Finally, there was an interaction effect between gender

54 and condition at T1 on awareness of one's own fat intake. Further exploration of this interaction effect showed that the overall condition effect on awareness of one's own fat intake was fully attributable to the women in the population studied. Women in the Maastricht region were more realistic about their own fat intake at T1 than women in the control region $(\mathrm{OR}=1.869 ; \mathrm{p}=.003)$. 


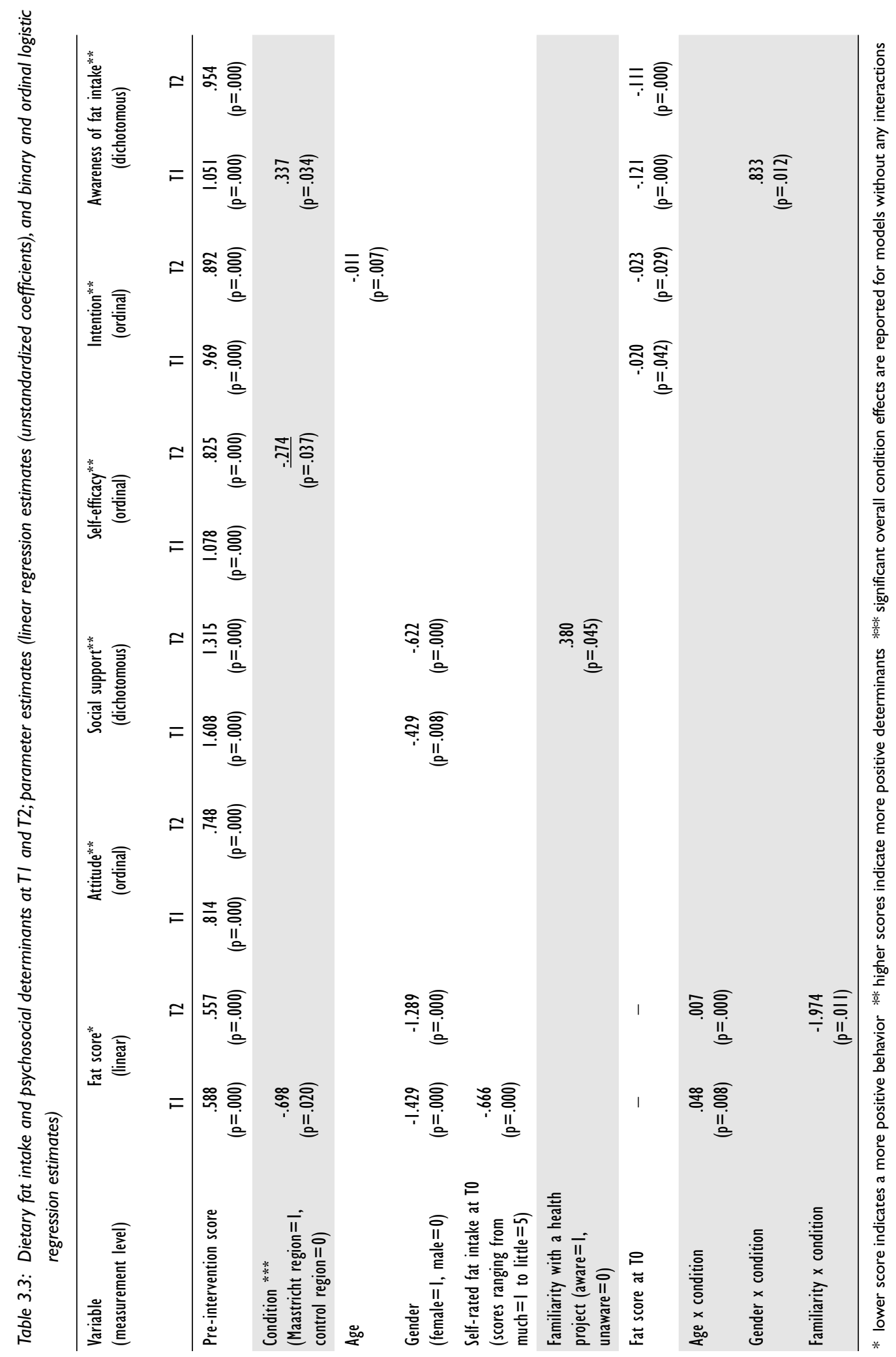




\section{Physical activity and psychosocial determinants}

Table 3.4 shows the parameter estimates for physical activity and its determinants. There were no overall condition effects on physical activity and its determinants. At $\mathrm{T} 1$, the attitude $(\mathrm{OR}=1.397 ; \mathrm{p}=.029)$ and self-efficacy $(\mathrm{OR}=1.742$; $\mathrm{p}=.001)$ towards increasing physical activity were more positive among respondents who were familiar with a health project in their community than among those who were not familiar with such a health project. Furthermore, there was an interaction effect between age and condition on the intention to increase physical activity in the future at T1. Further exploration of this interaction revealed that the intention towards increasing physical activity level was more positive among respondents younger than 49 years in the Maastricht region than among respondents of that age in the control region $(\mathrm{OR}=1.543 ; \mathrm{p}=.015)$. There was also an interaction at T2 between familiarity with a health project and condition on awareness of one's own physical activity level. Further exploration of this interaction effect showed that respondents who were familiar with a health project in the Maastricht region were more realistic about their physical activity level than respondents who were familiar with a health project in the control region, but this effect was not statistically significant $(p=.056)$.

\section{DISCUSSION}

The major goal of the Hartslag Limburg community intervention was and is to reduce cardiovascular diseases in the Maastricht region by encouraging the general population to reduce their fat intake, to increase their level of physical activity, and to stop smoking. The development and implementation of the project were based on community organization principles as well as on health education theories and methods.

The present study found a significant difference between the Maastricht region and the control region, in favor of the Maastricht region, with respect to dietary fat intake, especially among respondents younger than 49 years.

Respondents in the Maastricht region were also more realistic about their fat intake but had lower self-efficacy expectations towards decreasing their fat intake than respondents in the control region. With respect to physical activity, only a limited effect on intentions was found.

The decline in dietary fat intake over time in the Maastricht region relative to the control region, especially for the younger half of the studied population, is a promising result. Although overall mean fat scores (Table 3.2) do not clearly illustrate this result, the necessary adjustment procedures for factors like gender and age did clarify the difference. The higher self-efficacy expectations towards decreasing fat intake at the final measurement in the control region may not be 


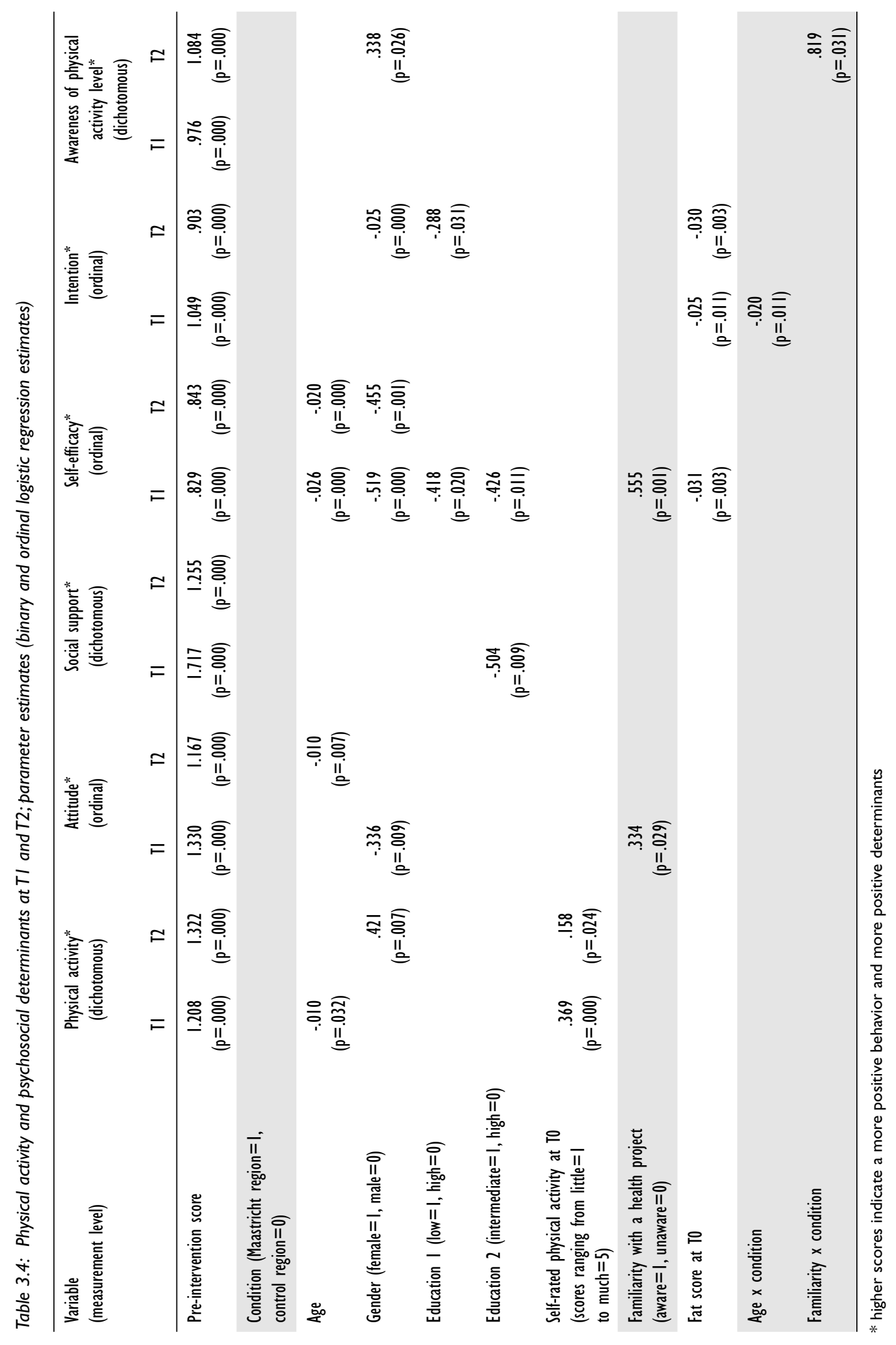


incompatible with the decline in fat intake in the Maastricht region, because self-efficacy was measured in relation to behavior change (i.e., 'eating less fat') and not in relation to present behavior (i.e., 'eating a low fat diet'). Therefore, respondents who had reduced their fat scores (i.e., respondents in the Maastricht region) might have become less confident about their ability to further decrease their fat intake.

With respect to physical activity, the results were less promising. In fact, the overall prevalence of physical inactivity had increased in both regions at the first posttest relative to baseline values. At the second posttest, the prevalence of physical inactivity was about the same as at baseline. Since each survey was conducted in the same month (May) to minimize seasonal confounding, a possible explanation for the initial decline in physical activity might be the weather conditions in that particular spring. Although no positive effects on physical activity levels were found, the intention towards increasing physical activity levels was more positive among the younger half of the population in the Maastricht region than among those in the control region.

Furthermore, familiarity with a health project in general had a positive effect on some effect measures. Besides, there was some indication for a condition effect in favor of the Maastricht region in case of the familiarity group.

As we mentioned in the introduction, most of the registered activities in the Maastricht region were aimed at nutrition, and this might be an explanation for the positive results on dietary fat intake. However, it should be mentioned that although the effects were especially found among the younger half of the population, the activities did not particularly focus on this group. Furthermore, preliminary analysis of the process evaluation data of the Hartslag Limburg Community Intervention revealed, for example, that there is a growing participation of local organizations and community members, and intersectoral collaboration between local organizations in the Maastricht region, so longer-term measures of individual behaviors may show greater changes.

It is difficult to compare the effects of the Hartslag Limburg community intervention with those observed in other Dutch or foreign community projects, because effect measurements differed between projects, different behaviors were studied, and effects were measured over different time periods. Nevertheless, some comparisons can be made. Like the present study, the most recent community-based CVD prevention programs found few significant program effects (e.g., Winkleby et al., 1997). Some other projects studying the same behaviors as the present study, however, reported some positive effects on dietary behavior or reported an increased prevalence of regular physical activity (e.g., Van Assema et al., 1994; Browson et al., 1996; Tudor-Smith et al., 1998). Possible explanations frequently mentioned for the modest or absent intervention effects in community CVD prevention programs are: secular trends, i.e., it might be difficult to generate enough additional exposure in experimental communities to exceed secular trends in control communities; smaller than expected net differences in behavior change; ineffective interventions; and inaccurate survey data and/or measures (e.g., Carleton et al., 1995; Browson et al., 1996; 
Winkleby et al., 1997). Although the present study found that the familiarity with a health project in the Maastricht region exceeded that in the control region, these data also suggest a substantial perceived exposure to health promotion interventions in the control region, in spite of the fact that no similar prevention project was started in the control region between 1998 and 2002. Further, preliminary analysis of the process evaluation data of the Hartslag Limburg Community Intervention revealed that although familiarity with nutritional as well as physical activity and smoking cessation activities was higher in the Maastricht region, actual participation in physical activity and smoking cessation activities was higher in the control region. Unfortunately, baseline values with regard to familiarity and participation are unknown. Also, the net differences in behavior change found in the present study were smaller than expected. Although there are several indications of effective individual components of the intervention program (Brug et al., 1998; Van Assema et al., 1998; Ronda et al., 2001a), process data also showed that actual participation of the general population in activities did not exceed $15 \%$, indicating that the intervention did not reach a large enough fraction of the population to show greater changes. Finally, the possibility of inaccurate survey data and/or measures can not be neglected, and therefore it is important to note some limitations of the present study. Firstly, the response at baseline was $55.5 \%$. This is certainly not optimal, although regarded as quite acceptable for a mail survey (Miller, 1994). Nevertheless, the response rate in the present study may indicate low external validity because the representativeness of the sample is not assured (Windsor et al., 1994). Compared with the general Dutch population, more highly educated respondents were somewhat (5\%) over-represented in the Maastricht region while low education levels were somewhat $(7 \%)$ over-represented in the control region, which means that intermediate education levels were under-represented in both regions (Statistics Netherlands, 1997). Secondly, there was a substantial dropout in the sample from baseline to endpoint (31.5\%), which is an intrinsic feature of the longitudinal nature of the study. Dropouts were found to be younger and less educated than those who remained in the sample. However, our analyses controlled for potential confounding or interaction with condition by the above-mentioned factors. A further disadvantage of the cohort design is repeated questioning, implying the possibility that the survey itself may have an effect on the behavior of participants, especially when there is differential re-examination bias in the intervention and control condition (Koepsell et al., 1992; Salonen et al., 1986). In addition, the results are based on selfreports. Although the relative validity and reliability of the instruments used in the present study have been found to be better than or comparable to those used in other studies (Block et al., 1989; Pols et al., 1996), self-reports are often biased. Respondents in the intervention condition in particular may be inclined to overreport desirable health behaviors and underreport undesirable behaviors (Koepsell et al., 1992; Windsor et al., 1994). To reduce this possible differential bias, due to both repeated testing and the use of self-reports, questions about health promoting activities were included in the questionnaire in both regions, 
giving both intervention and control participants the suggestion that they had been included in the intervention condition.

A further measurement issue is the use of single item assessments for the determinants of the CVD risk behaviors, since single item assessments may be not sensitive enough to detect small intervention effects. However, practical limitations (survey questionnaire size) made us decide to use these single items for assessment of determinants. Secondary analysis showed that these assessments had significant and quite strong associations with intentions, which is a clear indication of the predictive validity of the assessments of the psychosocial factors. The use of self-report data is 'usual practice' in community research (e.g., Brownson et al., 1995; Tudor-Smith et al., 1998). Because of practical constraints (i.e. large samples) it is hardly possible to use more objective impact indicators in community analyses. For example, taking and analyzing bloodsamples to evaluate dietary fat intake, or using accelerometers to assess levels of physical activity, is very expensive and time consuming. Such measurements may also interact with intervention activities and may lead to lower response rates (Windsor et al., 1994). However, especially the physical activity indicator that was used in the present study might not have been accurate enough to detect changes.

A further limitation of the present study is its design. The study included only one intervention and one control region although both consist of several municipalities. Allocation to intervention or control region was nonrandom, and 'blinding' of communities was not possible. In community research, it is rarely possible to involve several communities and to allocate these at random to intervention or control conditions. Cost and feasibility considerations usually limit the intervention and evaluation to a small number of communities, and allocation to treatment groups is often done beforehand by funding agencies or the communities themselves (Koepsell et al., 1992). Most community interventions have used the 'one-group-per-condition' design and this design is well accepted in community intervention research (e.g., Carleton et al., 1995; TudorSmith et al., 1998; Vartiainen et al., 1998). To partly overcome the design weakness, our analyses of differences between the Maastricht and the control region did use the pre-intervention level of the outcome variables as an independent variable in all effect analyses. The ability to adjust for baseline differences is one of the major advantages of the cohort design (Salonen et al., 1986). Overall, although the present study has several limitations, often intrinsic to community research, one of the major strengths of the evaluation study of the Hartslag Limburg Community Intervention was the use of multilevel analysis to take into account possible dependencies among individuals from the same municipality, and the comprehensive data collection at different levels. 


\section{Conclusions and implications}

The evaluation provides us with valuable information about dietary fat intake and physical activity levels and their determinants, and about changes over time. Although there were few significant intervention effects, the decrease in dietary fat intake over time in the Maastricht region was a promising result. However, the results of the present study should be seen against the background of the results of the process evaluation and the results of the effect evaluation at the organizational level, to allow the effectiveness of the community intervention as a whole to be judged.

In summary, the results of the present study lend some support to the assumption that a reduction in CVD-related behaviors can be achieved by means of a community intervention. 



\title{
CHAPTER 4
}

\author{
THE DUTCH HEART HEALTH COMMUNITY \\ INTERVENTION 'HARTSLAG LIMBURG': \\ EFFECTS ON SMOKING BEHAVIOR
}

Accepted for publication as:

Ronda, G., Van Assema, P., Candel, M., Ruland, E., Steenbakkers, M., Van Ree, J. and Brug, J. (in press) The Dutch Heart Health Community Intervention

'Hartslag Limburg': Effects on Smoking Behaviour. European Journal of Public Health. 


\begin{abstract}
Background and Methods: A pretest-posttest control group design with two posttests was used to evaluate the effects of a regional Dutch Heart Health Community Intervention on smoking behavior and its determinants. At baseline, a cohort research population of 1,200 smokers was recruited in the intervention region and in a control region. Data was gathered by means of short structured telephone interviews. Results: No significant differences were found between the intervention region and the control region on smoking behavior and its determinants. Conclusion: It is concluded that the regional intervention was unable to exceed secular trends in smoking cessation.
\end{abstract}




\section{INTRODUCTION}

In 1998, a regional cardiovascular diseases (CVD) prevention program, integrating a community strategy and a high-risk strategy, was started in the Maastricht region of the province of Limburg, called Hartslag Limburg (Dutch for Heartbeat Limburg). Hartslag Limburg is a joint project of the municipal authorities of the Maastricht region, the Maastricht Regional Public Health Institute (RPHI), community social work organisations, the regional community health care organisation, general practitioners, Maastricht University, the University Hospital, and various local organisations, clubs and companies. In January 2001, the World Health Organisation (WHO) selected Hartslag Limburg as one of twelve so-called 'field projects', based on its potential to meet pre-established criteria of the WHO project 'Towards Unity for Health' (Boelen, 2001). The major goal of the community intervention is to reduce CVD risk among the 180,000 inhabitants of the region by encouraging behavioral change, i.e., dietary fat reduction, increased physical activity, and smoking cessation. The project is to continue at least until 2003.

The implementation of the Hartslag Limburg community intervention in the Maastricht region involved several smoking cessation activities. The most important was the regional mass media-led smoking cessation campaign 'Proficiat' ('Congratulations') implemented in January and February 2000 and 2001 (Ruland et al., 2001). This campaign, organised by the RPHI, consisted of radio commercials, advertisements and messages in papers, billboards along roads, and posters and postcards in waiting rooms and public buildings. Additionally, there were smaller local activities, organised by working groups consisting of representatives of local organisations, such as a non-smoking campaign for the parents of children in playgroups (Ruland et al., 2001). It was supposed that the inhabitants of the Maastricht region would feel more involved with these regional activities than with a national mass media-led smoking cessation campaign 'Dat kan ik ook' ('I can do that too') that was implemented around the turn of the century in the Netherlands. This national campaign consisted of various television programmes, an info line, non-smoking courses, mailings to various organizations, billboards in bus shelters, brochures, posters, et cetera.

This report presents the effects of the Hartslag community intervention on smoking behavior. A description of the full project has been published elsewhere (Ruland et al., 1999).

METHODS

\section{Design and sample}

To assess differences between the Maastricht and a control region (where there was no community intervention), a pretest-posttest control group design was 
used, with two posttests (Cook and Campbell, 1979). The baseline measurement was conducted in April 1998, the first posttest in April 2000, and the second posttest in April 2001. At baseline, a cohort research population of 1,200 smokers (age 18 and over) was recruited in each region by taking a stratified random sample of 6,500 inhabitants in each region from the computerized telephone registers, based on the number of inhabitants in each municipality included in the region.

The control region was comparable with respect to the incidence and prevalence of CVD, number of inhabitants, number of municipalities, and degree of urbanization.

\section{The questionnaire}

Data on smoking behavior and its determinants was gathered by means of short structured telephone interviews. Smoking behavior was assessed by asking respondents whether they had smoked in the last seven days (yes/no). Only smokers were further questioned at baseline. Smokers were asked if they had made quit attempts in the past year. Measurements of a selection of psychosocial determinants of smoking behavior were included in order to assess intermediate intervention effects. The selection of these psychosocial factors was based on the Theory of Planned Behavior and the Transtheoretical Stages of Change (Ajzen, 1991; Prochaska and DiClemente, 1992). Smokers were asked to evaluate their attitudes towards smoking cessation on a 'bad-good' scale, and on an 'unpleasant-pleasant' scale. Furthermore, smokers were asked if they intended to stop smoking in the future (intention), how confident they were about their ability to stop smoking (self-efficacy), and if they experienced support from important others to stop smoking (perceived social support). All items, with the exception of perceived social support (yes/no), could be answered on bipolar five-point scales.

Smokers were also asked if they intended to stop smoking within the next six months (yes/no) and, if so, whether they planned to do this within the next 30 days (yes/no). Afterwards, they were classified into three stages of change: 'in preparation' if they reported the intention to stop smoking within 30 days, 'in contemplation' if they intended to stop smoking within six months but not within 30 days, and 'in precontemplation' if they had no intentions to stop smoking.

Furthermore, the posttests included questions measuring respondents' familiarity with smoking cessation campaigns. Finally, respondents were questioned about their age and education.

\section{Statistical analysis}

A multiple logistic regression analysis was conducted to identify potential dropout bias (with attendance versus dropout as the dependent variable and 
baseline values for gender, age, education, and condition as the independent variables). Further multiple logistic regression analysis was used to identify potential baseline differences between the Maastricht region and the control region. The independent variables in this analysis were the baseline values for gender, age and education. Only respondents who completed all surveys were included. These preliminary analyses were performed using the SPSS 10.0 statistical package (SPSS, 2000).

Differences in smoking behavior and its psychosocial determinants between the Maastricht region and the control region at posttests were studied with multilevel regression analysis, using the MlwiN statistical package (Rasbash et al., 1999). Multilevel regression analysis was used to take into account possible dependencies among individuals within the same municipality (Snijders and Bosker, 1999). If the multilevel analysis revealed that individuals within municipalities could be regarded as independent, analyses were repeated using 'ordinary' regression within the SPSS statistical package (SPSS, 2000).

The main independent variable included in all effect analyses was condition. In addition, the pre-intervention score of the outcome variable, gender, age, and education were included as independent variables in all analyses. The intention at baseline to quit smoking in the future was included as a further independent variable in the analyses of behavioral change. Differences were considered to be statistically significant if $\mathrm{p}<0.05$.

\section{RESULTS}

\section{Respondents}

Overall, 8,939 inhabitants (4,242 in the Maastricht region and 4,697 in the control region) were reached by telephone. The proportion of current smokers in this group was $34.6 \%$ (35.4\% in the Maastricht region and $34.0 \%$ in the control region). Of those who smoked $21.6 \%$ refused the interview $(19.1 \%$ in the Maastricht region and $24.0 \%$ in the control region). Attrition rate from baseline (T0) to second posttest (T2) was 37.9\%. The net attrition rate (after the exclusion of unreachable respondents) from T0 to T2 was $18.7 \%$. Overall, 1,508 respondents completed all three questionnaires: 772 in the experimental region and 736 in the control region. Attrition did not differ between the two regions. Moreover, there were no significant differences between dropouts and those who participated in all three measurements with respect to age, gender and education. Respondents from the Maastricht region were significantly older, more often female, and were more highly educated than respondents from the control region (Table 4.1). 
Table 4.I: Baseline demographic characteristics, smoking behavior, and familiarity with smoking cessation campaigns in the Maastricht region $(n=772)$ and the control region $(n=736)$

\begin{tabular}{|c|c|c|c|c|}
\hline Variable & Group & TO & $\mathrm{TI}$ & $\mathrm{T} 2$ \\
\hline \multirow[t]{2}{*}{ Age (mean and SD in years)* } & Maastricht & $49.8(13.6)$ & & \\
\hline & control & $45.7(14.1)$ & & \\
\hline \multicolumn{5}{|l|}{ Gender ( $\%$ and number) ${ }^{*}$} \\
\hline \multirow[t]{2}{*}{ - male } & Maastricht & $39.2(303)$ & & \\
\hline & control & $46.6(343)$ & & \\
\hline \multirow[t]{2}{*}{ - female } & Maastricht & $60.8(469)$ & & \\
\hline & control & $53.4(393)$ & & \\
\hline \multicolumn{5}{|l|}{ Education ( $\%$ and number $)^{*}$} \\
\hline \multirow[t]{2}{*}{- low } & Maastricht & $35.5(274)$ & & \\
\hline & control & $36.7(270)$ & & \\
\hline \multirow[t]{2}{*}{ - intermediate } & Maastricht & $47.2(364)$ & & \\
\hline & control & $50.3(370)$ & & \\
\hline \multirow[t]{2}{*}{ - high } & Maastricht & $17.4(134)$ & & \\
\hline & control & $13.0(96)$ & & \\
\hline Smoking behavior & Maastricht & $100.0(772)$ & $87.7(677)$ & $81.3(628)$ \\
\hline (\% and number of smokers) & control & $100.0(736)$ & $85.7(63 \mathrm{I})$ & $81.4(599)$ \\
\hline $\begin{array}{l}\text { Familiarity with regional campaign } \\
\text { (\% and number familiar) }\end{array}$ & Maastricht & & $16.8(130)$ & $42.4(327)$ \\
\hline Familiarity with national campaign & Maastricht & & $70.7(546)$ & \\
\hline$(\%$ and number familiar) $* *$ & control & & $76.2(561)$ & \\
\hline
\end{tabular}

* significant baseline (T0) differences between Maastricht and control region (logistic regression analysis)

** only measured at $\mathrm{TI}$

Familiarity with the regional smoking cessation campaign in the Maastricht region was much higher in 2001 (T2) than in 2000 (T1) (02 (1)=38.46; $\mathrm{p}=.000)$. Familiarity with the national smoking cessation campaign, which was only measured at T1, was high in both regions (Table 4.1).

\section{Differences between the Maastricht and the control region}

There were no overall condition effects on smoking behavior and its determinants, although some indications of a minor intervention effect on social support $(\mathrm{OR}=1.23 ; \mathrm{p}=.099)$ and stage of change $(\mathrm{OR}=1.28 ; \mathrm{p}=.084)$ were present at T2 (Table 4.2). 


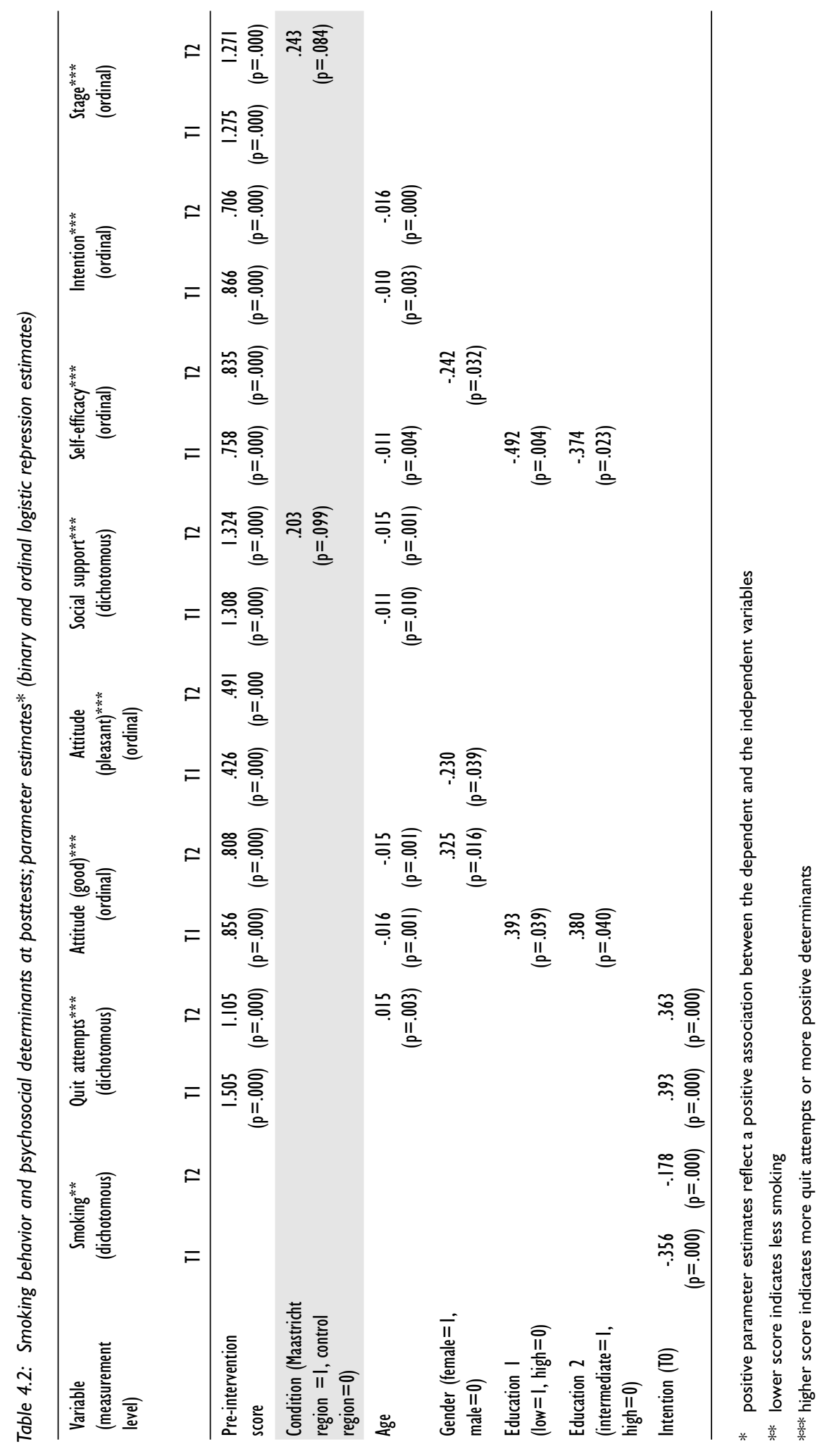




\section{DISCUSSION}

The present study found no significant differences between the Maastricht region and a control region on smoking behavior and its determinants. A possible explanation for the lack of intervention effects are secular trends, i.e., there may not have been enough additional exposure in the Maastricht region to exceed secular trends like the national smoking cessation campaign or spontaneous abstinence. Secular trends are frequently mentioned as a possible explanation for modest or absent intervention effects in community CVD prevention programs (Carleton et al., 1995; Winkleby et al., 1997). Process data of the Hartslag Limburg Community Intervention revealed that the focus of the intervention had mostly been on intervention activities aimed at nutrition and physical activity. Fewer activities for smoking cessation were developed and implemented.

Furthermore, the (reported) participation in smoking cessation activities was greater in the control region than in the Maastricht region. The multiple risk factor approach in Hartslag Limburg may have reduced the potential effect on smoking behavior because intermediaries as well as the target population may have preferred diet or physical activity as more attractive targets for behavior change.

The present study had some limitations. Firstly, the results are based on selfreports. Further, the psychological factors were measured with single items. Finally, although the regions were matched on several characteristics, the study included only one intervention and one control region, and there were differences in gender, age and education. In an attempt to overcome this design weakness to some extent, the pre-intervention score of the outcome variables, gender, age, and education were included as independent variables in the effect analyses.

In conclusion, the results of the present study do not show a significant impact of the Hartslag Limburg intervention on smoking, i.e., the regional intervention could not accelerate the secular trend. 


\title{
CHAPTER 5
}

\author{
THE DUTCH HEART HEALTH COMMUNITY \\ INTERVENTION 'HARTSLAG LIMBURG': \\ DESIGN AND RESULTS OF A PROCESS STUDY
}

Submitted for publication as:

Ronda, G., Van Assema, P., Ruland, E., Steenbakkers, M. and Brug, J. The Dutch Heart Health Community Intervention 'Hartslag Limburg': Design and Results of a Process Study. 


\begin{abstract}
Hartslag Limburg, a cardiovascular diseases (CVD) prevention program, integrates a community strategy and a high-risk strategy. This paper presents the design and results of a process study on the community intervention. The study was conducted to describe the course of action during the intervention, and to examine why expected effects were or were not achieved. Data was collected using multiple data sources and/or methods to measure indicators of intervention implementation. The results indicate that the community analysis and the subsequent organization of nine local Health Committees had been satisfactory. However, some factors that might influence the actual functioning of the Health Committees could be improved. Furthermore, the expert training for the members of these Committees had not yet been carried out as planned, and there were doubts about the added value of collaboration with experts thus far. Environmental strategies were felt to need more attention and ensuring longterm continuation requires continuous effort. Most of the 293 intervention activities had focused on nutrition, while smoking cessation activities had been given lowest priority. It is concluded that the process evaluation has provided information about successful and less successful elements of the community intervention, and insight into the 'black box' behind the progam.
\end{abstract}




\section{INTRODUCTION}

In 1998, a regional cardiovascular diseases (CVD) prevention program, integrating a community strategy and a high-risk strategy, was started in the Maastricht region of the province of Limburg, called Hartslag Limburg (Dutch for Heartbeat Limburg). Hartslag Limburg is a joint project of the municipal authorities of the Maastricht region, the Maastricht Regional Public Health Institute (RPHI), community social work organizations, the regional community health care organization, general practitioners, Maastricht University, the University Hospital, and various local organizations, clubs and companies. In January 2001, the World Health Organization (WHO) selected Hartslag Limburg as one of twelve so-called 'field projects', based on its potential to meet pre-established criteria of the WHO project 'Towards Unity for Health' (Boelen, 2001). The major goal of the community intervention is to reduce CVD risk by encouraging behavioral change, i.e., dietary fat reduction, increased physical activity, and smoking cessation, among the general population in the Maastricht region, and specifically among low socioeconomic status groups in four districts of the city of Maastricht. The Maastricht region has approximately 180,000 inhabitants and consists of the city of Maastricht (the capital of the province of Limburg, 120,000 inhabitants) and four smaller adjacent municipalities (12,000 to 21,000 inhabitants each). The community intervention is to continue at least until 2003, but the evaluation studies covered the first three years. A description of the full project has been published elsewhere (Ruland et al., 1999).

This article presents the process evaluation of the community intervention. A community intervention is a very complex event, with numerous actors and many interactions. In a community-based approach, the distinction between the interveners and the target population is definitely not clear-cut and should in fact disappear. These factors may facilitate the implementation and dissemination of intervention activities, but also present serious challenges to the evaluation of the intervention program, because of the resulting lack of control. Therefore, in evaluating community-based interventions it is of the utmost importance that the intervention process is monitored as closely as possible. Contemporary evaluation literature indeed emphasizes the importance of process evaluation as well as effect evaluation, especially for complex programs like community interventions (e.g., Scheirer, 1994; McGraw et al., 1996; Goodman, 1998; Cunningham et al., 2000). Process evaluation complements effect evaluation by providing data on the actual planning and implementation of a program, i.e., it opens the 'black box' behind a program (Scheirer, 1994;

Goodman, 1998). In addition, process measures can provide feedback on the quality of the actual planning and implementation of a project, to make it more congruent with what was intended (Sheirer, 1994). 


\section{Design and conceptual framework of the community intervention program and its evaluation study}

The importance of using a theoretical model to guide evaluation is generally accepted (Koepsell et al., 1992; Goodman, 1998; Cooksy et al., 2001). The theoretical framework of Hartslag Limburg's community project was based on upto-date program planning and evaluation models, and consists of several stages (Table 5.1) (e.g., Green and Kreuter, 1999). The framework indicates how the program was expected to produce its postulated effects and served as the program planning and evaluation framework (Ronda et al., in press). Briefly, the model postulates that a reduction in CVD was expected to be achieved by changes in related risk behaviors. Behavioral change was expected to be achieved by changes in psychosocial determinants of risk behaviors such as awareness, attitudes, social influences, and self-efficacy expectations related to smoking, diet, and exercise, and stage of change related to the risk behaviors (Weinstein, 1988; Ajzen, 1991; Prochaska and DiClemente, 1992). Changes in the determinants were expected if the project resulted in sufficient activities that are tailored to and effective in changing these determinants, and that reach the target population. It was further postulated that the organization, development, implementation, and dissemination of these activities could best be achieved by applying certain community principles, i.e., participation of the community in the planning and implementation of the project, intersectoral collaboration between local organizations, link-up with the current situation (e.g., supporting pre-existing initiatives), long-term continuation of the project, a social network approach (i.e., spreading information from network members to other network members), a multi-media and multi-method strategy (i.e., using various mass media channels and various educational strategies), environmental changes (e.g., healthier foods in cafeterias), and activities tailored to various target groups (Bracht and Kingsbury, 1990; Minkler and Wallerstein, 1998). These community principles were expected to be achieved through a thorough community analysis in each of the communities and the subsequent setting up of nine (five municipal and four neighborhood) intersectoral local Health Committees. These Committees were to organize, each within its own community, activities that facilitate and encourage people to adopt a healthier lifestyle. The Committees consisted of community members and were to be professionally supported by a health educator from the RPHI, a social worker, civil servants of the five municipalities, and a so-called neighborhood assistant in the four Maastricht neighborhoods. This professional support was made possible by a grant from the Netherlands Heart Foundation. It was expected that this initial project funding could be replaced by permanent municipal funding in the

74 future. Furthermore, quality control was an important project component, and was expected to be achieved by collaboration with experts in the planning and implementation of activities, and expert training for the members of the Health Committees. 
Table 5. I: Conceptual framework of the community project and the evaluation study

\begin{tabular}{|c|c|c|c|c|c|}
\hline A Health & B Risk behaviors & $\begin{array}{l}\text { C Psychosocial } \\
\text { determinants }\end{array}$ & $\begin{array}{l}\text { D Prevention } \\
\text { activities }\end{array}$ & E Community principles & F Project components \\
\hline- CVD & $\begin{array}{l}\text { - high fat intake } \\
\text { - smoking } \\
\text { - not enough } \\
\quad \text { physical activity }\end{array}$ & $\begin{array}{l}\text { - attitudes } \\
\text { - social influences } \\
\text { - self-efficacy } \\
\text { - awareness } \\
\text { - stage of change }\end{array}$ & $\begin{array}{l}\text { - number } \\
\text { - reach } \\
\text { - effects }\end{array}$ & $\begin{array}{l}\text { - participation } \\
\text { - intersectoral collaboration } \\
\text { - link-up with current } \\
\text { situation } \\
\text { - long-term continuation } \\
\text { - social network approach } \\
\text { - multi-media and } \\
\text { multi-method strategy } \\
\text { - environmental strategy } \\
\text { - activities for various } \\
\text { target groups }\end{array}$ & $\begin{array}{l}\text { - community analyses } \\
\text { - Health Committees } \\
\text { - quality control }\end{array}$ \\
\hline
\end{tabular}

Evaluation measures were developed for all the stages of the intervention and evaluation framework, except for stage A (Health), since no detectable effects on this stage could be expected within a limited number of years. The present process study focused on the actually achieved prevention activities (stage D), the application of community principles (stage E), and the implementation of the various planned project components (stage F). So, the present study was conducted to describe the actual course of action during the intervention, to assess if the intervention was conducted as originally planned and if the organization of the project was as intended, and to gain insight into the reasons why expected effects were or were not achieved. The effect study of the Hartslag Limburg community intervention showed a statistically significant, although limited, intervention effect on fat reduction, especially among the younger half of the population studied, as well as on awareness of one's own fat intake. Further, an intervention effect on the intention towards increasing physical activity in the future was found among the younger half of the population (Ronda et al., in preparation). No significant intervention effects were found on smoking behavior and its psychosocial determinants (Ronda et al., in press). 


\section{METHODS}

\section{Data collection}

Data collection took place from the start of the implementation of the project in September 1998, until May 2001, by means of 'triangulation', i.e., using multiple data sources and/or methods to measure the same indicators or variables (McGraw et al., 1996; Goodman, 1998). Process measures and their instruments were grouped by the stages of the conceptual framework (Table 5.2).

In order to obtain information about the implementation of project components and the application of community principles, an independent researcher conducted semi-structured individual face-to-face interviews with the project management team, i.e., the general project manager, the community project coordinator and a health educator, in February 2000. They were asked to describe what had actually happened and to evaluate the specific elements on a five-point 'negative-positive' scale (score ranges from -2 to +2 ). These interviews lasted about 90 minutes.

For the same purposes, the researcher conducted 22 semi-structured individual face-to-face interviews with a selection of members of the Health Committees, i.e., the chairperson and two other members, between September and November 2000. They were also asked to evaluate the specific project components and community principles on a five-point 'negative-positive' scale (score ranges from -2 to +2 ). Furthermore, they were questioned about specific factors that may influence the functioning of the Committees (Kegler et al., 1998; Bracht et al., 1999). The average duration of these interviews was 60 minutes.

Further, to monitor the composition of the Health Committees, the minutes of their meetings were collected and an inventory was made of the average number of meetings, the average number of members, and the organizations represented by the members, from the start of the implementation of the project in September 1998 until May 2001.

In order to obtain information about community principles and intervention activities, the researcher conducted brief, structured telephone and face-to-face interviews with the organizers of activities, i.e., members of the Health Committees or professionals in the field, between September 1998 and May 2001. Information was gathered about the behavioral targets of the activities, the year of implementation, the target group, the number of participants, and the involvement of other organizations and/or individual volunteers. In addition, the main channel of communication, i.e., the means of message dissemination, was assessed. Channels included face-to-face single sessions (e.g., meetings providing nutritional information and education), face-to-face multiple sessions (e.g., courses to encourage physical activity), mass media (television, radio, newspaper, and widely distributed printed materials), special events (e.g., health fairs), activities to achieve environmental changes (e.g., grocery store shelf labeling), and individualized written information (e.g., computer-tailored 
Table 5.2: Process measures and data collection instruments by conceptual stage

\begin{tabular}{|c|c|c|c|}
\hline Process measure & Instrument & Source & Time \\
\hline $\begin{array}{l}\text { Project components (stage F) } \\
\text { - community analyses } \\
\text { - Health Committees } \\
\text { - quality control } \\
\text { - expert training for members of } \\
\text { Health Committees } \\
\text { - collaboration with experts }\end{array}$ & $\begin{array}{l}\text { - semi-structured } \\
\text { face-to-face interviews } \\
\text { - structured brief } \\
\text { telephone interviews } \\
\text { - structured brief } \\
\text { face-to-face interviews } \\
\text { - document review }\end{array}$ & $\begin{array}{l}\text { - project management } \\
\text { team } \\
\text { - members of Health } \\
\text { Committees } \\
\text { - organizers of activities }\end{array}$ & $\begin{array}{l}\text { - February } 2000 \\
\text { - September- } \\
\text { November } 2000 \\
\text { - September } 1998 \\
\text { until May 2001 }\end{array}$ \\
\hline $\begin{array}{l}\text { Community principles (stage E) } \\
\text { - participation } \\
\text { - intersectoral collaboration } \\
\text { - link-up with current situation } \\
\text { - long-term continuation } \\
\text { - social network approach } \\
\text { - multi-media and multi-method strategy } \\
\text { - environmental strategy } \\
\text { - activities for various target groups }\end{array}$ & $\begin{array}{l}\text { - semi-structured } \\
\text { face-to-face interviews } \\
\text { - structured brief } \\
\text { telephone interviews } \\
\text { - structured brief } \\
\text { face-to-face interviews } \\
\text { - structured brief written } \\
\text { questionnaires } \\
\text { - structured additional } \\
\text { questions in posttest } \\
\text { questionnaires for effect } \\
\text { evaluation, sent by mail } \\
\text { - document review }\end{array}$ & $\begin{array}{l}\text { - participants of activities } \\
\text { - samples of general } \\
\text { population } \\
\text { - minutes of meetings }\end{array}$ & $\begin{array}{l}\text { - February } 2000 \\
\text { - September- } \\
\text { November } 2000 \\
\text { - September } 1998 \\
\text { until May } 2001 \\
\\
\text { - September } 1998 \\
\text { until May } 2001 \\
\text { - May 200I } \\
\\
\\
\text { - September } 1998 \\
\text { until May } 2001\end{array}$ \\
\hline $\begin{array}{l}\text { Prevention activities (stage D) } \\
\text { - number of activities } \\
\text { - characteristics of activities }\end{array}$ & $\begin{array}{l}\text { - structured brief } \\
\text { telephone interviews } \\
\text { - structured brief } \\
\text { face-to-face interviews }\end{array}$ & - organizers of activities & $\begin{array}{c}\text { - September } 1998 \\
\text { until May } 2001\end{array}$ \\
\hline $\begin{array}{l}\text { - characteristics of participants } \\
\text { - satisfaction of participants with } \\
\text { activities } \\
\text { - intermediate effects }\end{array}$ & $\begin{array}{l}\text { - structured brief written } \\
\text { questionnaires }\end{array}$ & - participants of activities & $\begin{array}{c}\text { - September } 1998 \\
\text { until May } 2001\end{array}$ \\
\hline $\begin{array}{l}\text { - familiarity with project and its } \\
\text { activities } \\
\text { - participation in activities }\end{array}$ & $\begin{array}{l}\text { - structured additional } \\
\text { questions in posttest } \\
\text { questionnaires for effect } \\
\text { evaluation, sent by mail }\end{array}$ & $\begin{array}{l}\text { - samples of general } \\
\text { population }\end{array}$ & - May 2001 \\
\hline
\end{tabular}


nutrition education). The main objective of the activity was also assessed, including objectives such as raising attention and providing information, increasing knowledge and raising awareness, as well as behavior change.

Information about community principles and prevention activities was obtained between September 1998 and May 2001 by providing participants with brief, structured questionnaires to evaluate group activities. Self-rated fat intake was assessed by asking participants whether they rated there own fat intake as low or high on a five-point scale. Self-rated physical activity was assessed by asking participants whether they were regularly physically active (yes/no). Participants were also asked to indicate their satisfaction with particular aspects of the activity on five-point scales, or by means of a report mark. Participants were also asked to indicate whether the activity they participated in encouraged them to change their behavior in the future, and whether they were encouraged to participate in future activities (yes/no). Demographic data were gathered as well.

Finally, in order to obtain information about familiarity with a project and activities, and participation in activities, nine additional questions were added to the questionnaires of the second posttest of the effect evaluation, in May 2001.

\section{Data analyses}

The face-to-face interviews with semi-structured questions were recorded and transcribed, and notes were made by the interviewer. Subsequently, the transcriptions were organized by topic and summarized. The SPSS 10.0 statistical package (SPSS, 2000) was used to obtain descriptive statistics (frequencies and means) on quantitative data from the interviews or questionnaires. A multiple logistic regression analysis was conducted to identify potential differences in age, gender, and education, according to familiarity with, or participation in a project. Differences were considered to be statistically significant if $\mathrm{p}<0.05$.

\section{RESULTS}

The results are presented in terms of the process measures, grouped by the stages of the conceptual framework (Table 5.2).

\section{$78 \quad$ Project components}

\section{Community analyses}

The major goals of the community analyses, conducted by the RPHI and two social work organizations, were to help introduce the project to the participat- 
ing communities, to achieve early community involvement, and to evaluate the local situations. Key persons in the nine communities were interviewed about issues such as the major problems in their municipality or neighborhood, and the community sectors which should be asked to participate in the Health Committees. Reports on the results of these community analyses were sent to all key persons. There were differences of opinion between the members of the project management team about the quality of the community analyses, ranging from rather negative to rather positive. However, the general attitude was that the results of the analyses were quite acceptable.

\section{Health Committees}

The members of the sectors that had been identified as important during the community analysis phase were approached to participate in the Health Committees. Nine Health Committees were set up: one in each of the four smaller municipalities, one in each of four underprivileged Maastricht neighborhoods, and a regional Committee to coordinate and implement regional activities. Each Committee was supported by a health educator from the Maastricht RPHI, a social worker and a civil servant of the municipal authorities. The health educator encouraged and assisted the Committee in organizing healthy behavior promoting activities, which had been selected on the basis of earlier studies (Ronda and Van Assema, 1997), but also in developing their own activities. There were some substantial differences between the Health Committees. Firstly, the Maastricht districts already had existing Committees, managed by a social worker, before Hartslag Limburg started. Because of Hartslag Limburg, these Committees reoriented their activities mainly towards the CVD risk behaviors. Secondly, these neighborhood Committees were not supported by a civil servant, but a so-called neighborhood assistant was added to the staff, and the other members of these Committees usually did not represent a particular organization but were active inhabitants of the neighborhood. Thirdly, contrary to what had been planned beforehand, there was no separate Health Committee for the city of Maastricht as a whole. Because of the different situations in the various districts of Maastricht, with its different neighborhood communities, there was not much interest in participating in an overall Maastricht Committee. As an alternative, a regional Health Committee was set up, consisting of health educators from the RPHI and managed by the community project coordinator and the general project manager. The members of the project management team evaluated the organization of the Committees as positive, although some comments were made about different levels of organization in the various communities.

The community intervention was officially started in October 1998 with a regional campaign to promote physical activity among those over 55, which was organized by the RPHI in collaboration with a national organization and many other organizations and volunteers in the region (NOC*NSF, 1999). At about the same time, the Health Committees officially started their activities. 
Table 5.3: Overview of numbers of members, numbers of meetings per year, and distribution of health activities by Health Committees

\begin{tabular}{|c|c|c|c|c|c|c|c|c|c|c|}
\hline Variable & 悹 & 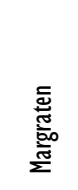 & 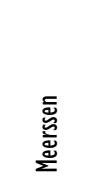 & 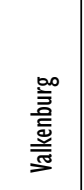 & 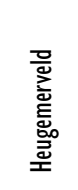 & 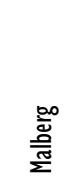 & 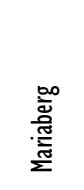 & 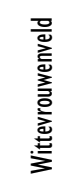 & 丞 & $\begin{array}{l}\overline{\bar{c}} \\
\overline{\mathrm{g}}\end{array}$ \\
\hline Number of members & $9\left(9^{*}\right)$ & $9\left(8^{*}\right)$ & $14\left(13^{*}\right)$ & $10\left(9^{*}\right)$ & $6\left(3^{*}\right)$ & $4\left(4^{*}\right)$ & $10\left(3^{*}\right)$ & $3\left(3^{*}\right)$ & $4\left(4^{*}\right)$ & $x$ \\
\hline Number of meetings per year & 6 & 6 & 6 & 6 & 12 & 8 & 12 & 8 & 12 & $x$ \\
\hline Nutritional activities ( $\mathrm{n}$ ) & 5 & 20 & 14 & 17 & 15 & 31 & 26 & 18 & 20 & 166 \\
\hline Physical activity activities (n) & 5 & 5 & 9 & 15 & 9 & 10 & 15 & 10 & 6 & 84 \\
\hline Smoking activities (n) & 2 & 1 & I & - & 1 & 3 & 3 & - & 4 & 15 \\
\hline Activities relating to several behaviors ( $\mathrm{n}$ ) & 3 & 2 & 2 & 4 & 4 & 3 & 3 & 5 & 2 & 28 \\
\hline Total number of activities (n) & 15 & 28 & 26 & 36 & 29 & 47 & 47 & 33 & 32 & 293 \\
\hline
\end{tabular}

* number of members representing an organization

Table 5.3 shows an overview of the number of members and the number of meetings per year for each Health Committee. The average number of members was eight, ranging from three to fourteen. The average number of meetings per year was also eight (6-12), and the average number of organizations represented in each of the Health Committees was five (2-11). Organizations represented in the neighborhood Committees included a social work organization and the RPHI. In addition, the Malberg Committee included a representative of the neighborhood platform. The municipal Committees included representatives of the municipal council, the RPHI, and a social work organization (with the exception of the community of Meerssen). In addition, the municipal Committees included representatives of several other organizations, such as women's organizations, organizations for the elderly, public health organizations, socio-cultural organizations, sports clubs, et cetera. Meanwhile, the initial financial support that the Health Committees received from the Netherlands Heart Foundation has been replaced by municipal funding.

During the research period, 293 activities were registered (Table 5.3), excluding activities primarily trying to draw attention to the project and its specific activities, such as television, radio, and newspaper commercials. The average number of activities organized by each Health Committee was approximately 33 (range 15 to 47). More information about the specific activities are given in the section on 'prevention activities' below. Several factors may influence the functioning of Health Committees, such as the quality of communication in the 
Committee, the sense of commitment to the Committee, the task orientation during the meetings, the professionalism of the leaders of the Committee, the staff time devoted to the Committee, the creation of special task forces or smaller subgroups to plan or implement specific activities, the way in which conflicts are solved, equality among the members of the Committee, the decision-making process, and the perceived benefits and costs (Kegler et al., 1998; Bracht et al., 1999). Although the overall functioning of the Health Committees was given a positive evaluation, the quality of communication, the staff time, and the creation of special task forces were felt to need improvement.

Moreover, two neighborhood committees perceived to be understaffed.

\section{Quality control}

An interim assessment by both the project management team and the members of the Health Committees revealed that the expert training of the members of the Health Committees had not been carried out as planned, i.e., in most cases there had not yet been a training. Furthermore, although the average score of the Health Committee members on the question of collaboration with experts in the planning and implementation of activities was positive (mean=1.86), some members of the project management team gave a fairly negative assessment of the collaboration with experts. The project management team agreed about the importance of this collaboration, but members were doubtful about the added value of the collaboration thus far.

\section{Community principles}

\section{Participation and intersectoral collaboration}

Members of the project management team differed in their assessment of the participation of inhabitants in the project and its activities. They agreed that the participation was growing, but they had different opinions about the level of participation at the time of evaluation. The intersectoral collaboration between the various organizations involved in the project and its activities was evaluated as mostly positive by the members of the project management team.

The participation of inhabitants (mean $=-0.05)$, and the intersectoral collaboration (mean $=0.00)$ were not given a very positive evaluation by the members of the Health Committees. Nevertheless, the interviews with the organizers of activities revealed that $58 \%$ of the activities had been organized and/or implemented by the Health Committees in collaboration with individual volunteers, and as many as $93 \%$ of the activities in collaboration with one or more other organizations. Furthermore, of those who participated in group activities, almost $12 \%$ indicated to be encouraged to help organize or implement (future) activities.

\section{Link-up with the current situation and long-term continuation}

Linking up with the current situation and thinking about the long-term continuation of the project and its activities were evaluated as satisfactory by the pro- 
ject management team, although they indicated that the long-term continuation required more and constant attention. The members of the Health Committees were positive about linking up with the current situation (mean=1.67), but rather negative about long-term continuation $($ mean $=-0.48)$, indicating that in most Committees, thinking about continuation has not yet been an issue.

Social network approach, multi-media and multi-method strategy, and environmental strategy

The use of a social network approach was evaluated as satisfactory by the members of the project management team, and the use of a multi-media and a multi-method strategy as rather positive. However, the members differed in their judgement on the organization and implementation of environmental strategies, expressing doubts about the availability of such activities. The members of the Health Committees evaluated both the use of a social network approach and the use of a multi-media and multi-method strategy as rather positive, with means of 1.18 , and 1.00 , respectively. They were less positive about the organization and implementation of activities that affected the environment (mean= -0.22), indicating that there were hardly any activities that affected the environment. This was confirmed in the interviews with the organizers of activities. Finally, questionnaire research among intervention participants revealed that almost $32 \%$ indicated to have heard of the activities they participated in through friends or family, i.e., through their social network.

\section{Activities for various target groups}

The project management team agreed that the planning and implementation of activities directed at various target groups, particularly those aimed at men and the working population, needed more attention. The members of the Health Committees were rather positive about the availability of activities for various target groups (mean $=0.81$ ). The interviews with the organizers of the activities revealed that the main target group for the implemented activities were adults in general. Fifteen percent of the sample of the general population reported to have participated in at least one intervention activity. The mean age of this group was 54 years $(\mathrm{SD}=16)$, nearly $67 \%$ were female, and nearly $41 \%$ had a low level of education. The mean age of those who participated in group activities was 59 years $(\mathrm{SD}=13)$, nearly $94 \%$ were female, and nearly $50 \%$ reported a low level of education.

\section{Prevention activities}

82 Number and characteristics of intervention activities

As mentioned above, 293 activities had been registered (Table 5.3). The Health Committees were most active in organizing activities relating to nutrition, followed by activities relating to physical activity. Activities relating to smoking cessation were given the lowest priority. Examples of (ongoing) activities, often extensively pretested, include computer-tailored nutrition education (Brug et al., 
Table 5.4: Overview of health activities $(n=293)$ by selected key variables

\begin{tabular}{|c|c|c|c|}
\hline Variable & $\mathrm{n}$ & Variable & $\mathrm{n}$ \\
\hline \multicolumn{2}{|l|}{ Year of implementation (start) } & Target group (main) & \\
\hline - 1998 (from September) & 18 & - youngsters & 80 \\
\hline-1999 & 100 & - adults & 140 \\
\hline-2000 & 124 & - older adults & 20 \\
\hline - 2001 (until May) & 51 & - all & 53 \\
\hline \multicolumn{2}{|l|}{ Channel of communication (main) } & Participants & \\
\hline - face-to-face; single session & 147 & $-\leq 10$ & 73 \\
\hline - face-to-face; multiple sessions & 64 & $-11-25$ & 78 \\
\hline - mass media & 7 & $-26-50$ & 44 \\
\hline - special events & 70 & $-51-100$ & 19 \\
\hline - environmental & 4 & $->100$ & 34 \\
\hline - tailored written information & I & - unknown & 45 \\
\hline \multicolumn{2}{|l|}{ Objective (main) } & \multicolumn{2}{|l|}{ Organizations involved } \\
\hline - attention/information & 71 & - yes & 272 \\
\hline - knowledge/awareness & 152 & - no & 21 \\
\hline \multirow[t]{4}{*}{ - behavior change } & 70 & & \\
\hline & & Volunteers involved & \\
\hline & & - yes & 171 \\
\hline & & - no & 122 \\
\hline
\end{tabular}

1998), nutrition education tours in supermarkets (Van Assema et al., 1998), nutritional meetings (Van Assema et al., 1997), a regional campaign to promote physical activity among individuals over 55 (NOC*NSF, 1999), a daily regional television program called 'Heartbeat on the move' to promote physical activity (Ronda et al., 2001a), walking and cycling months (Ruland et al., 2001), a regional smoking cessation campaign (Ruland et al., 2001), and a non-smoking campaign for the parents of children in playgroups (Ruland et al., 2001).

Over $42 \%$ of the activities were implemented in 2000 (Table 5.4). The most frequently used channel of communication could be categorized as 'face-to-face single session' and increasing knowledge and awareness of one's own behavior was the main objective of about $50 \%$ of the activities. Nearly $27 \%$ of the activities had between 11 and 25 participants. The lowest number of participants was that in a cooking course for children (4 participants), and the highest in a four day walking event (2,500 participants on one day). In general, the organizers of activities evaluated their planning and implementation as positive. They were especially pleased with the enthusiasm of the participants. Some negative aspects that came up were mainly organizational such as inappropriate space for activities or lack of personnel. 
Table 5.5: Overview of participants' characteristics and satisfaction, and intermediate effects $(n=l, 746)$

\begin{tabular}{ll}
\hline Variable & \\
\hline & \\
Age (mean) & 59.1 (SD=I3.3) \\
Gender (\%) & \\
- female & 93.8 \\
- male & 6.2 \\
Education (\%) & \\
- low & 49.5 \\
- intermediate & 42.0 \\
- high & 8.4 \\
Self-rated fat intake (\% (rather) high) & 19.2 \\
Self-rated physical activity (\% not regular) & 14.0 \\
Acquainted with activity through (\%) & \\
- mass-media & 12.5 \\
- friends/family & 31.6 \\
- club/association/company and suchlike & 52.6 \\
- several sources & 3.3 \\
Atmosphere during activity (\% (rather) pleasant) & 98.6 \\
Information received new (\% (rather) new) & 75.2 \\
Information received interesting (\% (rather) interesting) & 79.1 \\
Report mark for activity (mean), out of I0 & 8.3 (SD=I.0) \\
Report mark for instructor (mean), out of I0 & $8.7(\mathrm{SD}=1.0$ ) \\
Encouraged to eat less fat (\% yes) & 79.5 \\
Encouraged to increase physical activity (\% yes) & 74.6 \\
Encouraged to participate in (future) activities (\% yes) & 62.9 \\
Encouraged to help organize/implement (future) activities (\% yes) & 11.7 \\
\hline
\end{tabular}

* percentage of those involved in activities relating to the specific behavior

Characteristics and satisfaction of participants, and intermediate effects (Table 5.5) Information from participants in group activities primarily directed at adults came from 1,746 participants in the following activities: informational and educational meetings mainly focusing on nutrition but also on physical activity $(\mathrm{n}=1,144)$, nutritional meetings $(\mathrm{n}=319)$, nutrition education tours in supermarkets $(\mathrm{n}=161)$, physical activity courses (country dancing, aerobics and yoga) ( $n=61)$, group walks $(n=53)$, and a cooking course $(n=8)$.

About $19 \%$ of those who participated in nutritional activities rated their own fat intake as high, and $14 \%$ of those who participated in physical activity activities said they were not regularly physically active. More than half of the respondents had heard about the activities through clubs or such organizations.

Participants' level of satisfaction with the activities was high. Almost $80 \%$ of the 
participants in nutritional activities said they had been encouraged to eat less fat in the future, and almost $75 \%$ of physical activity participants reported they felt encouraged to increase physical activity; almost $63 \%$ indicated to have been encouraged to participate in future activities. The most notable difference between the activities was that the percentage of participants who had heard about the activity through friends/family was much higher for the cooking meetings $(49.4 \%)$, the group walks $(69.8 \%)$, and the country dancing courses $(87.9 \%)$ than for the other activities (average 31.6\%). Further, the percentages of men in the yoga $(18.8 \%)$ and country dancing courses (12.1\%) were higher than average $(6.2 \%)$. Finally, the participants in nutrition tours in supermarkets more often had an intermediate $(47.3 \%)$ or high $(15.5 \%)$ level of education than the average for all activities ( $42 \%$ and $8.4 \%$ respectively).

\section{Familiarity with a project and activities, and participation in activities}

Overall, 24.3\% of the 1,990 respondents in the Maastricht region who completed the second posttest of the effect evaluation were familiar with a health project, with some differences between the participating communities (Table 5.6). Of those who were familiar with a health project, $55.9 \%$ provided a project name and $56.9 \%$ could mention a goal of the project. Of those who mentioned a name, $47.0 \%$ actually mentioned 'Hartslag' literally. Most other names that were mentioned could be connected with the Hartslag project, e.g., in that they referred to one of the participating organizations. All the goals that were mentioned fitted into the Hartslag community project goals. Familiarity with smoking cessation activities was greatest. Almost $15 \%$ of the population sample indicated that they were participating, or had participated, in at least one activity relating to nutrition, smoking cessation or physical activity during the intervention period. Participation in activities was greatest for physical activity, followed by nutritional activities. Familiarity in general was much higher than actual participation in activities.

Respondents were also asked to mention names of activities with which they were familiar or in which they were involved relating to nutrition, smoking and physical activity. Overall, $19.6 \%$ were able to mention a name with regard to physical activity activities, $17.7 \%$ with regard to nutritional activities, and $12.7 \%$ with regard to non-smoking activities. Many people did not mention specific names but mentioned organizations that had set up and/or implemented the activities. The name Hartslag was mentioned most frequently, followed by names of participating or connected organizations such as The Green Cross and The Netherlands Heart Foundation.

Familiarity and participation differed according to age, gender, and education (Table 5.6). Women and the older half of the population studied were more often familiar with a project, could more often mention names and goals, were more often familiar with physical activity activities, and participated more often in physical activity and nutritional activities. Women were more often familiar with nutritional activities, while the younger half of the studied population 
Table 5.6: Familiarity of inhabitants with health projects and activities, and participation in activities, by municipality and neighborhood, and by gender, age and educational level $(n=1,990)$

\begin{tabular}{|c|c|c|c|c|c|c|c|c|c|c|c|c|c|}
\hline Variable & $\begin{array}{l}\text { s } \\
\text { s } \\
\text { 产 }\end{array}$ & 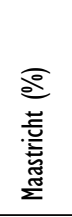 & 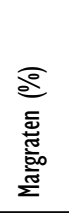 & 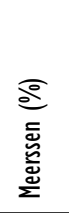 & 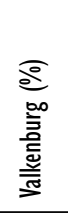 & 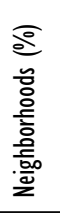 & 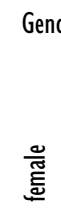 & $(\%)$ & 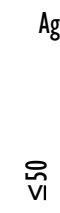 & 옷 & 흐 & 惡 & 冟 \\
\hline Familiar & & & & & & & & & & & & & \\
\hline $\begin{array}{l}\text { with project } \\
\text { Name of }\end{array}$ & 22.9 & 21.0 & 20.9 & 23.4 & 31.7 & 27.5 & 27.6 & $20.3^{*}$ & 20.3 & $28.3^{*}$ & 25.2 & 23.7 & 24.3 \\
\hline $\begin{array}{l}\text { project } \\
\text { Goal of }\end{array}$ & I4.I & 12.3 & 10.9 & 12.3 & 18.3 & 14.0 & 15.9 & $10.8^{*}$ & 10.4 & $16.8^{*}$ & 13.8 & 13.5 & 13.6 \\
\hline $\begin{array}{l}\text { project } \\
\text { Familiarity } \\
\text { with } \\
\text { activities }\end{array}$ & 14.1 & 14.0 & 12.1 & 10.8 & 18.9 & 13.5 & 15.3 & $12.1^{*}$ & 12.2 & $15.5^{*}$ & 10.8 & 14.4 & $17.0 *$ \\
\hline - nutrition & 57.4 & 58.0 & 60.7 & 55.3 & 55.9 & 43.5 & 60.0 & $51.5^{*}$ & 59.6 & 52.6 & 44.6 & 60.2 & $64.2^{*}$ \\
\hline $\begin{array}{l}\text { - smoking } \\
\text { - physical }\end{array}$ & 60.9 & 60.7 & 63.0 & 57.3 & 58.0 & 53.0 & 57.6 & 61.3 & 65.3 & $53.2^{*}$ & 47.7 & 63.7 & $67.5^{*}$ \\
\hline $\begin{array}{c}\text { activity } \\
\text { Participation } \\
\text { in activities }\end{array}$ & 56.4 & 54.3 & 59.7 & 55.5 & 57.1 & 46.5 & 58.9 & $51.9^{*}$ & 54.0 & $57.5^{*}$ & 48.2 & 58.8 & $60.6^{*}$ \\
\hline - nutrition & 8.5 & 7.0 & 8.8 & 7.5 & 8.9 & 3.5 & 9.3 & $5.8^{*}$ & 6.3 & $9.0^{*}$ & 8.5 & 7.2 & 7.8 \\
\hline $\begin{array}{l}\text { - smoking } \\
\text { - physical }\end{array}$ & 2.4 & 2.0 & 2.8 & 1.0 & 3.3 & 2.0 & 2.1 & 2.4 & 2.0 & 2.3 & 3.0 & 1.9 & 1.9 \\
\hline activity & 9.3 & 11.0 & 7.2 & 8.0 & 11.2 & 8.0 & 10.9 & $7.0^{*}$ & 5.8 & $12.3^{*}$ & II.I & 9.0 & 6.1 \\
\hline
\end{tabular}

* significant differences (logistic regression analysis)

were more often familiar with smoking activities. The more highly educated respondents were more often able to mention a goal of the project, and were more often familiar with activities relating to all three the behaviors than the less highly educated ones.

\section{DISCUSSION}

The major goal of the Hartslag Limburg community intervention is to reduce cardiovascular diseases in the Maastricht region by encouraging the general 
population to reduce their fat intake, to increase their level of physical activity, and to stop smoking. The present process evaluation was conducted to describe the actual course of action during the intervention, and to assess whether the intervention was being conducted as originally planned, using multiple data sources, methods, and measures. We will discuss the results, implications, and limitations of this process evaluation according to the framework presented in Table 5.1.

The process evaluation provided information about successful and less successful aspects of the Hartslag Limburg project. With respect to the project components, it can be concluded that the community analyses as well as the subsequent organization of the Health Committees were satisfactory. In fact, the organization of the Health Committees demonstrated the 'success' of the community analyses. Some aspects that may influence the functioning of the Health Committees could be improved, i.e., the quality of communication, the staff time, the creation of special task forces and the number of members of the Committees. Quality control was a weak link at the time of data collection. This insufficient quality control, together with the less than optimal functioning of the Health Committees, might explain why certain community principles were not yet achieved. Particularly, ensuring long-term continuation, in terms of manpower and financial support, requires continuous efforts from all involved in the project. Environmental strategies also need more attention, especially since there is increasing recognition of the importance of the environment in shaping behavior (Booth et al., 2001). Nevertheless, the realization of the community principles was, on the whole, quite satisfactory, which is also apparent from the large number of intervention activities that were implemented. However, the majority of the activities were only offered once and most of these mainly aimed at increasing knowledge and awareness. Nevertheless, most of those who participated in group activities indicated to be encouraged to change their risk behavior. This was encouraging, although group activities constituted only a part of the overall program of activities. Finally, although familiarity with the intervention activities was high, only a minority of the population reported actual participation.

We used the process evaluation data to interpret und understand the outcomes of the effect study (Ronda et al., in press; Ronda et al., in preparation). Several other heart health community interventions have made use of process data to assist with the interpretation of the findings of effect studies. All of them documented aspects like the intervention intensity or 'exposure dose' in someway and compared this information with outcome data (Flora et al., 1993; Winkleby et al., 1997).

It seems reasonable to assume that the modest effects of the Hartslag Limburg community intervention on fat intake, fat intake awareness, and intentions to increase physical activity, as well as the absence of effects on smoking behavior and its determinants can partially be explained by the pattern of implemented activities, as most intervention activities focused on nutrition. Furthermore, since actual (reported) participation in at least one intervention activity did not 
exceed $15 \%$, the intervention may not have reached a large enough fraction of the population to result in greater changes. However, the present process study also revealed that participation by the community and intersectoral collaboration between local organizations in the Maastricht region was still growing at the time of data collection, so longer-term measures of individual behaviors may show greater changes.

Secular trends are often mentioned as a possible explanation for modest or absent intervention effects in community intervention research (Carleton et al., 1995; Browson et al., 1996; Winkleby et al., 1997). Secondary analysis of our process data showed that, although familiarity with projects and activities was greater in the Maastricht region, the actual (reported) participation in physical activity and smoking cessation activities was greater in the control region, in spite of the fact that no similar prevention project was started in the control region between 1998 and 2002.

From the effect evaluation study it became clear that Hartslag Limburg especially affected dietary habits and physical activity intentions among the younger half of the population ( $\leq 48$ years). This process study can offer no explanation for this. The prevention activities in the Maastricht region did not particularly focus on this group, and the mean age of the participants in these activities was over 50 years.

It is also worth mentioning that smoking cessation received the least attention, even though it might be argued that smoking cessation should be given first priority for health risk reduction in terms of relative risk (Schram et al., 2001). This result illustrates the dilemmas of community-based interventions. What is most important in terms of relative risk (smoking) may not be what the community organizers are interested in (nutrition), which in turn may be not what the general public are interested in (physical activity). On the other hand, one might also argue that the prevalence of a high fat intake (65\%) and an inadequate physical activity level (58\%) was much higher than the prevalence of smoking (28\%) at baseline in the Maastricht region (Ronda et al., in press), justifying the behavioral targets of the implemented activities. Moreover, nutrition can play a very important role in CVD risk reduction (Stamler 1992; Schram et al., 2001)

Finally, the present interim process data collected were also used to give rapid feedback to the project management team and intermediaries during the planning and implementation of the project. This feedback was often experienced as encouraging and has led to adjustment of existing activities as well as decisions being made about future activities. The Hartslag Limburg project is still ongoing, and the results of the present process evaluation may help improve the planning and implementation of future project components and activities.

It is important to note some limitations of the present study. First, it proved very complicated and time-consuming to organize a thorough and comprehensive process evaluation to gain in-depth information about the intervention from those who were involved in the planning and implementation of the 
intervention. Our aim was continuous data collection, and a data collection scheme was designed in which the interviews and questionnaires all had a particular time and place allocated to them. However, community interventions tend to not follow strict planning schemes, and therefore the process evaluation scheme also had to be adapted to planning changes. Thus, data collection was sometimes less organized than we had intended. For example, monthly brief telephone interviews with the chairpersons of the nine Health Committees had been planned to collect data about intervention activities. In practice, these appointments were often canceled by either the researcher or the chairpersons, and took place irregularly. Nevertheless, we did manage to register all activities and several characteristics of these activities. Furthermore, since we tried to measure multiple project components and community principles at the same time, these could not be measured very extensively. With the help of triangulation, however, the reliability of the results was optimized. Finally, information from participants of intervention activities was only collected after the activity was underway, i.e., no pretests were used. This meant that it was impossible to assess changes in risk behavior or their determinants induced by specific intervention activities, so that we had to rely on the overall effect for the community intervention that was assessed in the effect evaluation study (Ronda et al., in press; Ronda et al., in preparation).

In conclusion, this process study has opened, at least partially, the 'black box' behind a planned, multi-component community intervention project, which may be beneficial to the future of the Hartslag Limburg project, as well as other health promotion community interventions. 



\title{
CHAPTER 6
}

\author{
THE DUTCH HEART HEALTH COMMUNITY \\ INTERVENTION 'HARTSLAG LIMBURG': RESULTS \\ OF AN EFFECT STUDY AT ORGANIZATIONAL LEVEL
}

Submitted for publication as:

Ronda, G., Van Assema, P., Ruland, E., Steenbakkers, M., Van Ree, J. and Brug, J. The Dutch Heart Health Community Intervention 'Hartslag Limburg': Results of an Effect Study at Organizational Level. 


\begin{abstract}
Background: Hartslag Limburg, a cardiovascular diseases (CVD) prevention program, integrates a community strategy and a high-risk strategy to reduce CVD risk behaviors. This article presents the results of the effect evaluation study of the community intervention at the organizational level. Organizational changes were an intermediate goal of the Hartslag Limburg community intervention, as these are assumed to be a prerequisite for changes at the individual level.

Methods: A pretest-posttest control group design was used. The baseline measurement was conducted in 1998 and the posttest in 2001. At baseline, 700 organizations were selected in the Maastricht region, and 577 in a control region. All organizations that were potentially significant agents in health promoting activities were included. Results: At posttest, the number of activities per organization involved in activities relating to healthy eating, smoking behavior or physical activity was higher in the Maastricht region than in the control region.

Furthermore, the overall posttest percentage of organizations involved in at least one activity relating to physical activity was higher in the Maastricht region than in the control region. Discussion: It is concluded that the present study provided valuable information about organizational involvement in health promoting activities, and about changes over time in a large community-based intervention. However, because of the limitations of the study, the importance of measuring change at different social levels in community-based programs, and the scarcity of effect studies of community interventions at the organizational level, further research on this subject is warranted.
\end{abstract}




\section{INTRODUCTION}

In 1998, a regional cardiovascular diseases (CVD) prevention program, integrating a community strategy and a high-risk strategy, was started in the Maastricht region of the province of Limburg, called Hartslag Limburg (Dutch for Heartbeat Limburg). Hartslag Limburg is a joint project of the municipal authorities of the Maastricht region, the Maastricht Regional Public Health Institute (RPHI), community social work organizations, the regional community health care organization, general practitioners, Maastricht University, the University Hospital, and various local organizations, clubs and companies. In January 2001, the World Health Organization (WHO) selected Hartslag Limburg as one of twelve so-called 'field projects', based on its potential to meet pre-established criteria of the WHO project 'Towards Unity for Health' (Boelen, 2001). The major goal of the community intervention is to reduce CVD risk among the general population in the Maastricht region by encouraging behavioral change, i.e., dietary fat reduction, increased physical activity, and smoking cessation. The community intervention is to continue at least until 2003, but evaluation studies covered the first three years. A description of the entire project has been published elsewhere (Ruland et al., 1999).

Contemporary health promotion and community evaluation literature emphasizes the importance of program effect measurement at different social levels (e.g., Nutbeam, 1998; Glasgow et al., 1999; Cheadle et al., 2000; Kegler et al., 2000). The evaluation design that was used to evaluate the community part of Hartslag Limburg consisted of an effect study and a process study, with measures at both the individual and organizational level (Ronda et al., in press). This article presents the results of the effect evaluation study of the community intervention at the organizational level. Measurement at the organizational level was especially relevant because organizational changes, particularly in terms of increased availability of CVD health promoting activities, were an intermediate goal of the Hartslag Limburg community intervention, as these are assumed to be a prerequisite for changes at the individual level. Therefore, as part of the intervention, nine local Health Committees were set up in the Maastricht region. Each Committee consisted of approximately ten members who were generally representatives of local organizations that might play a key role in health promoting activities. Moreover, each Committee was supported by a health educator from the Maastricht RPHI, a social worker and a representative of the municipal authorities. These Committees were to organize, together with other organizations that were potentially agents in health promoting activities, activities that facilitate and encourage people to adopt a healthier lifestyle.

The objective of the present study was to evaluate the effects of the community intervention on organizational involvement in health promotion and (CVD) health promoting activities. 


\section{METHODS}

\section{Design and sample}

Changes at the organizational level were tested by means of a pretest-posttest control group design (Cook and Campbell, 1979). The baseline measurement was conducted in 1998 and the posttest in 2001. At baseline, 700 organizations were selected in the Maastricht region, and 577 in a control region. All organizations that were potentially significant agents in health promoting activities were included, i.e., work sites with more than 50 employees, schools, supermarkets, (para)medical practices, civic and social clubs, sports clubs, health organizations, residents' associations, and libraries. Names and addresses of these organizations were obtained from the local Chambers of Commerce and from telephone directories. We found more organizations, of all types, in the Maastricht region than in the control region (with the exception of sports clubs and libraries). This explains the difference in the overall number of organizations.

The control region was comparable to the intervention region in terms of the incidence and prevalence of CVD, number of inhabitants, number of municipalities, and degree of urbanization, and there were no plans in place for similar prevention projects in the near future.

\section{The questionnaire}

Data was gathered by means of structured questionnaires, sent by mail to organization representatives (two attempts were made). At pretest and posttest, respondents were asked whether there were persons within their organization with a specific responsibility for health issues (yes/no). They were also asked to indicate, by means of a report mark (range 1-10), to what extent health promotion fitted in with the objectives of their organization. Furthermore, they were asked to evaluate whether their organizations could contribute to health promoting activities in their region, or could influence the type of health promoting activities organized in their region, both on five-point scales with answers ranging from 'certainly not' to 'certainly'. Further, respondents were asked whether their organizations had plans for organizing health promoting activities in the future (yes/no), and whether they had any plans for collaboration with other organizations in the future (yes/no). At posttest, respondents were asked to evaluate whether their organization had increased or decreased its involvement in health promoting activities in the last three years, on a five-

94 point scale with answers ranging from 'considerably increased' to 'considerably decreased'. In addition, respondents were asked, at pretest and posttest, whether their organization was involved in activities relating to dietary behavior, smoking behavior or physical activity in the last year (yes/no) and, if so, in how many activities their organization was involved, and how often the activity had 
been offered (once, weekly, monthly, continuously or otherwise). They were also asked to give a brief description of the activity. The questionnaire included examples of possible health promoting activities, e.g., courses, workshops, lectures, environmental changes (i.e., changes to healthier foods in cafeterias, establishment of non-smoking areas, providing fitness facilities), the distribution of brochures and pamphlets, articles in company magazines, et cetera.

\section{Statistical analysis}

Descriptive statistics (frequencies or means) were used to describe all variables of interest. Chi-square analyses were conducted to identify potential response differences between the Maastricht and the control region, overall and for each organization type. A multiple logistic regression analysis was conducted to identify potential dropout bias (with attendance versus dropout as the dependent variable and condition and the baseline values for involvement in activities relating to dietary behavior, smoking behavior and physical activity as the independent variables). In addition, chi-square analyses were conducted to identify potential dropout bias per organization type. A further multiple logistic regression analysis was used to identify potential baseline differences between the Maastricht region and the control region. The dependent variable was a binary variable reflecting condition (Maastricht region versus control region). The independent variables in this analysis were the baseline values for involvement in activities relating to dietary behavior, smoking behavior and physical activity. Only respondents who completed both surveys were included.

Differences between the Maastricht and the control region at posttest, both overall and for particular organization types, were studied using linear, logistic and ordinal regression analyses. The main independent variable included in all analyses was condition (Maastricht region versus the control region).

Furthermore, we controlled for the pre-intervention score of the outcome variable. All analyses were performed using the SPSS 10.0 statistical package (SPSS, 2000). Differences were considered to be statistically significant if $\mathrm{p}<0.05$.

\section{RESULTS}

\section{Respondents and baseline differences}

Response to the baseline survey was $46.2 \%(\mathrm{n}=590 ; 338$ (48.3\%) in the Maastricht region and 252 (43.7\%) in the control region). The overall response did not differ between the two regions. However, the initial response among the (para)medical services was higher in the control region, while that among 


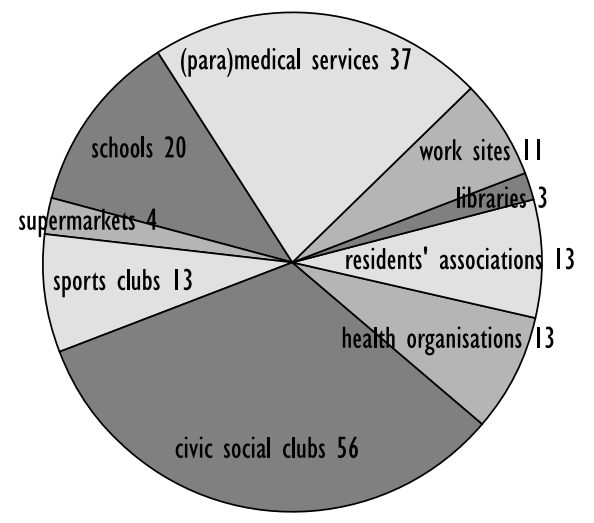

Maastricht region

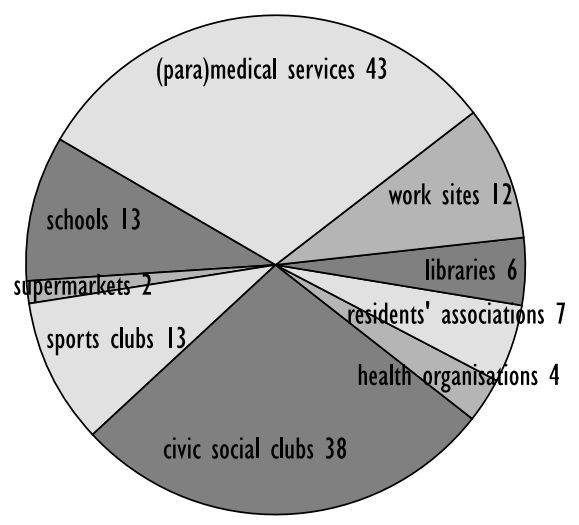

Control region

Figure 6.I: Respondents (200I) (n) by type of organization, Maastricht region $(n=170)$ and control region $(n=138)$

the civic and social clubs was higher in the Maastricht region. Attrition rate was $47.8 \%$ in the total group. Overall, 308 respondents completed both questionnaires: 170 in the Maastricht region and 138 in the control region. Attrition did not differ between the two regions, neither overall nor for the various organization types. However, dropouts were less often involved in activities regarding physical activity. Among those who completed both questionnaires there were no baseline differences between the Maastricht region and the control region in terms of involvement in activities relating to dietary behavior, smoking behavior and physical activity. Figure 6.1 shows the distribution of the remaining respondents by type of organization and region.

\section{Posttest differences in organizational involvement in health promotion and (CVD) health promoting activities}

At posttest there were no significant differences between the Maastricht and the control region in the percentage of organizations including a person(s) with a specific responsibility for health issues, nor in the report mark for the extent to which health promotion fitted in with the objectives of the organization, or the perceived opportunities to contribute to or influence the type of health promoting activities in the region. However, both regions had had a substantial increase in the percentage of organizations including a person(s) with a specific responsibility for health issues (Table 6.1). Furthermore, there was no posttest difference between the two regions in perceived involvement in activities over 
Table 6.1: Organizational involvement in health promotion and health promoting activities in the Maastricht region $(n=170)$ and the control region $(n=138)$, at baseline and at posttest

\begin{tabular}{|c|c|c|c|c|}
\hline \multirow[t]{2}{*}{ Variable } & \multicolumn{2}{|c|}{ Maastricht region } & \multicolumn{2}{|c|}{ Control region } \\
\hline & 1998 & 2001 & 1998 & 2001 \\
\hline \multicolumn{5}{|l|}{ General information } \\
\hline - person(s) with a specific responsibility for health issues (\% yes) & 33.3 & 47.8 & 43.8 & 50.9 \\
\hline - health promotion fits in with objectives (mean score; range $\mathrm{I}-10)^{*}$ & 6.3 & 6.6 & 6.7 & 6.7 \\
\hline - perceived opportunities to contribute to activities in region & & & & \\
\hline (mean score; range $1-5)^{*}$ & 3.7 & 3.7 & 3.7 & 3.7 \\
\hline \multicolumn{5}{|l|}{ - perceived opportunities to influence the type of activities in region (mean } \\
\hline score; range $1-5)^{*}$ & 3.3 & 3.2 & 3.2 & 3.2 \\
\hline - greater or smaller perceived involvement in activities in last three $>$ & & & & \\
\hline (mean score; range I-5)* & - & 3.3 & - & 3.3 \\
\hline \multicolumn{5}{|l|}{ Plans for future activities and collaboration with other organizations } \\
\hline - organizing future activities (\% yes) & 56.6 & 57.9 & 57.4 & 50.0 \\
\hline - collaborating with other organizations ( $\%$ yes) & 37.9 & 63.2 & 40.4 & 70.0 \\
\hline
\end{tabular}

* higher scores indicate a more positive opinion

the last three years (Table 6.1 ). About $30 \%$ of the organizations in both regions indicated that they had become more involved in health promoting activities in the last three years. Nor were there significant posttest differences between the Maastricht and the control region with regard to plans for future activities and collaboration with other organizations. However, both regions had substantially increased their plans for collaboration with other organizations (Table 6.1).

Overall, at baseline, $64.1 \%$ of the organizations in the Maastricht region and $68.1 \%$ in the control region were involved in at least one health promoting activity relating to healthy eating, smoking behavior or physical activity. At posttest, these percentages were $71.2 \%$ and $73.9 \%$ respectively. The mean number of activities per organization involved in these activities was 2.93 in the Maastricht region and 2.94 in the control region at baseline, versus 3.12 and 2.55 respectively at posttest. This posttest difference was statistically significant $(\mathrm{p}=.019)$. Table 6.2 gives an overview of the numbers of activities per organization in the Maastricht and the control region, at baseline and posttest. 
Table 6.2: Numbers of organizations involved in at least one health promoting activity relating to healthy eating, smoking behavior or physical activity, and numbers of activities per organization in the Maastricht region $(n=170)$ and the control region $(n=138)$, at baseline and at posttest

\begin{tabular}{|c|c|c|c|c|c|c|c|c|}
\hline \multirow{3}{*}{$\begin{array}{l}\text { Activities } \\
\text { per organi- } \\
\text { zation }\end{array}$} & \multicolumn{4}{|c|}{ Maastricht region } & \multicolumn{4}{|c|}{ Control region } \\
\hline & \multicolumn{2}{|c|}{1998} & \multicolumn{2}{|c|}{2001} & \multicolumn{2}{|c|}{1998} & \multicolumn{2}{|c|}{2001} \\
\hline & $\begin{array}{c}\text { Organiza- } \\
\text { tions }\end{array}$ & Activities & $\begin{array}{c}\text { Organiza- } \\
\text { tions }\end{array}$ & Activities & $\begin{array}{l}\text { Organiza- } \\
\text { tions }\end{array}$ & Activities & $\begin{array}{c}\text { Organiza- } \\
\text { tions }\end{array}$ & Activities \\
\hline I & 23 & 23 & 21 & 21 & 25 & 25 & 34 & 34 \\
\hline 2 & 28 & 56 & 32 & 64 & 19 & 38 & 27 & 54 \\
\hline 3 & 23 & 69 & 31 & 93 & 22 & 66 & 15 & 45 \\
\hline 4 & 19 & 76 & 14 & 56 & 12 & 48 & 12 & 48 \\
\hline 5 & 7 & 35 & 13 & 65 & 6 & 30 & 8 & 40 \\
\hline 6 & 5 & 30 & 4 & 24 & 4 & 24 & 3 & 18 \\
\hline 7 & 2 & 14 & 1 & 7 & 4 & 27 & 3 & 21 \\
\hline 8 & 2 & 16 & 3 & 24 & I & 8 & $x$ & $x$ \\
\hline 10 & $x$ & $x$ & 1 & 10 & I & 10 & $x$ & $x$ \\
\hline 13 & $x$ & $x$ & I & 13 & $x$ & $x$ & $x$ & $x$ \\
\hline Total & 109 & 319 & 121 & $377^{*}$ & 94 & 276 & 102 & $260^{*}$ \\
\hline
\end{tabular}

* significant difference in the (mean) number of activities per organization involved in activities between the Maastricht region and the control region (linear regression analysis)

Table 6.3 presents the percentage of organizations involved in at least one health promoting activity per area of activity (healthy eating, smoking behavior or physical activity). The posttest percentage of organizations involved in at least one activity relating to physical activity was significantly higher in the Maastricht region than in the control region $(\mathrm{OR}=2.26 ; \mathrm{p}=.006)$. Among (para)medical services, the posttest percentages involved in at least one activity relating to healthy eating $(\mathrm{OR}=3.16 ; \mathrm{p}=.045)$ and to physical activity $(\mathrm{OR}=3.33 ; \mathrm{p}=0.042)$ were significantly higher in the Maastricht region than in the control region. Among civic and social clubs, the posttest percentage involved in at least one activity relating to physical activity was significantly higher in the Maastricht region than in the control region $(\mathrm{OR}=3.56$; $p=0.022$ ) 
Table 6.3: Involvement in at least one activity, by area of activity and type of organization** in the Maastricht region $(n=170)$ and the control region $(n=138)$, at baseline and at posttest

\begin{tabular}{|c|c|c|c|c|c|c|c|c|c|c|c|c|}
\hline & \multicolumn{4}{|c|}{ Nutrition (\%) } & \multicolumn{4}{|c|}{ Smoking (\%) } & \multicolumn{4}{|c|}{ Physical activity (\%) } \\
\hline & \multicolumn{2}{|c|}{$\begin{array}{c}\text { Maastricht } \\
\text { region }\end{array}$} & \multicolumn{2}{|c|}{ Control region } & \multicolumn{2}{|c|}{$\begin{array}{c}\text { Maastricht } \\
\text { region }\end{array}$} & \multicolumn{2}{|c|}{ Control region } & \multicolumn{2}{|c|}{$\begin{array}{l}\text { Maastricht } \\
\text { region }\end{array}$} & \multicolumn{2}{|c|}{ Control region } \\
\hline & 1998 & 2001 & 1998 & 2001 & 1998 & 2001 & 1998 & 2000 & 1998 & 2001 & 1998 & 2001 \\
\hline Work sites & 9.1 & 0 & 16.7 & 8.3 & 36.4 & 27.3 & 41.7 & 50.0 & 36.4 & 27.3 & 33.3 & 16.7 \\
\hline $\begin{array}{l}\text { (Para)medical } \\
\text { services }\end{array}$ & 43.2 & $56.8^{*}$ & 60.5 & $44.2^{*}$ & 43.2 & 62.2 & 53.5 & 60.5 & 62.2 & $73.0^{*}$ & 67.4 & $55.8^{*}$ \\
\hline Schools & 75.0 & 60 & 69.2 & 69.2 & 75.0 & 75.0 & 46.2 & 69.2 & 75.0 & 75.0 & 84.6 & 84.6 \\
\hline Supermarkets & 25.0 & 75.0 & 0 & 100 & 0 & 0 & 0 & 0 & 0 & 0 & 0 & 50.0 \\
\hline Sports clubs & 7.7 & 0 & 15.4 & 15.4 & 0 & 0 & 15.4 & 0 & 100 & 100 & 100 & 100 \\
\hline $\begin{array}{l}\text { Civic and social } \\
\text { clubs }\end{array}$ & 17.9 & 33.9 & 13.2 & 26.3 & 10.7 & 14.3 & 10.5 & 13.2 & 46.4 & $58.9^{*}$ & 34.2 & $31.6^{*}$ \\
\hline $\begin{array}{l}\text { Health organi- } \\
\text { zations }\end{array}$ & 46.2 & 46.2 & 25.0 & 0 & 15.4 & 23.1 & 0 & 25.0 & 23.1 & 53.8 & 25.0 & 25.0 \\
\hline $\begin{array}{l}\text { Residents' as- } \\
\text { sociations }\end{array}$ & 7.7 & 7.7 & 0 & 0 & 0 & 7.7 & 0 & 14.3 & 30.8 & 23.1 & 28.6 & 28.6 \\
\hline Libraries & 33.3 & 33.3 & 50.0 & 66.7 & 66.7 & 33.3 & 50.0 & 33.3 & 33.3 & 66.7 & 50.0 & 33.3 \\
\hline Overall & 30.6 & 37.1 & 34.8 & 34.1 & 26.5 & 31.8 & 31.2 & 36.2 & 52.4 & $60.6^{*}$ & 55.1 & $49.3^{*}$ \\
\hline
\end{tabular}

* significant difference between Maastricht and control region (logistic regression analysis)

** the small number of organizations representing some of the types of organizations (Figure 6.I) do not allow meaningful interpretation of differences for these types of organizations

Overall, about $25 \%$ of the activities relating to healthy eating, smoking behavior or physical activity were offered once, while $25 \%$ were offered weekly and $25 \%$ continuously. Examples of activities that were offered once included informational and educational meetings, the distribution of brochures and posters, the removal of a cigarette vending machine, and walks and cycle tours. Activities offered weekly included various physical activity courses and projects and lessons at schools. Activities offered continuously included advice during consultations, assistance in smoking cessation by means of medication, continuous information and education, and the distribution of brochures and posters. In the Maastricht region, the name 'Hartslag' was frequently mentioned as such in the activities described. 


\section{DISCUSSION}

The major goal of the Hartslag Limburg community intervention is to reduce CVD risk among the general population in the Maastricht region. Organizational changes, especially in terms of increased availability of CVD health promoting activities, were assumed to be a prerequisite for individual changes. The present evaluation was conducted to study the effects of the community intervention on the involvement of various organizations in such activities.

At posttest, the number of activities per organization involved in activities relating to healthy eating, smoking behavior or physical activity was higher in the Maastricht region than in the control region. Furthermore, the overall posttest percentage of organizations involved in at least one activity relating to physical activity was higher in the Maastricht region than in the control region. It was especially the (para)medical services and civic and social clubs in the Maastricht region which were more often involved in these activities. In addition, (para)medical services in the Maastricht region were also more often involved in activities relating to healthy eating. There were no further significant differences between the Maastricht and the control region at posttest. A comparable study, conducted in the United States, found an increase in the number of health promoting activities and the number of sites sponsoring these programs in the experimental county (Cohen et al., 1986).

The results of the present study support the findings of the process study and the effect study at the individual level of the Hartslag Limburg community intervention. The process data showed that the focus of the intervention had mostly been on intervention activities aimed at promoting healthy eating and physical activity. Activities for smoking cessation were less frequently developed and implemented. Further, the effect evaluation at the individual level showed that the limited impact of the project was indeed on diet and physical activity. A significant decrease in fat intake was found, as well as a greater awareness of fat intake and a greater motivation for physical activity among the younger half of the population studied. However, since organizational change is assumed to precede changes in risk behaviors and their behavioral determinants, it can be expected that longer-term measurements of individual behavior may show greater changes, especially since empirical support for the relationship between concepts at organizational level and health outcomes is growing (Kegler et al., 2000).

A recently conducted study found that secular trends masked communitylevel program effects (Bauman et al., 1999). Both our process study and our effect study at the individual level revealed a substantial perceived exposure to health promoting activities in the control region. The present study also shows

100 a substantial increase in the number of organizations involved in activities relating to smoking cessation, as well as the number of organizations including a person(s) with a specific responsibility for health issues, and the number of organizations with plans for collaboration with other organizations in the control region. These findings may have masked further intervention effects. 
It is important to mention some limitations of the present study. First, it proved difficult to reach the same representatives of the various organizations at posttest as at pretest; several organizations had gone through changes in personnel and/or management. Furthermore, in spite of the fact that the questionnaires were pretested among various organization types, it appeared that some organizations were inclined not to mention some activities in which they were obviously involved. For instance, all schools should normally have been involved in activities relating to physical activity, since gymnastics are compulsory at schools in the Netherlands. However, some schools probably did not take the trouble to report these lessons, because they are a regular part of the curriculum. Next, although response at baseline and dropout did not differ between the two regions, the response at baseline was certainly not high, and there was a substantial dropout in the sample from baseline to endpoint. Moreover, several types of organizations were represented by too few examples to allow potential differences between the two regions to be tested for these types of organizations, or to allow a meaningful interpretation of such differences.

In conclusion, this study has provided us with valuable information about organizational involvement in health promoting activities, and about changes over time in a large community-based intervention. Community interventions tend to, and ought to be, autonomous and therefore difficult to plan. In such interventions it is extremely important to monitor what has really happened during the intervention. Since intermediary organizations are of key importance in the organization and implementation of intervention activities, it should be standard procedure to evaluate their role. Our study showed that the number of health promoting activities as well as the number of organizations involved in activities to promote physical activity had increased in the Maastricht region. This is a promising result because organizational change is assumed to be a precursor of individual change. However, because of the limitations of our study, and the scarcity of effect studies of community interventions at the organizational level, further research on this subject is warranted. 



\section{CHAPTER 7}

\section{GENERAL DISCUSSION}

This thesis reports on the evaluation of the Hartslag Limburg community intervention. The purpose of this final chapter is to relate the main findings of the various evaluation studies to each other and to discuss several possible explanations for the findings. In addition, it presents an overall conclusion about the Hartslag Limburg community intervention, and provides some recommendations for the evaluation of community intervention projects. 


\section{MAIN FINDINGS}

The conceptual framework of the Hartslag Limburg community intervention was based on program planning and evaluation models, and this chapter discusses the main findings of the various studies according to the stages of the framework (Table 7.1). The framework indicated how the program was expected to produce its postulated effects and served as the program's planning and evaluation framework. The model postulates that a reduction in CVD among the population in the Maastricht region could be achieved by means of changes in related risk behaviors, i.e., high saturated fat intake, smoking and inadequate physical activity level. Behavioral change was expected to result from changes in psychosocial determinants of the risk behaviors such as behavioral awareness, attitudes, social influences, self-efficacy expectations, and stages of change related to the risk behaviors. Changes in the determinants were only expected if the project resulted in sufficient activities that were tailored to and effective in changing these determinants, and if these activities actually reached the target population. It was further postulated that the organization, development, implementation, and dissemination of these activities could best be achieved by applying certain community principles: participation of the community in the planning and implementation of the project, intersectoral collaboration between local organizations, adjustment to the current situation, longterm continuation of the project, a social network approach, a multi-media and multi-method strategy, environmental changes, and activities tailored to various target groups. Finally, these community principles were expected to be achieved by means of a thorough community analysis in each of the communities, followed by the creation of nine intersectoral local Health Committees, collaboration with experts in the planning and implementation of activities, and expert training for the members of the Health Committees (quality control).

The baseline results of the Maastricht region supported the appropriateness of the conceptual model that was used for the development of intervention activities, and the need to carry out a comprehensive CVD prevention community project. It was found, as expected, that substantial proportions of the respondents were engaged in one or more of the three risk behaviors under study, and that many respondents were not aware of their risk behavior with respect to fat intake and physical activity. Furthermore, a considerable percentage of the respondents had no intentions towards changing the CVD risk behaviors, and self-efficacy towards smoking cessation, perceived social support towards changing the CVD risk behaviors, and perceived behavior of others were far from optimal. These baseline results also provided input for the identification of specific objectives of the intervention program.

Table 7.2 shows an overview of the various evaluation studies that were conducted to allow conclusions to be drawn about the Hartslag Limburg community intervention, with their data sources, study designs, data collection methods, objectives and results. As regards the project components, the results of the 
Table 7.I: Conceptual framework of the community project and the evaluation study

\begin{tabular}{|c|c|c|c|c|c|}
\hline A Health & B Risk behaviors & $\begin{array}{l}\text { C Psychosocial } \\
\text { determinants }\end{array}$ & $\begin{array}{l}\text { D Prevention } \\
\text { activities }\end{array}$ & E Community principles & F Project components \\
\hline- CVD & $\begin{array}{l}\text { - high fat intake } \\
\text { - smoking } \\
\text { - not enough } \\
\text { physical activity }\end{array}$ & $\begin{array}{l}\text { - attitudes } \\
\text { - social influences } \\
\text { - self-efficacy } \\
\text { - awareness } \\
\text { - stage of change }\end{array}$ & $\begin{array}{l}\text { - number } \\
\text { - reach } \\
\text { - effects }\end{array}$ & $\begin{array}{l}\text { - participation } \\
\text { - intersectoral collaboration } \\
\text { - link-up with current } \\
\text { situation } \\
\text { - long-term continuation } \\
\text { - social network approach } \\
\text { - multi-media and } \\
\text { multi-method strategy } \\
\text { - environmental strategy } \\
\text { - activities for various } \\
\text { target groups }\end{array}$ & $\begin{array}{l}\text { - community analyses } \\
\text { - Health Committees } \\
\text { - quality control }\end{array}$ \\
\hline
\end{tabular}

process study indicated that the community analysis and the subsequent organization of nine local Health Committees had been satisfactory. However, some factors that might influence the actual functioning of the Health Committees could be improved, such as the quality of communication, the staff time, the creation of special task forces and the number of members of the committees. Expert training of the members of the Health Committees was a weak point at the time of data collection. Nevertheless, the implementation of these project components was found to have indeed resulted in the application of the various community principles. The application of most of the principles was already quite satisfactory at this time (e.g., a social network approach and a multi-media and multi-method strategy), and/or there were indications for their application or achievement in the near future (e.g., participation of inhabitants and intersectoral collaboration between organizations). However, it was also found that environmental strategies needed more attention and that ensuring long-term continuation required continuous effort.

As expected, the adequate implementation of project components and the subsequent application of community principles had indeed resulted in the development and implementation of a large number of intervention activities, organized by the Health Committees together with other organizations. The process evaluation showed that 293 intervention activities had been implemented in the Maastricht region during the research period. The effect study among organizations found that this meant a significant increase in the number of activities per organization involved in CVD health promoting activities in the Maastricht region as compared to the control region. Most of the 293 implemented intervention activities that were identified by the process evaluation had focused on nutrition, followed by 
activities relating to physical activity. Activities to promote smoking cessation were found to be less prevalent. This was also reflected in the effect study among organizations, which found an increase in the percentage of organizations involved in activities relating to physical activity, and in the percentage of medical and paramedical services involved in activities relating to nutrition in the Maastricht region as compared to the control region. Although a large number of intervention activities had been implemented, for most of these activities no proof for the effectiveness is available, nor were the present studies aimed at testing individual activities. However, it is obvious that if individual intervention activities are of poor quality, i.e., if there are not enough activities that are tailored to and effective in changing the psychosocial determinants of the CVD risk behaviors, no effects on CVD risk behaviors and their psychosocial determinants can be expected. The process evaluation revealed that the majority of the activities were only offered once and most of the activities were aimed at increasing knowledge and awareness. Unfortunately, information from participants in intervention activities was only collected after the activity was underway, i.e., no pretests were used. This meant that it was impossible to assess changes in risk behavior or their determinants induced by specific intervention activities. Nevertheless, a large majority of the participants in activities relating to physical activity and nutrition reported that they felt encouraged to eat less fat or to increase their physical activity in the future. Some activities were selected and implemented on the basis of their proven effectiveness and reach in earlier studies (Ronda and Van Assema, 1997). Specific nutritional activities in particular have been extensively tested in controlled studies (Van Assema et al., 1997; Van Assema et al., 1998; Brug et al., 1998). Ideally, all intervention activities should have been tested before in controlled studies. However, not many of such activities were available, and it would have limited community participation in the choice of activities.

The process study also revealed that although familiarity with activities relating to the three CVD risk behaviors was quite high, the actual participation of the general population in activities did not exceed $15 \%$. There were some differences in familiarity with activities according to educational level. More highly educated people were found to be more familiar with activities than those less highly educated. However, the actual participation in activities did not differ with educational level. Moreover, $50 \%$ of those who participated in group activities indicated that they had a low level of education. In summary, although there are indications that several intervention components may have been effective, the total package of intervention activities may not have been of sufficient quality (in terms of effectiveness in changing the psychosocial determinants of the CVD risk behaviors), quantity (especially in terms of the number of smoking cessation activities, and intensity (in terms of reach and participa-

106 tion), to result in substantial changes in the population studied after the two and a half year intervention period. The results of the effect study at the individual level on the CVD risk behaviors and their psychosocial determinants may, at least partially, be explained by the above pattern of findings. A significant posttest difference was found between the Maastricht region and the control region, in 
favor of the Maastricht region, with respect to dietary fat intake, especially among respondents aged $\leq 48$ years (median age). Respondents in the Maastricht region were also more realistic about their fat intake but had lower self-efficacy expectations towards decreasing their fat intake than respondents in the control region. With respect to physical activity, only a limited effect on intentions was found among respondents younger than 49 year. No significant posttest differences were found between the Maastricht region and the control region in smoking behavior and its determinants. However, the findings in the earlier stages of the framework also revealed that community participation and intersectoral collaboration between local organizations in the Maastricht region was still growing at the time of data collection, and organizational changes were assumed to precede changes in risk behaviors and their psychosocial determinants. Longer-term measurements may thus show more, or greater, changes in individual behaviors or their determinants.

Finally, the greater self-efficacy expectations towards decreasing fat intake that were found in the final posttest in the control region may not be incompatible with the decline in fat intake in the Maastricht region, because self-efficacy was measured in relation to behavior change (i.e., 'eating less fat') and not in relation to present behavior (i.e., 'eating a low fat diet'). Therefore, respondents who had reduced their fat scores (i.e., respondents in the Maastricht region) may have become less confident about their ability to further decrease their fat intake.

This problem could have been prevented if we had framed the psychosocial determinants of the target behaviors according to whether the respondents did or did not perform the target behavior (i.e., measuring the determinants in relation to behavior change in case of not performing the target behavior and measuring the determinants in relation to present behavior in case of performing the target behavior). This was, however, not feasible in the present study, as it would only have been possible if interactive methods of data collection were used.

\section{EXPLANATIONS OF FINDINGS AT THE INDIVIDUAL LEVEL}

Results of the evaluation Hartslag Limburg community intervention revealed that many components that were assumed to precede individual changes were favorably evaluated. However, the effects on the CVD risk behaviors and their psychosocial determinants were limited. Most community-based CVD prevention projects have found a similar pattern. Possible explanations frequently mentioned for the modest or absent intervention effects on individual behaviors in community CVD prevention programs are: 1) ineffective intervention, 2) secular trends, 3) poor study designs, and 4) inadequate measurement tools (e.g., Luepker et al., 1994; Carleton et al., 1995; Brownson et al., 1996; Winkleby et 
Table 7.2: Overview of the evaluation studies described in this thesis

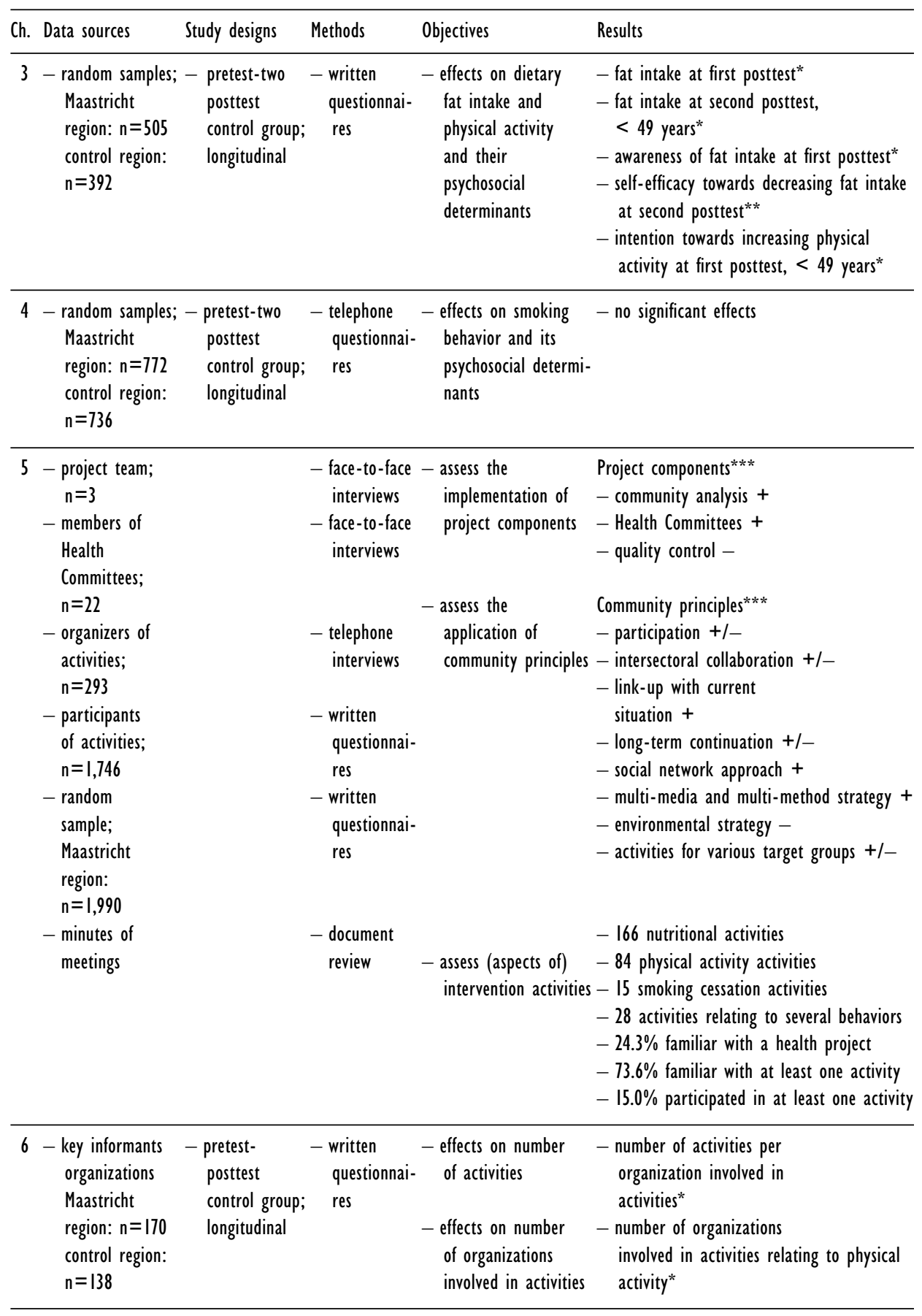

\footnotetext{
* significant difference between Maastricht region and control region in favor of Maastricht region, $p<0.05$

** significant difference between Maastricht region and control region in favor of control region, $\mathrm{p}<0.05$

**** global assessment based on reported scores (+=satisfactory; +/=-uncerain; -=unsatisfactory)
} 
al., 1997; Mittelmark, 1999). The first explanation, relating to the quality, quantity and intensity of intervention activities, has already been discussed. Although the issues are partially interlinked, each of the remaining issues is discussed separately below. The strengths and weaknesses of the various studies described in this thesis are considered, as they might support a given explanation or might provide evidence for its rejection.

\section{Secular trends}

Secular trends are frequently mentioned as explanation for modest or absent intervention effects in community-based heart health programs (e.g., Luepker et al., 1994; Winkleby et al., 1997). In other words, it might be difficult to generate enough additional exposure in experimental communities to exceed secular trends in control communities. Additional questions in the posttest of the individual level effect study of the Hartslag Limburg community intervention revealed that although familiarity with a health project in the Maastricht region exceeded that in the control region, these data also suggested a substantial perceived exposure to health promotion interventions in the control region. Further, these data also revealed that although familiarity with activities on nutrition, physical activity and smoking cessation was higher in the Maastricht region, reported participation in activities on physical activity and smoking cessation was higher in the control region. Unfortunately, baseline values on familiarity and participation were not measured. The study among organizations showed a substantial increase for both regions in the number of organizations involved in activities relating to smoking cessation, as well as the number of organizations including one or more persons with a specific responsibility for health issues, and the number of organizations with plans for collaboration with other organizations. A recently conducted study, which examined the secular trend explanation, found that secular trends did indeed mask community-level program effects (Bauman et al., 1999). In summary, the various Hartslag Limburg evaluation studies found evidence for unanticipated secular changes in behaviors, CVD health promoting activities, and participation in these activities.

\section{The study design}

The study used to evaluate the effects of the Hartslag Limburg community intervention on individual behaviors and their psychosocial determinants had a pretest-posttest control group design, with two posttests. Only one intervention group and one control group were included, and allocation to the intervention or control condition was nonrandom. Furthermore, it was decided to assemble a cohort sample at baseline and to follow these subjects until the final posttest. Both these issues give rise to questions about the internal and external validity of the results. The one-group-per-condition design and nonrandom allocation is discussed first, followed by the use of a longitudinal sample. 


\section{One-group-per-condition design without randomization}

The effect study included only one intervention and one control region, and allocation to the intervention or control region was nonrandom. Since both issues are interrelated, they are discussed together. Many community interventions have used the 'one-group-per-condition' design. Although this is a well accepted design in the field of community intervention research (e.g., Carleton et al., 1995; Tudor-Smith et al., 1998), it certainly has important limitations, especially as regards the validity of causal inference. However, cost and feasibility considerations usually limit the intervention and evaluation to a small number of communities, and allocation to treatment groups is often decided beforehand by funding agencies or the communities themselves (Koepsell et al., 1992), as was also the case in Hartslag Limburg. Although randomization might be important to ensure valid results, the number of communities available is likely to remain small, so randomization alone is no guarantee for the statistical equivalence of groups (Koepsell et al., 1992; Potvin and Richard, 2001). Furthermore, because communities are complex systems, open to numerous external and internal influences, even the inclusion of many communities and random allocation to intervention and control conditions cannot guarantee the validity of causal inference (Potvin and Richard, 2001). Some authors even question the appropriateness of randomizing large numbers of communities, for example because it is hardly possible to create standard programs for implementation in various experimental communities (Kim et al., 1994). Other authors have emphasized the need to incorporate multiple communities (Murray, 1995). In Hartslag Limburg, the experimental and control region were matched on several characteristics, viz. incidence and prevalence of CVD, number of inhabitants, number of municipalities, and degree of urbanization. Nevertheless, a number of significant differences were found at baseline between the Maastricht and the control region. In an attempt to overcome this design weakness to some extent, the pre-intervention score of the outcome variables, as well as those variables identified as being statistically different $(p<0.05)$ between respondents from the Maastricht region and the control region, were included as independent variables in the analyses of differences between the Maastricht and control region. Another problem with the onegroup-per-condition design is that observations within such groups are often correlated, and ignoring this possibility may lead to inappropriate conclusions about the statistical significance of results. However, in the one-group-per-condition design, the variation due to the group cannot be estimated apart from the variation due the study condition (Varnell et al., 2001). In Hartslag Limburg, the intervention and control region consisted of several municipalities, and multilevel analysis was used to take possible dependencies among individu-

I 10 als within the same municipality into account (Hedeker et al., 1994). Several other community projects have used statistical procedures to adjust for dependencies among individuals within municipalities (e.g., Carleton et al., 1995; Brownson et al, 1996). Multilevel analysis evaluation of community-based interventions is regarded as superior, but has not often been applied so far. 
Nevertheless, traditional criteria for rigour are not applicable in evaluations of community programs or might even be inappropriate, and this is why many authors have emphasized the importance of the use of triangulation (e.g., Koepsell et al., 1992; Nutbeam, 1998; Potvin and Richard, 2001). In the case of Hartslag Limburg this was achieved by combining information from the various evaluation studies, as a way of improving confidence in research findings.

\section{Longitudinal samples}

Longitudinal as well as repeated cross-sectional designs have been used to evaluate community health programs, and both sampling approaches have been used in several large and well-known heart health programs (e.g., Luepker et al., 1994; Carleton et al., 1995). Because of practical and cost considerations, it was decided to assemble a cohort sample at baseline and to follow these subjects until the final posttest in the effect studies of the Hartslag Limburg community intervention. Both sampling approaches have their relative merits (Salonen et al., 1986; Diehr et al., 1995). Re-examination of the same cohort offers the ability to adjust for baseline differences in, e.g., risk behaviors (Salonen et al., 1986). Because several baseline differences were found in the effect studies of the Hartslag Limburg community intervention, the ability to adjust for these differences proved to be very important. Another advantage is that the cohort design has a greater statistical power to detect changes than a cross-sectional design if the bias is relatively small and the sample size is limited (Diehr et al., 1995). However, several factors may have affected the external and internal validity of the results of our effect evaluation. First, the response rates of the studies which used mail surveys were certainly not high. However, as it is generally accepted that a well-conducted mail survey can only net a $45-55 \%$ response rate (Miller, 1994), our response rates were quite acceptable for a mail survey. Furthermore, response at baseline did not differ between the two regions. Nevertheless, the response rates may have resulted in poor external validity, because the representativeness of the sample could not be not assured (Windsor et al., 1994).

Secondly, there was a substantial dropout rate in the samples from baseline to endpoint, and dropout may be related to the behavior being evaluated (Koepsell et al., 1992). Dropout is an intrinsic feature of the cohort design. Although dropout did not differ between the two regions, the high dropout may have resulted in poor external validity (Windsor et al., 1994). However, the analyses of differences between the Maastricht and the control region controlled for differences between dropouts and those who remained in the samples. A further consequence of the cohort design that might have affected internal validity is repeated questioning, implying the possibility that the survey itself may have had an effect on participants' self-reported behavior. This becomes especially important if there is differential re-examination bias in the intervention and control condition (Koepsell et al., 1992; Salonen et al., 1986). To reduce this possible bias in the intervention condition, questions about health promoting activities were included in the questionnaires in both regions, giving both intervention and control participants the impression that they were in an interven- 
tion condition. Although cohort designs are more susceptible to a variety of biases than cross-sectional designs, the inclusion of a control community limits this problem to a certain extent (Diehr et al., 1995; Potvin and Richard, 2001). The cohort tends to be biased to a similar degree in both experimental and control communities, so that experimental-control comparisons are less biased (Diehr et al., 1995; Potvin and Richard, 2001).

\section{Inadequate measurement tools}

The possibility that the survey data themselves are inaccurate should also be considered. The results of the studies are based on self-reports. Self-reported data are usually assumed to be 'soft' data, while objectively obtained data, such as physiological measurements, are assumed to provide 'harder' evidence (Windsor et al., 1994). However, the use of self-report data is 'usual practice' in community research (e.g., Brownson et al., 1995; Tudor-Smith et al., 1998). Because of practical constraints (e.g., large samples) it is hardly possible to use more objective impact indicators in community research, and self-reports is often the only feasible method for collecting data on health behaviors (Koepsell et al., 1992). For example, taking and analyzing blood samples to evaluate dietary fat intake, or using accelerometers to assess levels of physical activity, is very expensive and time-consuming. Such measurements may also interact with intervention activities and may lead to lower response rates (Windsor et al., 1994). Furthermore, a criterion of primary concern in terms of the hardness of data might be reliability, and soft measures can provide useful and reliable data (Feinstein, 1977; Windsor et al., 1994). The question of the validity and reliability of the instruments used for the effect studies of Hartslag Limburg at the individual level is discussed below. The first aspect discussed is the validity and reliability of the instruments that were used to measure the CVD risk behaviors, followed by the use of single-item assessments for the psychosocial determinants of the risk behaviors.

Dietary fat intake was assessed using a validated questionnaire covering nineteen (groups of) food products resulting in a fat consumption score ranging from 0 to 80 points (Van Assema et al., 2001). The relative validity of the questionnaire was investigated by comparison with a seven-day diet record. Pearson correlation between the two methods was 0.71 for total fat intake and 0.69 for saturated fat intake, while the Pearson correlation for test-retest reliability was 0.72 . These relative validity data are of the same order as, or better than, those reported for other food frequency questionnaires assessing dietary fat intake (Block et al., 1989; Coates et al., 1995). Physical activity levels were assessed with a newly developed short questionnaire, based on the recommended levels

II2 of physical activity to promote health. The recommended level of physical activity for adults is to engage in at least 30 minutes of moderate-intensity physical activity on at least five, but preferably all, days of the week (Kemper et al., 2000). The relative validity of the questionnaire was investigated by comparison with a seven-day physical activity record. The Spearman rank order coefficient 
between the two methods was 0.50 , while the Spearman rank order coefficient for test-retest reliability was 0.73 . (Koremans et al., 2000). These relative validity data were of the same order as those reported for other physical activity questionnaires (Richardson et al., 1995; Pols et al., 1996; Pols et al., 1997; Wareham et al., 2002). However, it should be mentioned that the physical activity indicator may not have been accurate enough to detect changes. Smoking behavior was assessed by asking respondents whether they had smoked in the last seven days. Self-reports of smoking behavior have proved to be fairly valid among adults who participate in community studies, compared with a biochemical marker of smoking status (Koepsell et al., 1992). Based on the results of other studies assessing relative validity and reliability, and the 'fairly general' agreement that if correlations are greater than 0.5 , an instrument can be regarded as valid, it was concluded that the questionnaires used in Hartslag Limburg to assess the CVD risk behaviors were acceptable, though certainly not ideal, for use in large population studies (Koepsell et al., 1992; Richardson et al., 1995; Pols et al., 1996; Pols et al., 1997; Block et al., 1989; Coates et al., 1995; Plesko et al., 2000).

A further measurement issue is the use of single-item assessments for the determinants of the CVD risk behaviors, since single-item assessments may be not sensitive enough to detect small intervention effects. Practical limitations (survey questionnaire size), however, made us decide to use these single items for assessment of determinants. Secondary analysis showed that these assessments had significant and quite strong associations with intentions, which is a clear indication of the predictive validity of these assessments of psychosocial factors.

Although the relative validity and reliability of the instruments used in the effect studies of Hartslag Limburg were found to be better than or comparable to those used in other studies, it is well-known that self-reports may often be biased. In particular, respondents exposed to the intervention condition may be inclined to overreport desirable health behaviors and underreport undesirable behaviors (Koepsell et al., 1992; Windsor et al., 1994). As was mentioned above, we attempted to reduce this possible bias by including questions about health promoting activities in the questionnaires in both regions, giving both intervention and control participants the impression that they were an intervention condition.

\section{CONCLUSIONS}

There is much debate about what counts as evidence in health promotion and community research, and how to evaluate community interventions (e.g., Nutbeam 1998; McQueen and Anderson, 2001; Potvin and Richard, 2001; Rychetnik et al., 2002). It seems to have become generally accepted, however, 
that no 'single' evaluation can answer the question about the effectiveness of complex multi-component community interventions. Experimental or quasiexperimental designs that assess effects on risk behaviors can at best provide part of the picture in a multi-level intervention (e.g., Nutbeam, 1998; Rychetnik et al., 2002). It is extremely important for the interpretation of results to monitor the implementation process and to provide a framework with a hierarchy of outcomes (e.g., Nutbeam, 1998; Rychetnik et al., 2002). Evidence can best be built from data that are derived from several different sources and from different methods that can be combined and compared. The concept of research 'triangulation' is a promising approach to improve confidence in research findings (Nutbeam, 1998). In line with these recommendations, the evaluation of the Hartslag Limburg community intervention was based on a hierarchical conceptual framework, and research triangulation was used to assess the effectiveness of the project.

Our first conclusion is that the baseline data definitely warranted the development and implementation of a comprehensive CVD risk prevention program. Furthermore, we were able to identify successful and less successful elements of the Hartslag Limburg community intervention. With respect to the project components, the community analyses and the subsequent organization of the Health Committees were successful. However, some aspects that may influence the functioning of the Health Committees could be improved, viz. the quality of communication, the staff time, the creation of special task forces, expert-training for the members, and the number of members. With respect to the community principles, it is a hopeful sign that the participation of inhabitants, the intersectoral collaboration between organizations, and the intervention activities aimed at various target groups were already improving at the time of data collection. A strong link with the existing situation, the use of a social network approach, and the use of a multi-media and multi-method strategy had already been successfully established at that time. However, environmental strategies, i.e., changing the broader context in which individuals live, and long-term continuation of the project needed more attention. With respect to the intervention activities, it can be concluded that the project has been successful in achieving an increase in CVD prevention activities as well as increasing the number of organizations active in CVD promoting activities in the region during the first two and a half years of the intervention. At the same time, there is doubt about the total package of intervention activities, in terms of quantity (especially the number of smoking cessation activities), quality (effectiveness in changing psychosocial determinants), and diffusion (i.e., reach and participation). It must be concluded that only limited effects on CVD risk behaviors and their psychosocial determinants were found. Nevertheless, we consider the effects on fat intake as a

II4 promising result, and longer-term measurement may show more or greater changes in all three risk behaviors or their determinants, as there were various indications that elements of the project were still developing at the time of the study. Furthermore, the project has succeeded in reaching less educated inhabitants, and no differences in effect were found for various levels of education. 
Since health promoting activities are often assumed to reach especially more highly educated people (e.g., Finnegan and Viswanath, 1999), this can be regarded as a relative success.

It is concluded that after two and a half years of Hartslag Limburg, some promising results have been achieved, but that the presence of a secular trend towards more heart healthy behavior, as well as study design limitations, and the less than optimal (though still growing) quantity, quality and diffusion of intervention activities, prevented more convincing results, or the detection of such results. Despite its limitations, the findings of the evaluation may be beneficial for the future of Hartslag Limburg, as well as other health promotion community interventions.

\section{RECOMMENDATIONS FOR EVALUATION RESEARCH}

Based on our experience with the actual evaluation design for the Hartslag Limburg community intervention, some recommendations can be made that might be beneficial for future evaluation studies on community interventions. These recommendations are largely in line with generally accepted recommendations for community evaluation research.

The use of a hierarchical theoretical framework, with evaluation measures for all stages of the framework, is strongly recommended. The use of such a framework yields information about relationships between various stages, as well as about proximal and distal outcomes of the intervention. In the evaluation of the Hartslag Limburg community intervention, the use of the framework proved to be very important because the limited findings of the effect study at the individual level could largely be explained by the findings from the studies in the earlier stages of the framework. In addition to the use of a framework, it is recommended to gather information at different social levels, because community interventions focus not only on individual behaviors but also on the broader context in which individuals live.

Next, it is recommended to use the data that are gathered during the planning and implementation of a project to give rapid feedback to those involved in this planning and implementation. In Hartslag Limburg, this feedback was often experienced as encouraging and has led to the adjustment of existing activities as well as decisions being made about future activities.

It is also obvious that measurements need to be as valid and reliable as possible to assess the implementation of project components and the application of community principles. In Hartslag Limburg, these components and principles were not measured very extensively, and although the data could be used to explain findings in the later stages of the conceptual framework, quantitative testing to examine these relationships was not possible. 
Further, it is recommended to test intervention activities, before they are implemented in the community, in controlled studies. Pretest-posttest designs allow the effectiveness of specific intervention activities to be assessed when they are implemented in the community.

The use of at least two pretests is recommended to allow secular trends to be identified. For the same purpose, and to demonstrate links between exposure 'dose' and actual behavior change, valid measures to assess exposure to interventions in both experimental and control regions should be developed.

The use of multiple posttests at various points in time is recommended to study effects. The effect study used for Hartslag Limburg may have 'missed' effects, because measurements were conducted while the project was still developing. It is therefore recommended to use repeated cross-sectional surveys, in addition to a longitudinal design.

In sum, the results of the Hartslag Limburg community intervention are encouraging and the rationale for the community approach to prevent CVD seems valid. However, assessing the effectiveness of the entire Hartslag project will require the results of the process and effect evaluations of the high-risk project, as well as the project's cost-effectiveness, to be related to the results of the evaluation described in this thesis. 


\section{REFERENCES}

Ajzen, I. (199I) The theory of planned behavior. Organizational Behavior and Human Decision Processes, 50, I79-2II.

Baranowski, T., Perry, C. L. and Parcel, G. S. (1997) How individuals, environments, and health behavior interact. In Glanz K., Lewis F. M. and Rimer B. K. (eds), Health Behavior and Health Education:Theory, Research, and Practice. San Francisco, California, p. 164.

Bauman, K. E., Suchindran, C. M. and Murray, D. M. (1999) The Paucity of Effects in Community Trials: Is Secular Trend the Culprit? Preventive Medicine, 28, 426-429.

Blackburn, H. (1992) Community programs in coronary hearth disease prevention and health promotion: Changing community behavior. In Marmot, M. and Elliott, P. (eds), Coronary heart disease epidemiology: From aetiology to public health. Oxford University Press, Oxford, pp. 495-5।4.

Block, G., Clifford, C., Naughton, M. D., Henderson, M. and McAdams, M. (1989) A brief dietary screen for dietary fat intake. Journal of Nutrition Education, 2 I, 199-207.

Boelen, C. (200I) "Towards Unity for Health": status report; Towards Unity for Health, 3, 5-6. WHO, Geneva.

Bokma, J.,Vries de, M. and Vries de, M. (1994) Hart op weg? Evaluatie Zuidoost Drenthe HARTstikke Goed! GGD Zuidoost-Drenthe, Rijksuniversiteit Groningen, Emmen/Groningen.

Booth, S. L., Laboratory, V. K., Mayer, J., Sallis, J. F., Ritenbaugh, C., Hill, J. O., Birch, L. L., Frank, L. D., Glanz, K., Himmelgreen, D. A., Mudd, M., Popkin, B. M., Rickard, K.A., Jeor, S. S. and Hays, N.P. (200I) Environmental and societal factors affect food choice and physical activity: Rationale, influences, and leverage points. Nutrition Reviews, 59, S2I-S39.

Bracht, N. and Kingsbury, L. (1990) Community organization principles in health promotion: A five-stage model. In Bracht, N. (ed), Health promotion at the community level. SAGE Publications, Newbury Park, pp. 66-88.

Bracht, N., Kingsbury, L. and Rissel, C. (1999) A five-stage community organization model for health promotion: empowerment and partnership strategies. In Bracht, N. (ed), Health promotion at the community level: New advances. SAGE Publications, Inc, Thousands Oaks, PP. 83-117.

Brownson, R. C., Smith, C.A., Pratt, M., Mack, N. E., Jackson-Thompson, J., Dean, C. G., Dabney, S. and Wilkerson, J. C. (1996) Preventing Cardiovascular Disease through Community-Based Risk Reduction:The Bootheel Heart Health Project. American Journal of Public Health, 86(2), 206-2I3.

Brug, J., Van Assema, P., Kok, G., Lenderink, T. and Glanz, K. (1994) Self-rated dietary fat intake: association with objective assessment of fat, psychosocial factors, and intention to change. Journal of Nutrition Education, 26, 218-223.

Brug, J., Hospers, H. J. and Kok, G. (1997a) Differences in psychosocial factors and fat consumption between stages of change for fat reduction. Psychology and Health, I 2, 719- 727.

Brug, J., Glanz, K. and Kok, G. (1997b) The relationship between self-efficacy, attitudes, intake compared to others, consumption, and stage of change related to fruit and vegetables. American Journal of Health Promotion, I 2, 25-30.

Brug, J., Glanz, K.,Van Assema, P., Kok, G. and Van Breukelen, G. (1998) The impact of computer-tailored feedback on fat, fruit, and vegetable intake. Health Education and Behavior, 25, 357-37I. 
Calfas, K. J., Long, B. J., Sallis, J. F.,Wooten,W. J., Pratt, M. and Patrick, K. (1996) A controlled trial of physician counseling to promote the adoption of physical activity. Preventive Medicine, 25, 225-233.

Carleton, R.A., Lasater, T. M.,Assaf,A. R., Feldman, H.A. and McKinlay, S. (1995) The Pawtucket Heart Health Program: Community Changes in Cardiovascular Risk Factors and Projected Disease Risk. American Journal of Public Health, 85(6), 777-785.

Cheadle,A., Sterling,T. D., Schmid, T. L. and Fawkett, S. B. (2000) Promising community-level indicators for evaluating cardiovascular health-promotion programs. Health Education Research, I5, 109-II6.

Coates, R. J., Serdula, M. K., Byers, T., Mokdad,A., Jewell, S., Leonard, S. B., Ritenbauch, C., Newcomb, P., Mares-Perlman, J., Chavez, N. and Block, G. (1995) A brief, telephone-administered food frequency questionnaire can be useful for surveillance of dietary fat intakes. Journal of Nutrition, I 25, I473-I 483.

Cohen, R.Y., Stunkard,A. and Felix, M. R. J. (1986) Measuring Community Change in Disease Prevention and Health Promotion. Preventive Medicine, I5, 4I I-42I.

Commers, M. and De Leeuw, E. (200I) Hoe oordeelt de bevolking over gezondheidsdeterminanten? Tijdschrift voor Gezondheidswetenschappen, 79, 39-47.

Cook,T. D. and Campbell, D.T. (1979) Quasi-experimentation: Design and analysis issues for field settings. Rand McNally, Chicago.

Cooksy, L. J., Gill, P. and Kelly, P.A. (200I) The program logic model as an integrative framework for a multimethod evaluation. Evaluation and Program Planning, 24, I I9- 128.

Cunningham, L. E., Michielutte, R., Dignan, M., Sharp, P. and Boxley, J. (2000) The value of process evaluation in a community-based cancer control program. Evaluation and Program Planning, 23, 13-25.

De Vries, H., Dijkstra, M. and Kuhlman, P. (1988) Self-efficacy: the third factor besides attitude and subjective norm as a predictor of behavioral intentions. Health Education Research, 3 , 273-282.

DeVries, H. and Backbier, E. (1994) Self-efficacy as an important determinant of quitting among pregnant women who smoke: the 0-pattern. Preventive Medicine, 23, 167- 174.

De Vries, H. and Mudde, A. N. (1998) Predicting stage transitions for smoking cessation applying the attitude-social influence-efficacy model. Psychology and Health, I3, 369-385.

DeVries, H. and Brug, J. (1999) Computer-tailored interventions motivating people to adopt health promoting behaviours: Introduction to a new approach. Patient Education and Counseling, 36, 99-105.

Diehr, P., Martin, D. C., Koepsell, T., Cheadle, A., Psaty, B. M. and Wagner, E. H. (1995) Optimal survey design for community intervention evaluations: cohort or cross-sectional? Journal of Clinical Epidemiology, 48, I46I-I472.

European Commission (1999) A Pan-EU Survey on Consumer Attitudes to Physical Activity, Bodyweight and Health. Office for Official Publications of the European Communities, Luxembourg, pp. 5-39.

I 8 Ezatti M., Lopez,A. D., Rodgers,A.,Vander Hoorn, S. and Murray, C. J. L. (2002) Selected major risk factors and global and regional burden of disease. The Lancet, 360, 1347- 1360.

Feinstein,A. R. (1977) Clinical biostatistics XLI: Hard science, soft data, and the challenges of choosing clinical variables in research. Clinical Pharmacology and Therapeutics, 22, 485-498. 
Finnegan, J. R. and Viswanath, K. (1999) Mass Media and Health Promotion: Lessons Learned, With Implications for Public Health Campaigns. In Bracht, N. (ed), Health promotion at the community level. SAGE Publications, Thousands Oaks, Pp. II9-126.

Flora, J.A., Lefebvre, R. C., Murray, D. M., Stone, E. J.,Assaf,A., Mittelmark, M. B. and Finnegan, J. R. (1993) A community education monitoring system: methods from the Stanford FiveCity Project, the Minnesota Heart Health Program and the Pawtucket Heart Health Program. Health Education Research, 8, 8I-95.

Glasgow, R. E.,Vogt, T. M. and Boles, S. M. (1999) Evaluating the public health impact of health promotion interventions:The RE-AIM framework. American Journal of Public Health, 89(9), I322-1327.

Godin, G., Desharnais, R., Valois, P. and Bradet, R. (1995) Combining behavioral and motivational dimensions to identify and characterize the stages in the process of adherence to exercise. Psychology and Health, 10, 333-344.

Goodman, R. M. (1998) Principles and tools for evaluating community-based prevention and health promotion programs. Journal of Public Health Management Practice, 4(2), 37-47.

Green, L.W. and Kreuter, M.W. (199I) Health promotion planning:An educational and environmental approach. Mountain View, CA, Mayfield.

Green, L.W. and Kreuter, M.W. (1999) Health promotion planning:An educational and ecological approach. Mountain View, CA, Mayfield.

Hedeker, D., McMahon, S. D. and Jason, L.A. (1994) Analysis of clustered data in community psychology: with an example from a worksite smoking cessation program. American Journal of Community Psychology, 22(5), 595-6I5.

Hedeker, D. and Gibbons, R. D. (1996) A computer program for mixed-effects ordinal regression analysis. Computer Methods and Programs in Biomedicine, 49(2), I57- 176.

Hildebrandt, V. H., Urlings, I. J. M., Proper, K. I., Ooijendijk, W.T. M. and Stiggelbout, M. (1999) Are the Dutch still sufficiently physically active? (Bewegen Nederlanders nog (wel) voldoende?). In Hildebrandt,V. H., Ooijendijk, W.T. M. and Stiggelbout, M. (eds), Trendrapport bewegen en gezondheid 1998-1999. Koninklijke Vermande, Lelystad, pp. 23-52.

Hill, J. O. and Peters, J. C. (1998) Environmental contributions to the obesity epidemic. Science, 280, I37I- I 374.

Hoeben, J. (1998) Leisure time physical activity (Lichamelijke activiteit in de vrije tijd). Maandbericht Gezondheidsstatistiek, 5, 18-26.

Jones, D.A., Ainsworth, B. E., Croft, J. B., Macera, C.A., Lloyd, E. E. and Yusuf, H. R. (1998) Moderate leisure-time physical activity. The Archives of Family Medicine, 7, 285- 289.

Kegler, M. C., Steckler, A., McLeroy, K. and Malek, S. H. (1998) Factors that contribute to effective community health promotion coalitions:A study of 10 Project ASSISt coalitions in North Carolina. Health Education \& Behavior, 25, 258-278.

Kegler, M. C., Twiss, J. M. and Look,V. (2000) Assessing Community Change at Multiple Levels: The Genesis of an Evaluation Framework for the California Healthy Cities Project. Health Education and Behaviour, 27, 760-779.

Kemper, H. C. G., Ooijendijk,W.T. M. and Stiggelbout, M. (2000) Consensus about the Dutch recommendation for physical activity to promote health (Consensus over de Nederlandse norm gezond bewegen). Tijdschrift voor Gezondheidswetenschappen, 78, I80183. 
Kim, S., Crutchfield, C., Williams, C. and Hepler, N. (1994) An innovative and unconventional approach to program evaluation in the field of substance abuse prevention: a thresholdgating approach using single system evaluation designs. In Kaftarian, S. J. and Hansen,W. B. (eds), Journal of Community Psychology, CSAP Special Issue, pp. 6I-78.

Koelen, M.A.,Vaandrager, L. and Colomér, C. (200I) Health promotion research: dilemmas and challenges. Journal of Epidemiology and Community Health, 55, 257-262.

Koepsell, T. D., Wagner, E. H., Cheadle,A. C., Patrick, D. L., Martin, D. C., Diehl, P. H., Perrin, E. B., Kristal,A. R.,Allan-Andryala, C. H. and Day, E. B. (1992) Selected methodological issues in evaluating community-based health promotion and disease prevention programs. Annual Reviews Public Health, 13, 31-57.

Konings-Dalstra, J.A.A. and Reitsma, J. B. (1999) Hart- en vaatziekten in Nederland. Nederlandse Hartstichting, Den Haag.

Koremans, G. M., Derks, H., Tuinstra, A., Diederiks, M. and Brug, J. (2000) A quick method to assess physical activity? (Een snelle methode om beweging te meten?). Humanities Working Papers, 5, 3-13.

Laforge, R. G.,Velicer,W. F., Richmond, R. L. and Owen, N. (1999) Stage distributions for five health behaviors in the United States and Australia. Preventive Medicine, 28, 6 I-74.

Lechner, L. and De Vries, H. (1995) Starting participation in an employee fitness program: attitudes, social influence, and self-efficacy. Preventive Medicine, 24, 627-633.

Lechner, L., Brug, J. and De Vries, H. (1997) Misconceptions of fruit and vegetable consumption. Journal of Nutrition Education, 29, 313-320.

Luepker, R.V., Murray, D. M., Jacobs, D. R., et al. (1994) Community Education for Cardiovascular Disease Prevention: Risk Factor Changes in the Minnesota Heart Health Program. American Journal of Public Health, 84, I383-I 393.

Marcus, B. H., Selby, V. C., Niaura, R. S. and Rossi, J. S. (1992) Self-efficacy and the stages of exercise behavior change. Research Quarterly for Exercise and Sport, 63, 60-66.

Marmot, M. G. (1992) Coronary heart disease: rise and fall of a modern epidemic. In Marmot, M. and Elliott, P. (eds), Coronary heart disease epidemiology: From aetiology to public health. Oxford University Press, Oxford, pp. 3-19.

McGraw, S. A., Sellers, D. E., Stone, E. J., Bebchuk, J., Edmundson, E.W., Johnson, C. C., Bachman, K. J. and Luepker, R.V. (1996) Using process data to explain outcomes. Evaluation Review, 20, 29I-3I2.

McQueen, D.V. and Anderson, L. M. (200I) What counts as evidence: issues and debates. In Rootman, I., Goodstadt, M., Hyndman, B., McQueen, D.V., Potvin, L., Springett, J. and Ziglio, E. (eds), Evaluation in health promotion: Principles and perspectives. WHO, Copenhagen, PP. 63-81.

Menotti,A. (1992) Coronary risk factors and non-cardiovascular disease. In Marmot, M. and Elliott, P. (eds), Coronary heart disease epidemiology: From aetiology to public health. Oxford University Press, Oxford, pp. 298-308.

Miller, T. I. (1994) Designing and conducting surveys. In Wholey, J. S., Hatry, H. P. and Newcomer, K. E. (eds), Handbook of practical program evaluation. San Francisco, California, Pp. 27I-292.

Minkler, M. and Wallerstein, N. (1998) Improving health through community organization and community building. In Minkler, M. (ed), Community organizing \& community building for health. Rutgers University Press, New Brunswick, pp. 30-52. 
Mittelmark, M. B. (1999) Health Promotion at the Communitywide level: Lessons From Diverse Perspectives. In Bracht, N. (ed), Health promotion at the community level. SAGE Publications, Thousands Oaks, pp. 3-27.

Murray, D. M. (1995) Design and analysis of community trials: Lessons from the Minnesota Heart Health Program. American Journal of Epidemiology, I42, 569-575.

NOC*NSF. (1999) 55-plus in Beweging! NOC*NSF,Arnhem.

Nunnally, J. C. (1967) Psychometric theory. McGraw-Hill, New York.

Nutbeam, D. (1998) Evaluating health promotion - progress, problems and solutions. Health Promotion International, 13, 27-44.

Pate, R. R., Pratt, M. and Blair, S. N. (1995) Physical activity and public health: a recommendation from the Centers for Disease Control and Prevention and the American College of Sports Medicine. Journal of the American Medical Association, 273, 402-407.

Plesko, M., Cotugna, N. and Aljadir, L. (2000) Usefulness of a brief fruit and vegetable FFQ in a college population. American Journal of Health Behavior, 24, 20 I-208.

Pols, M.A., Peeters, P. H., Kemper, H. C. and Collette, H. J. (1996) Repeatability and relative validity of two physical activity questionnaires in elderly women. Medicine and Science in Sports and Exercise, 28(8), 1020-1025.

Pols, M.A., Peeters, P. H. M., Ocké, M. C., Bueno-de-Mesquita, H. B., Slimani, N., Kemper, H. C. G. and Collette, H. J.A. (1997) Relative validity and repeatability of a new questionnaire on physical activity. Preventive Medicine, 26, 37-43.

Potvin, L. and Richard, L. (200I) Evaluating community health promotion program. In Rootman, I., Goodstadt, M., Hyndman, B., McQueen, D. V., Potvin, L., Springett, J. and Ziglio, E. (eds), Evaluation in health promotion: Principles and perspectives. WHO, Copenhagen, pP. 213-240.

Prochaska, J. O. and DiClemente, C. C. (1992) Stages of change in the modification of problem behaviors. Progress in Behavior Modification, 28, I84-218.

Rasbash, J., Browne,W., Goldstein, H., Yang, M., Plewis, I., Draper, D., Healy, M. and Woodhouse, G. (1999) A User's Guide to M/wiN. Institute of Education, London.

Reitsma, J. B. and Bonsel, G. J. (200I) Samenvatting Rapport Hart- en vaatziekten in Nederland 200I. Nederlandse Hartstichting, Den Haag.

Richardson, M.T., Ainsworth, B. E.,Wu, H., Jacobs, D. R. and Leon, A. S. (1995) Ability of the atherosclerosis risk in communities (ARIC)/Baecke questionnaire to assess leisure-time physical activity. International Journal of Epidemiology, 24, 685-693.

Ronda, G. and van Assema, P. (1997) Een voorstudie ten behoeve van de ontwikkeling van de werkboeken voor het regioproject 'Hartslag Limburg': Minder vet eten, meer bewegen, stoppen/ niet beginnen met roken. Maastricht University, Maastricht.

Ronda, G., Steenbakkers, M.,Van Assema, P. and Ruland, E. (200 la) Hartslag Beweeg TeeVee: Een provinciaal programma voor bewegingstimulering. GGD Nieuws, 3, 2 I-27.

Ronda, G.,Van Assema, P. and Brug, J. (200 lb) Stages of change, psychological factors and awareness of physical activity levels in the Netherlands. Health Promotion International, 16(4), 305-314.

Ronda, G.,Van Assema, P., Ruland, E., Steenbakkers, M. and Brug, J. (in press) The Dutch Heart Health Community Intervention 'Hartslag Limburg': Evaluation design and Baseline Data. Health Education. 
Ronda, G.,Van Assema, P., Candel, M., Ruland, E., Steenbakkers, M.,Van Ree, J. and Brug, J. (in press) The Dutch Heart Health Community Intervention 'Hartslag Limburg': Effects on Smoking Behaviour. European Journal of Public Health.

Rose, G. (1992) Strategies of prevention: the individual and the population. In Marmot, M. and Elliott, P. (eds), Coronary heart disease epidemiology: From aetiology to public health. Oxford University Press, Oxford, pp. 3II-324.

Ruland, E., Harting, J.,Van Limpt, P., Ronda, G., Van Assema, P., Van Ree, J., Gorgels, T., Vermeer, F. and Ament,A. (1999) 'Hartslag Limburg':A united approach in preventive care. GGD-ZZL, Maastricht.

Ruland, E., Harting, J., Van Limpt, P., Ronckers, S., Ronda, G., Steenbakkers, M. and Ament, A. (200I) 'Hartslag Limburg':Annual report 2000. GGD-ZZL, Maastricht.

Rychetnik, L., Frommer, M., Hawe, P. and Shiell,A. (2002) Criteria for evaluating evidence on public health interventions. Journal of Epidemiology and Community Health, 56, I 1 9-1 27.

Salonen, J.T., Kottke, T. E., Jacobs, D. R. and Hannan, P. J. ( 1986) Analysis of Community-Based Cardiovascular Disease Prevention - Evaluation Issues in the North Karelia Project and the Minnesota Heart Health Program. International Journal of Epidemiology, I5(2), I76- 182.

Scheirer, M.A. (1994) Designing and using process evaluation. In Wholey,W. S., Hatry, H. P. and Newcomer, K. E. (eds), Handbook of practical program evaluation. California, San Francisco, pp. 40-68.

Schram, D., Maas, I. A. M., Poos, M. J.J. C. and Jansen, J. (200I) De bijdrage van leefstijlfactoren aan de sterfte in Nederland. Tijdschrift voor Gezondheidswetenschappen, 79, 2 I I-2 16.

Shea, S. and Basch, C. E. (1990) A review of five major community-based cardiovascular disease prevention programs. Part II: Intervention strategies, evaluation methods, and results. American Journal of Health Promotion, 4(4), 279-287.

Shelley, E., Daly, L., Collins, C., Christie, M., Conroy, R., Gibney, M., Hickey, N., Kelleher, C., Kilcoyne, D., Lee, P., Mulcahy, R., Murray, P., O’Dwyer,T., Radic, A. and Graham, I. (1995) Cardiovascular risk factor changes in the Kilkenny Health Project. European Heart Journal, 16, 752-760.

Simpson, J. M., Oldenburg, B., Owen, N., Harris, D., Dobbins, T., Salmon,A.,Vita, P., Wilson, J. and Saunders, J. B. (2000) The Australian national workplace health project: design and baseline findings. Preventive Medicine, 3 I , 249-260.

Snijders, T.A. B. and Bosker, R. J. (1999) Multilevel analysis. An introduction to basic and advanced multilevel modelling. Sage, London.

SPSS for Windows (1997) Rel. 7.5. SPSS Inc, Chicago.

SPSS for Windows (2000) Rel. 10.0. SPSS Inc, Chicago.

Stamler, J. Established major coronary risk factors. (1992) In Marmot, M. and Elliott P. (eds), Coronary heart disease epidemiology: From aetiology to public health. Oxford University Press, Oxford, pp. 35-66.

Statistics Netherlands (1997) Survey Working Population 1996 (Enquête Beroepsbevolking 1996). Sdu/uitgeverij / CBS-publicaties, 's-Gravenhage, p. 80.

I22 Thompson, B. and Kinne, S. (1999) Social change theory:Applications to community health. In Bracht, N. (ed), Health promotion at the community level: New advances. SAGE Publications, Inc, Thousands Oaks, pp. 29-58. 
Tudor-Smith, C., Nutbeam, D., Moore, L. and Catford, J. (1998) Effects of the Heartbeat Wales programme over five years on behavioural risks for cardiovascular disease: quasi-experimental comparison of results from Wales and a matched reference area. British Medical Journal, 316, 818-822.

U.S. Department of Health and Human Services (1996) Physical Activity and Health:A Report of the Surgeon General. U.S. Department of Health and Human Services, Centers for Disease Control and Prevention, National Center for Chronic Disease Prevention and Health Promotion, Atlanta, pp. 3-8.

Van Assema, P., Steenbakkers, M., Kok, G., Eriksen, M. and De Vries, H. (1994). Results of the Dutch Community Project "Healthy Bergeyk". Preventive Medicine, 23, 394-40I.

Van Assema, P., Brug, J. and Kok, G. (1997) Nutrition education interventions in a community setting: 2 Dutch examples. Nutrition and Health, I 2, 45-54.

Van Assema, P., Brug, J., Glanz, K., Dolders, M. and Mudde, A. (1998) Nationwide implementation of guided supermarkets tours in the Netherlands:A dissemination study. Health Education Research, 13, 557-566.

Van Assema, P., Brug, J., Ronda, G. and Steenhuis, I. (200 I) The relative validity of a short Dutch questionnaire as a means to categorise adults and adolescents to total and saturated fat intake. Journal of Human Nutrition and Dietetics, 14, 377-390.

Van Mechelen,W. (1996) Health on the move (Gezondheid in beweging). Tijdschrift voor Sociale Gezondheidszorg, 74, 44-46.

Van Oers, J.A. M. (ed) (2002) Gezondheid op koers? Volksgezondheid Toekomst Verkenning 2002. Rijksinstituut voor Volksgezondheid en Milieu, Bilthoven.

Varnell, S. P., Murray, D. M. and Baker,W. L. (200I) An evaluation of analysis options for the one-group-per-condition design. Evaluation Review, 25, 440-453.

Vartiainen, E., Korhonen, H. J., Koskela, K. and Puska, P. (1998) Twenty year smoking trends in an community-based cardiovascular diseases prevention programme. European Journal of Public Health, 8, I54-159.

Vuori, I. (1998) Does physical activity enhance health? Patient Education and Counseling, 33, $97-$ 106.

Warehem, N. J., Jakes, R.W., Rennie, K. L., Mitchell, J., Hennings, S. and Day, N. E. (2002) Validity and repeatability of the EPIC-Norfolk Physical Activity Questionnaire. International Journal of Epidemiology, 31, I68-174.

Weinstein, N. D. (1988) The precaution adoption process. Health Psychology, 7, 355-386.

Wilhelmsen, L. and Johansson, S. (1992) Secondary prevention of coronary heart disease: drug intervention and life-style modification. In Marmot, M. and Elliott, P. (eds), Coronary heart disease epidemiology: From aetiology to public health. Oxford University Press, Oxford, pp. 397-4l4.

Windsor, R.A., Baranowski, T., Clark, N. and Cutter, G. (1994) Evaluation of health promotion, health education, and disease prevention programs. Mountain View, CA, Mayfield.

Winkleby, M.A., Feldman, H.A. and Murray, D. M. (1997) Joint analysis of Three U.S. Community Intervention Trials for Reduction of Cardiovascular Disease Risk. Journal of Clinical Epidemiology, 50(6), 645-658.

World Health Organization. (1997) The World Health Report 1997. Conquering suffering. Enriching humanity.WHO, Geneva. 



\section{SUMMARY}

This thesis reports on the evaluation of the Heart Health Community Intervention 'Hartslag Limburg' (Dutch for Heartbeat Limburg). Cardiovascular diseases (CVD) are the greatest cause of morbidity and mortality in the Netherlands, and lifestyle factors such as smoking, dietary habits and lack of physical activity are important determinants of CVD. Changing these factors is therefore important in reducing and preventing CVD. To meet this challenge, a regional CVD prevention program (Hartslag Limburg) has been started in the Maastricht region of the province of Limburg, integrating a community strategy and a high-risk strategy. The major goal of the project is to reduce CVD in the Maastricht region. Hartslag Limburg's community intervention attempts to encourage the general population in the Maastricht region to reduce their intake of saturated fat, to stop smoking, and to increase their level of physical activity.

The first part of this thesis further specifies the problem analysis and introduces the community intervention. The first chapter presents a brief overview of the community intervention program itself, the conceptual framework of the intervention, the evaluation design, and baseline data at the individual and organizational level collected by means of written questionnaires. The conceptual framework of Hartslag Limburg's community intervention was based on program planning and evaluation models, and consisted of several stages. It shows how the program was expected to produce its postulated effects and served as the program's planning and evaluation framework. Within this framework, community organization principles and methods and health education theories and methods were applied. Individual baseline data of the intervention region revealed that substantial proportions of the respondents were engaged in one or more of the three risk behaviors under study, high (saturated) fat intake, smoking and inadequate physical activity, and that many respondents were not aware of their risk behavior with respect to fat intake and physical activity. Furthermore, self-efficacy towards smoking cessation, perceived social support towards changing the CVD risk behaviors, perceived behavior of others, and intention to change the risk behaviors were far from optimal. The baseline results at the organizational level showed that there were good opportunities for involving various organizations in the health promoting activities incorporated in Hartslag Limburg, as well as for increasing collaboration between these organizations in health promoting activities. It was concluded that the baseline results confirmed the need to carry out a comprehensive community CVD prevention project, as well as the appropriateness of the conceptual model that was used for the development of intervention activities. The results also provided input for the identification of specific objectives of the intervention program.

The study described in the second chapter of this thesis aimed to contribute to a more thorough understanding of the motivation to increase physical activity levels, in order to identify specific objectives for physical activity promotion. The data for this study were derived from the baseline measurement in the intervention region. It was decided to investigate these factors in relation to 
physical activity, because new recommendations for physical activity were introduced in the Netherlands about the same time that the project started, making it especially important to gain insight into factors that could be related to behavior consistent with these new recommendations. The results indicated that almost $60 \%$ of the respondents did not meet the recommended target for physical activity to promote health. Half of these respondents were in the precontemplation stage of behavior change, and more than $60 \%$ were overestimating their physical activity level. Furthermore, respondents who were not aware of their inadequate physical activity level had a less positive intention to increase their level of physical activity than those who rated their own physical activity level as low. Respondents in the precontemplation and maintenance stages of behavior change had a less positive attitude, perceived less social support and had lower self-efficacy expectations towards increasing physical activity than those in the contemplation, preparation and action stages. It was concluded that interventions aimed at increasing physical activity in the population studied should be aimed at increasing awareness of personal activity levels and should be stage-matched.

The second and main part of this thesis discusses the various evaluation studies that were conducted to allow conclusions to be drawn about the effectiveness of the Hartslag Limburg community intervention and its various elements, and to provide feedback to the project management team and intermediaries during the planning and implementation of the project. Chapter 3 focuses on the effects of the community intervention on dietary fat intake and physical activity, as well as on their psychosocial determinants. A pretest-posttest control group design with two posttests was used to evaluate the intervention. At baseline, representative random cohort research samples were selected in the Maastricht region and in a control region. Data on fat intake and physical activity, and on the psychosocial determinants of these behaviors, was gathered by means of structured questionnaires, sent by mail. A significant posttest difference was found between the Maastricht region and the control region, in favor of the Maastricht region, with respect to dietary fat intake, especially among respondents aged $\leq 48$ years (median age). Respondents in the Maastricht region were also more realistic about their fat intake, but had lower self-efficacy expectations towards decreasing their fat intake than respondents in the control region. With respect to physical activity, only a limited effect on intentions was found among respondents younger than 49 years. It was concluded that, although there were few significant intervention effects, the decline in fat intake over time is a promising result.

Chapter 4 presents the effects of the community intervention on smoking behavior and its psychosocial determinants. At baseline, representative random I26 cohort research samples of smokers were selected in the Maastricht region and a control region. Data on smoking behavior and its determinants was gathered by means of short structured telephone interviews. No significant posttest differences were found between the Maastricht region and the control region in smoking behavior and its determinants. The results did not show a significant 
impact of the Hartslag community intervention on smoking. In other words, the regional intervention proved unable to significantly accelerate the secular trend in smoking cessation.

Chapter 5 presents the design and results of a process study on the community intervention. The study was conducted to describe the actual course of action during the intervention, to assess whether the intervention was being conducted as originally planned and whether the organization of the project was as intended, as well as to gain insight into the reasons why expected effects were or were not achieved. The study focused on the prevention activities actually achieved, the application of community principles, and the implementation of the various planned project components. Data was collected using multiple data sources and/or methods to assess indicators of intervention implementation. With regard to project components, the results indicated that the community analysis and the subsequent organization of nine local Health Committees had been satisfactory. However, some factors that might influence the actual functioning of the Health Committees could be improved, such as the quality of communication, the staff time, the creation of special task forces and the number of members of the committees. Quality control was a weak point at the time of data collection, especially in that the expert training of the members of the Health Committees had not been achieved. While the application of community principles, such as intersectoral collaboration between organizations and a social network approach, was, on the whole, quite satisfactory, environmental strategies were identified as needing more attention, and ensuring longer-term continuation required continuous effort. Most of the 293 intervention activities implemented had focused on nutrition, followed by activities relating to physical activity. Activities to promote smoking cessation were found to be less prevalent. It was concluded that the process evaluation had provided information about successful and less successful elements of the community intervention, as well as insight into the 'black box' behind the program.

Chapter 6 presents the results of the effect evaluation study at the organizational level. Measurement at the organizational level was especially relevant because organizational changes, particularly in terms of increased availability of CVD health promoting activities, were an intermediate goal of the Hartslag Limburg community intervention, as these are assumed to be a prerequisite of changes at the individual level. The study focused on organizational involvement in health promotion and (CVD) health promoting activities, using a pretest-posttest control group design. All organizations that were potentially significant agents in health promoting activities were included. Data was gathered by means of structured questionnaires, sent by mail to representatives of the organizations. At posttest, the number of activities per organization involved in CVD health promoting activities was higher in the Maastricht region than in the control region. Furthermore, the overall posttest proportion of organizations involved in at least one activity relating to physical activity was higher in the Maastricht region than in the control region. It was concluded that the increase in active organizations in the region is encouraging. 
The final chapter (Chapter 7) discusses the main findings of the various studies described in this thesis, leading to the overall conclusion that after two and a half years of Hartslag Limburg, some promising results have been achieved, but that the presence of a secular trend towards more heart healthy behavior, as well as study design limitations, and the less than optimal (though still growing) quantity, quality and diffusion of intervention activities, prevented more convincing results, or the detection of such results. 


\section{SAMENVATTING}

Dit proefschrift beschrijft de evaluatie van de community-interventie 'Hartslag Limburg'. Hart- en vaatziekten (HVZ) zijn de grootste oorzaak van ziekte en sterfte in Nederland, en leefstijlfactoren zoals roken, ongezonde voedingsgewoonten en een gebrek aan lichamelijke activiteit zijn belangrijke determinanten van HVZ. Verandering van deze factoren is daarom belangrijk in de preventie en reductie van HVZ. Om deze reden is in zuidelijk Zuid-Limburg 'Hartslag Limburg' gestart, een regionaal preventieprogramma dat een communitystrategie integreert met een hoogrisicostrategie. Het hoofddoel van het project is een vermindering van HVZ in de regio. De community-interventie van Hartslag Limburg probeert de algemene bevolking aan te sporen om minder verzadigd vet te eten, te stoppen met roken, en meer lichamelijke activiteiten te ontplooien.

Het eerste deel van dit proefschrift gaat nader in op de probleemanalyse en introduceert de community-interventie. Het eerste hoofdstuk presenteert een kort overzicht van de community-interventie, het achterliggende conceptuele kader, en de opzet van de evaluatie. Tevens beschrijft dit deel de resultaten van de voormeting op individueel en organisatieniveau, die verzameld zijn door middel van schriftelijke vragenlijsten. Het conceptuele kader van Hartslag Limburg's community-interventie was gebaseerd op diverse plannings- en evaluatiemodellen en bestond uit verschillende onderdelen. Dit kader gaf enerzijds aan hoe de veronderstelde effecten bereikt zouden moeten worden, en diende anderzijds als raamwerk voor de verdere planning en evaluatie van de interventie. Binnen dit kader werden zowel principes van community-organisatie toegepast, als theorieën, methoden, en modellen van gezondheidsvoorlichting.

Uit de voormeting op individueel niveau bleek dat in zuidelijk Zuid-Limburg de drie risicogedragingen, te weten een te hoge (verzadigd) vetinname, roken en te weinig lichamelijke activiteit, frequent voorkwamen. Daarnaast waren veel respondenten zich er niet van bewust dat ze te veel vet aten of te weinig beweging hadden. Bovendien waren de eigen-effectiviteit wat betreft stoppen met roken, het waargenomen gedrag van anderen, de waargenomen sociale steun van anderen en de intentie om de gedragingen te veranderen zeker niet optimaal. Uit de voormeting op organisatieniveau bleek dat er goede mogelijkheden waren om de verschillende organisaties bij gezondheidsbevorderende activiteiten te betrekken en om de samenwerking tussen die organisaties te verhogen. Geconcludeerd werd dat de uitkomst van de voormeting de noodzaak onderschreef van een grootschalige community-interventie ter preventie van HVZ. Ook bevestigde de voormeting de geschiktheid van het conceptuele kader voor de ontwikkeling van interventieactiviteiten. Daarnaast leidden de resultaten tot de identificatie van specifieke doelen voor het interventieprogramma.

Het onderzoek dat beschreven wordt in hoofdstuk 2 had tot doel meer inzicht te krijgen in factoren die de motivatie beïnvloeden om meer te gaan bewegen, en om specifieke doelen voor bewegingsactiviteiten te identificeren. Dit werd extra belangrijk geacht, omdat tegelijkertijd met de start van Hartslag Limburg in Nederland nieuwe aanbevelingen werden geïntroduceerd voor de hoeveel- 
heid lichamelijke activiteit die nodig is om gezondheid te bevorderen. Voor dit onderzoek werden gegevens gebruikt uit de voormeting op individueel niveau in zuidelijk Zuid-Limburg. Hieruit bleek dat bijna $60 \%$ van de respondenten niet aan de nieuwe norm voor voldoende beweging voldeed. Bovendien bevond de helft van deze respondenten zich ten aanzien van meer bewegen in de precontemplatiefase, terwijl meer dan $60 \%$ van hen de mate waarin zij lichamelijke actief waren overschatte. Daarnaast bleek dat degenen die hun lichamelijke activiteit overschatten een minder positieve intentie hadden om meer te gaan bewegen dan degenen die hun lichamelijke activiteit laag inschatten. Verder hadden respondenten in de precontemplatie- en de behoudfase een minder positieve attitude ten aanzien van het verhogen van hun lichamelijke activiteit, ervoeren zij minder sociale steun en bezaten zij een lagere eigen-effectiviteit ten aanzien van die verandering, dan respondenten in de contemplatie-, preparatieen actiefase. Geconcludeerd werd dat interventies die gericht zijn op het verhogen van de lichamelijke activiteit zich moeten richten op het verhogen van het bewustzijn van het eigen gedrag en rekening moeten houden met de verschillende fasen van gedragsverandering waarin mensen zich kunnen bevinden.

Het tweede en belangrijkste deel van dit proefschrift beschrijft de verschillende evaluatieonderzoeken die zijn uitgevoerd om de effectiviteit van (de verschillende onderdelen van) de community-interventie van Hartslag Limburg aan te kunnen tonen, en om tijdens de planning en uitvoering van het project feedback te kunnen geven aan het projectmanagementteam en aan de betrokken intermediairen. Hoofdstuk 3 richt zich op de effecten van de community-interventie op de vetinname en de lichamelijke activiteit en op de determinanten van deze gedragingen. Hiervoor werd een onderzoeksdesign gebruikt met een voormeting, twee nametingen en een controlegroep. Voor de voormeting werd zowel in de regio zuidelijk Zuid-Limburg als in een controleregio een aselecte, representatieve steekproef getrokken. De gegevens over de vetinname en de lichamelijke activiteit werden verzameld met behulp van gestructureerde schriftelijke vragenlijsten. Bij de nameting werd een significant verschil in vetinname tussen de beide regio's gevonden ten gunste van zuidelijk Zuid-Limburg, met name onder respondenten van 48 jaar (mediaan) en jonger. Respondenten in zuidelijk Zuid-Limburg waren tevens realistischer over hun vetinname dan respondenten in de controleregio, maar hadden tegelijkertijd een lagere eigeneffectiviteitsverwachting ten aanzien van het verlagen van hun vetconsumptie. Wat betreft lichamelijke activiteit werd in zuidelijk Zuid-Limburg slechts een beperkt gunstig effect gevonden op de intentie om meer te gaan bewegen, eveneens onder respondenten jonger dan 49 jaar. Ondanks het geringe aantal significante interventie-effecten, wordt de daling in de vetinname als gevolg van de community-interventie van Hartslag Limburg als een bemoedigend en veel-

130 belovend resultaat gezien.

Hoofdstuk 4 presenteert de effecten van de community-interventie op het rookgedrag en de determinanten van dat gedrag. Voor de voormeting werden in de regio zuidelijk Zuid-Limburg en in een controleregio aselecte, representatieve steekproeven van rokers geselecteerd. De gegevens werden verzameld met 
behulp van korte gestructureerde telefonische vragenlijsten. Bij de nameting werden geen significante verschillen gevonden tussen beide regio's. Dit effectonderzoek kon geen significante invloed aantonen op rookgedrag en de determinanten van dat gedrag, met andere woorden, de community-interventie van Hartslag Limburg bleek niet in staat om de seculaire trend in het stoppen met roken te overstijgen.

Hoofdstuk 5 beschrijft het design en de resultaten van de procesevaluatie van de community-interventie van Hartslag Limburg. Deze evaluatie werd uitgevoerd om te bepalen wat er nu daadwerkelijk gebeurde tijdens de interventie, of de interventie werd uitgevoerd zoals die was gepland, of de organisatie ervan verliep zoals die was bedoeld, en om inzicht te krijgen in de redenen van het optreden dan wel uitblijven van de effecten die van de interventie werden verwacht. Het onderzoek richtte zich op de daadwerkelijk geïmplementeerde activiteiten, de toepassing van community-principes en de implementatie van de verschillende projectcomponenten. Wat betreft de projectcomponenten bleken zowel de veldverkenningen als het daaropvolgende opzetten van de werkgroepen bevredigend te zijn verlopen. Desondanks zouden enkele factoren die het functioneren van de werkgroepen beïnvloeden verbeterd kunnen worden, zoals de kwaliteit van de communicatie, de tijd die de leiding in de werkgroep kan steken, de formatie van speciale subwerkgroepen, deskundigheidsbevordering van de werkgroepleden, en het aantal leden van de werkgroepen. De beoogde community-principes, zoals een intersectorale samenwerking en een sociale-netwerkbenadering, werden, over het geheel genomen, heel redelijk toegepast. Er bleek echter meer aandacht nodig voor de inzet van omgevingsstrategieën en ook de continuering van het project vereiste continue inspanning. De meeste van de 293 geïmplementeerde interventieactiviteiten richtten zich op voeding, gevolgd door activiteiten gericht op lichamelijke activiteit. Activiteiten op het gebied van stoppen met roken bleken het minste geïmplementeerd te zijn. De conclusie luidde dat de procesevaluatie waardevolle informatie over succesvolle en minder succesvolle elementen van de community-interventie had opgeleverd en tevens inzicht gaf in de 'black box' achter de interventie.

Hoofdstuk 6 presenteert de resultaten van de effectevaluatie op organisatieniveau. Deze evaluatie was van belang omdat organisatorische veranderingen, met name een toename van beschikbare gezondheidsbevorderende activiteiten ter preventie van HVZ, een intermediair doel was van de community-interventie van Hartslag Limburg, omdat aangenomen werd dat een groter activiteitenaanbod een voorwaarde vormt voor veranderingen op individueel niveau. Hiervoor werd een onderzoeksdesign gebruikt met een voormeting, een nameting en een controlegroep. Het onderzoek richtte zich op betrokkenheid van organisaties bij gezondheidsbevordering en bij gezondheidsbevorderende activiteiten gericht op de preventie van HVZ. Voor dit onderzoek werden alle organisaties die in potentie iets op het gebied van gezondheidsbevorderende activiteiten zouden kunnen doen benaderd. De gegevens werden verzameld door middel van gestructureerde vragenlijsten die naar een vertegenwoordiger van de organisatie werden gestuurd. Bij de nameting bleek dat het aantal gezondheidsbevorderende 
activiteiten per betrokken organisatie hoger was in de regio zuidelijk ZuidLimburg dan in de controleregio. Tevens bleek het percentage organisaties dat betrokken was bij ten minste een activiteit op het gebied van bewegen in de regio zuidelijk Zuid-Limburg te zijn gestegen ten opzichte van de controleregio. Deze toename in het aantal organisaties dat actief is in gezondheidsbevordering in de regio zuidelijk Zuid-Limburg wordt gezien als een bemoedigend resultaat van de community-interventie van Hartslag Limburg.

Hoofdstuk 7 ten slotte, vat de belangrijkste bevindingen van de diverse studies nog eens samen. Deze bevindingen leiden tot de uiteindelijke conclusie dat de community-interventie van Hartslag Limburg na tweeëneenhalf jaar enkele veelbelovende resultaten heeft bereikt. Echter, de bestaande seculaire trend tot gezonder gedrag, de minder dan optimale, maar nog steeds toenemende, hoeveelheid, kwaliteit en diffusie van interventieactiviteiten, en de beperkingen in het onderzoeksdesign, hebben verhinderd dat overtuigender resultaten tot stand kwamen dan wel konden worden aangetoond. 


\section{ACKNOWLEDGMENTS}

I would like to thank all people and organizations who have contributed to the studies described in this thesis and without whom the completion of this dissertation would not have been possible, as well as all collaborating partners in the ongoing 'Hartslag Limburg' project.

In particular, I would like to express my gratitude to:

Patricia van Assema and Hans Brug

Math Candel

Erik Ruland and Mieke Steenbakkers

Ellis Abbema and Janneke Harting

Jan van den Bogaard

Gaby Ronda, March 2003 


\section{CURRICULUM VITAE}

Gaby Ronda was born in Maastricht on March 25, 1955. After receiving her high school diploma in Maastricht in 1972, she started studying physical education in Tilburg, where she received her teaching qualification in 1976. Between 1976 and 1992, she worked as a physical education teacher in Eindhoven. In 1992, she started studying health sciences at Maastricht University. She graduated in Health Education with first class honors in 1996. Subsequently, she started working at the Department of Health Education and Promotion of the same university. From 1996 to 1998, she was employed as a research assistant. In March 1998 she started on the PhD project described in this thesis. Since December 2002, she has been working as a post-doc researcher. 